\title{
Design of a Heat Exchanger for a Supercritical CO2 Turbine System
}

\author{
Kehinde Oluwatobi Adenuga \\ West Virginia University, koa0003@mix.wvu.edu
}

Follow this and additional works at: https://researchrepository.wvu.edu/etd

Part of the Heat Transfer, Combustion Commons

\section{Recommended Citation}

Adenuga, Kehinde Oluwatobi, "Design of a Heat Exchanger for a Supercritical CO2 Turbine System" (2021). Graduate Theses, Dissertations, and Problem Reports. 8151.

https://researchrepository.wvu.edu/etd/8151

This Thesis is protected by copyright and/or related rights. It has been brought to you by the The Research Repository @ WVU with permission from the rights-holder(s). You are free to use this Thesis in any way that is permitted by the copyright and related rights legislation that applies to your use. For other uses you must obtain permission from the rights-holder(s) directly, unless additional rights are indicated by a Creative Commons license in the record and/ or on the work itself. This Thesis has been accepted for inclusion in WVU Graduate Theses, Dissertations, and Problem Reports collection by an authorized administrator of The Research Repository @ WVU. For more information, please contact researchrepository@mail.wvu.edu. 
Design of a Heat Exchanger for a Supercritical $\mathrm{CO}_{2}$ Turbine System

Kehinde Adenuga

Thesis submitted to the Benjamin M. Statler College of Engineering and Mineral Resources at West Virginia University

In partial fulfillment of the requirements for the degree of Master of Science in Mechanical Engineering

Hailin Li, Ph.D., Chair.

Kenneth H Means, Ph.D

Songgang Qiu, Ph.D

Department of Mechanical and Aerospace Engineering

Morgantown, West Virginia

2021

Keywords: Supercritical $\mathrm{CO}_{2}$, Heat exchanger, Pressure drop, Heat transfer coefficient, Thermal analysis

Copyright 2021 Kehinde Adenuga 


\section{ABSTRACT \\ Design of a Heat Exchanger for a Supercritical $\mathrm{CO}_{2}$ Turbine System}

Kehinde Adenuga

This research aims at designing a shell and tube heat exchanger which will drive a turbine operated on supercritical $\mathrm{CO}_{2}$. Hot gases from boiler (simulated using air) at $1500 \mathrm{~K}$ is introduced into the shell to heat up the supercritical $\mathrm{CO}_{2}$ at $10 \mathrm{MPa}$ flowing within tubes from $450 \mathrm{~K}$ to $1050 \mathrm{~K}$. The design was done using selected shell and tube heat exchanger empirical equations at predefined boundary conditions. The effect of shell and tube diameter on other design parameters was examined. It was observed that the number of tubes, tube external and internal side surface area, volumes of shell and tube, overall surface area and mass of tube material increases as the shell diameter increases from $6 \mathrm{~m}$ to $18 \mathrm{~m}$ at $2 \mathrm{~m}$ interval and this is due to the increase in cross sectional area. The shell length, the number of baffles, overall heat transfer coefficient, the pressure drop in both shell and tube sides all decreases as shell diameter increases at same rate as described previously, and this is attributed to a reduced velocity caused by the increased cross section area of tubes and baffle space. The increase in tube diameter from $0.0092 \mathrm{~m}$ to $0.12 \mathrm{~m}$ at $0.02 \mathrm{~m}$ intervals however leads to an increase in shell length, volume of tube material, number of baffles, shell side pressure drop, tube side pressure drop, overall area of the device ,tube external side surface area and tube internal side surface area. However, the overall heat transfer coefficient, total length of tubes and number of tubes decreases as the tube diameter increases at same rate as described previously. A decision was made on the selected heat exchanger based on fewer tubes, reduced mass of tube materials, low shell and tube pressure drop, and a high heat transfer coefficient. A selected geometry of shell diameter $8 \mathrm{~m}$, shell length $51.62 \mathrm{~m}$, tube diameter $0.102 \mathrm{~m}$, number of tubes 1509 and overall heat transfer coefficient $60.51 \mathrm{~W} / \mathrm{m}^{2} \mathrm{~K}$ was considered.

A CFD analysis was conducted using ANSYS 18.1 on the prototype of the selected heat exchanger device. The device geometry was built using the design modeler and it consist of the shell, tubes, air fluid, $\mathrm{CO}_{2}$ fluid and baffles The meshing and naming of unit parts was done while the set-up stage was achieved with the predefined boundary conditions and properties. The temperature distribution and thermal analysis of the heat exchanger was reported. 


\section{ACKNOWLEDGEMENTS}

First and foremost, all glory to God who has given me the grace and strength to start and finish this work. I would like to appreciate my parents Mr. and Mrs. M.M. Adenuga who has put so much efforts and resources in aiding me through my tertiary education journey. I would like to appreciate my advisor Dr. Hailin Li for his persistent efforts towards the success of this thesis. Appreciation to my committee member Dr. Songgang Qiu and Dr. Kenneth H Means for their support, help and input towards this thesis, and for the knowledge transferred. My regards also to Dr. Sam Mukdadi for allowing me work as a teaching assistance under his supervision. I also want to thank Dr. Slava Akkerman and Dr Adam Alas for their effective teachings and contributions regarding my course work.

My regards also to my colleagues Gideon Udochukwu, Samuel Ogunfuye and Lateef Kareem for their input and contribution during the process of writing this thesis work. I appreciate you all and am grateful. Finally, my appreciation goes to Pastor and Mrs. Adeniyi Adebisi and the RCCG Morgantown family for their support in the course of my graduate education at West Virginia University. 
Table of Contents

TITLE PAGE

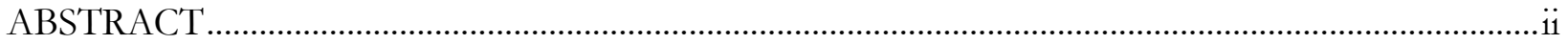

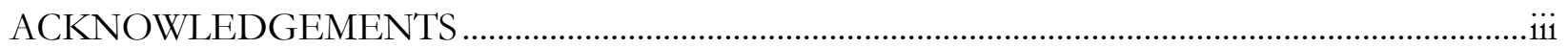

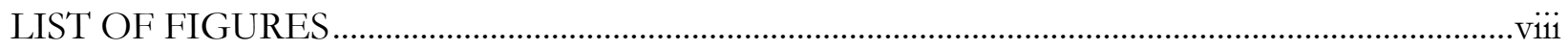

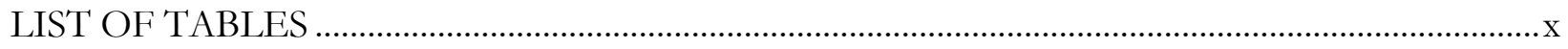

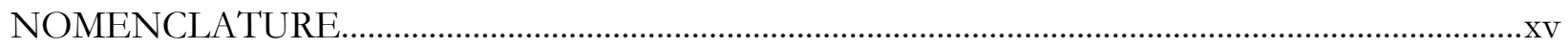

1 INTRODUCTION

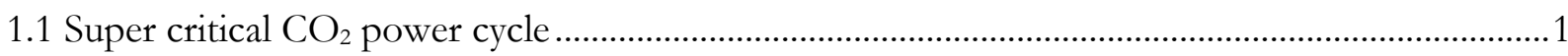

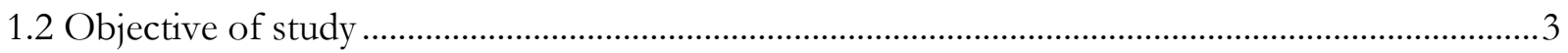

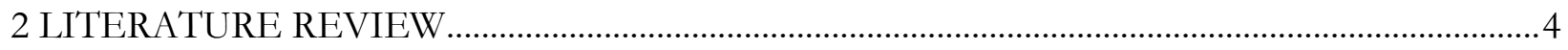

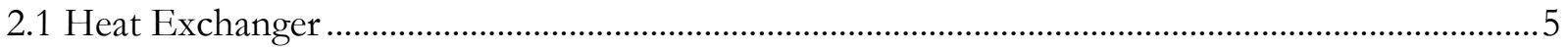

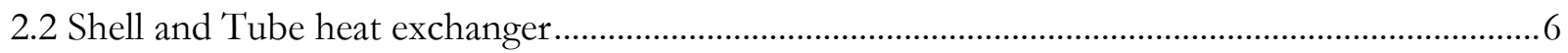

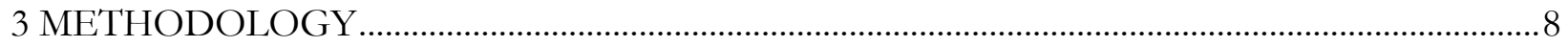

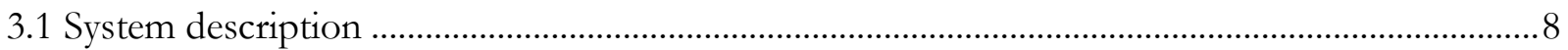

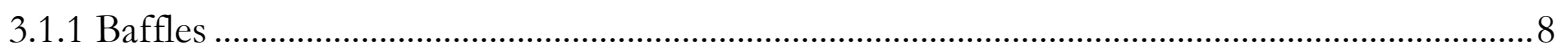

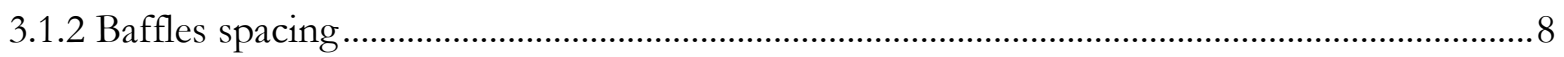

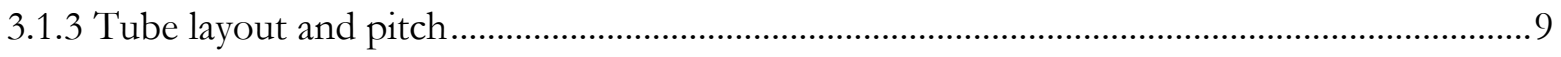

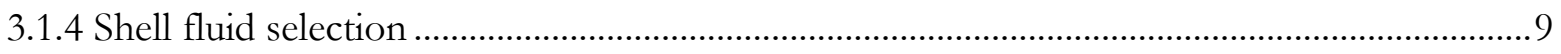

3.1.5 Tube material selection................................................................................................... 
3.1.6 Maximum allowable working pressure of the tube

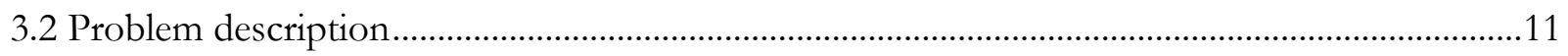

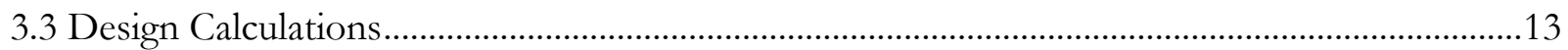

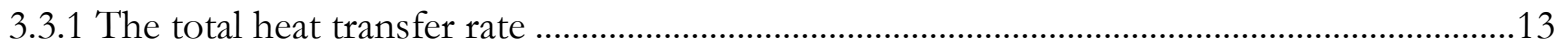

3.3.2 Logarithmic mean temperature difference ….......................................................................14

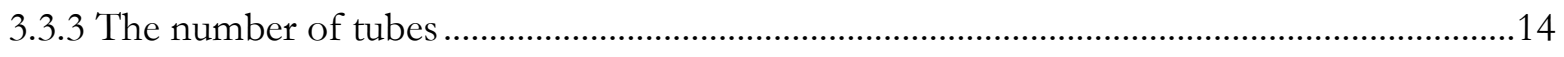

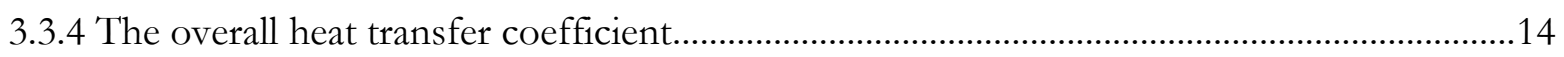

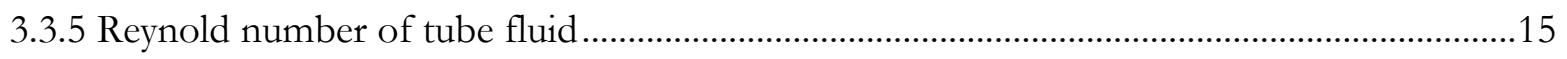

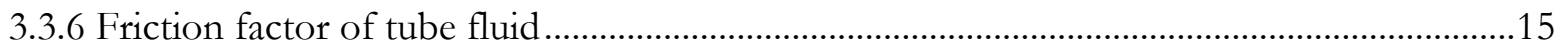

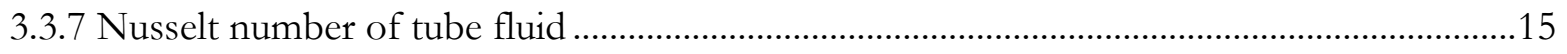

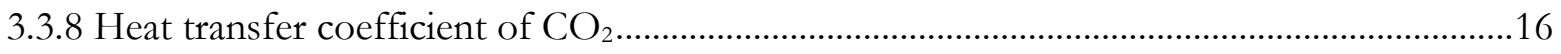

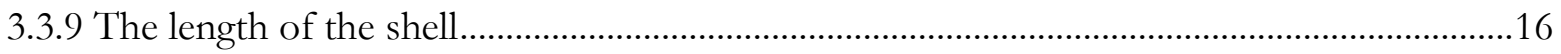

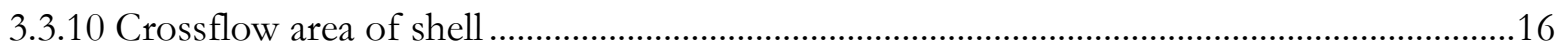

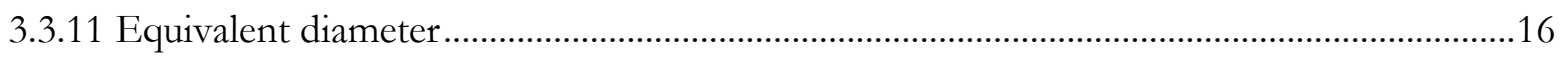

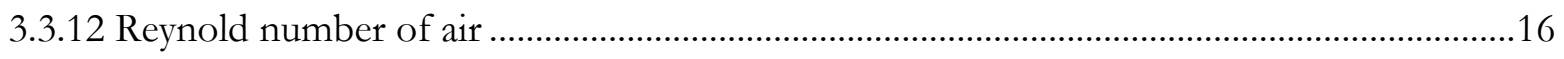

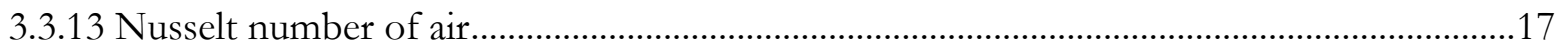

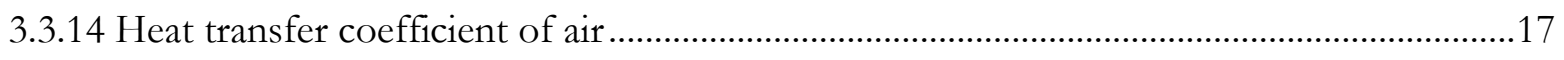

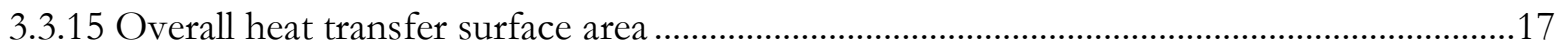

3.3.16 Shell side pressure drop …...........................................................................................17

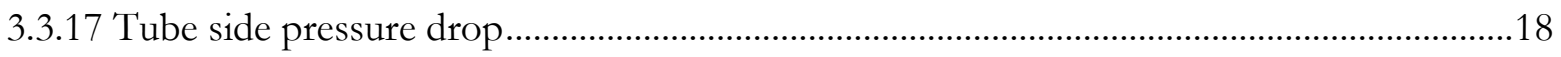


4.1 Effect of shell inner diameter on the design and performance parameters $\mathrm{di}=0.0092 \mathrm{~m}$,

$\mathrm{Ds},=6-18 \mathrm{~m} \mathrm{tt}=0.004 \mathrm{~m}$

Table 4. 1: Effect of shell inner diameter on the design and performance parameters $\mathrm{di}=0.0092 \mathrm{~m}$,

Ds, $=6-18 \mathrm{~m} \mathrm{tt}=0.004 \mathrm{~m}$

Figure 4. 1: Effect of shell inner diameter on the design and performance parameters $\mathrm{di}=0.0092$

$\mathrm{m}, \mathrm{Ds},=6-18 \mathrm{~m} \mathrm{tt}=0.004 \mathrm{~m}$.

4.2 Effect of inner tube diameter on the design and performance parameters, $\mathrm{Ds}=8 \mathrm{~m}, \mathrm{di}=0.028-$

$0.120 \mathrm{~m}$ ts. $=0.075 \mathrm{~m}$

4.4 Effect of tube and shell diameter on shell length, $m$

4.5 Effect of tube and shell diameter on total volume of tube material, $\mathrm{m}^{3}$ .30

4.6 Effect of tube and shell diameter on volume of shell material, $\mathrm{m}^{3}$ .31

4.7 Effect of tube and shell diameter on tube side pressure drop, Pa.....

4.8 Effect of tube and shell diameter on shell side pressure drop, bar

4.10 Effect of tube and shell diameter on overall heat transfer coefficient, $W / \mathrm{m}^{2} \mathrm{~K}$

4.11 Effect of tube and shell diameter tube internal side surface area, $\mathrm{m}^{2}$. .36

4.12 Effect of Tube pitch on shell and tube side pressure drop Ds $=8 \mathrm{~m}, \mathrm{di}=0.102, \mathrm{~B}=$

$5.6 \mathrm{~m}, \mathrm{Pt}=1.2-2.0$

4.13 Selected shell and tube heat exchanger .40 


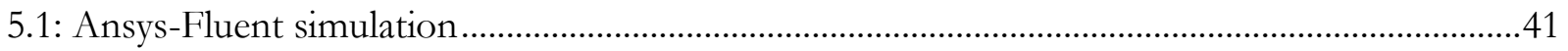

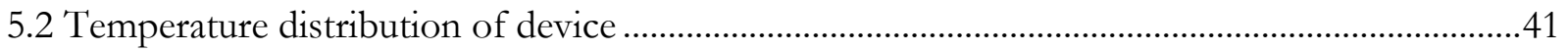

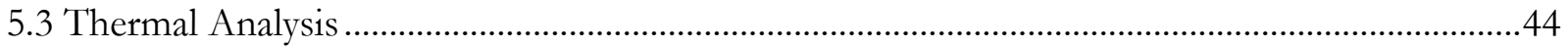

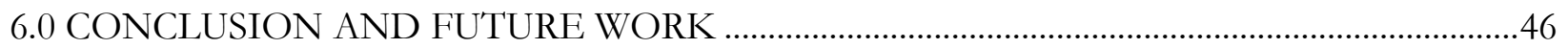

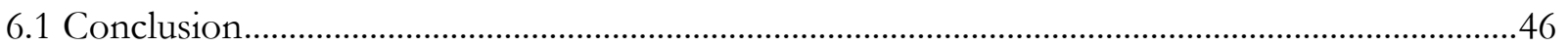

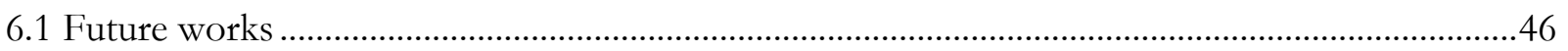

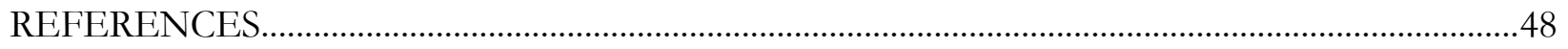

APPENDIX 1 . Orthographic projection of heat exchanger device …...................................................52 


\section{LIST OF FIGURES}

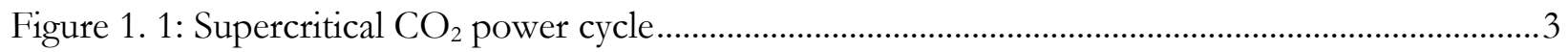

Figure 2. 1 :Heat exchanger classification based on flow configuration ...............................................6

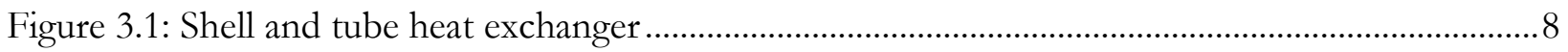

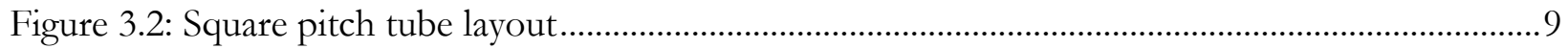

Figure 4. 1: Effect of shell inner diameter on the design and performance parameters $d i=0.0092 \mathrm{~m}$,

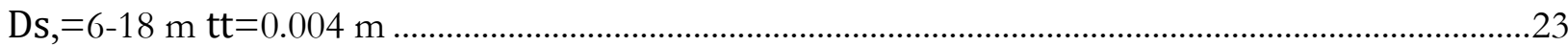

Figure 4. 2: Effect of inner tube diameter on the design and performance parameters, $D s=8 \mathrm{~m}$,

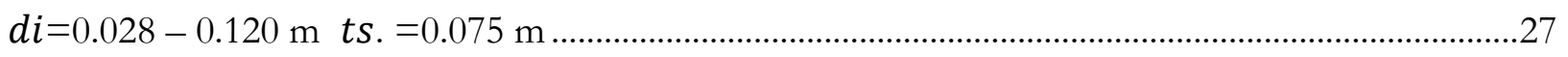

Figure 4. 3: Effect of tube and shell diameter on tube number............................................................28

Figure 4. 4: Effect of tube and shell diameter on shell length, m........................................................29

Figure 4. 5: Effect of tube diameter on side surface area to volume ratio. .............................................30

Figure 4. 6: Effect of tube and shell diameter on total volume of tube material, $\mathrm{m}^{3}$...........................31

Figure 4. 7: Effect of tube and shell diameter on volume of shell material, $\mathrm{m}^{3}$..................................32

Figure 4. 8: Effect of tube and shell diameter on tube side pressure drop, Pa.....................................33

Figure 4. 9: Effect of tube and shell diameter on shell side pressure drop, bar ....................................34

Figure 4. 10: Effect of shell and tube diameter on the velocity of air, $\mathrm{m} / \mathrm{s}$..........................................35

Figure 4. 11: Effect of tube and shell diameter on overall heat transfer coefficient, $\mathrm{W} / \mathrm{m}^{2} \mathrm{~K} \ldots \ldots \ldots \ldots . . .36$

Figure 4. 12: Effect of tube and shell diameter on tube internal side surface area, $\mathrm{m}^{2} \ldots \ldots \ldots \ldots \ldots \ldots \ldots \ldots . . . . . . . . . . .17$

Figure 4. 13: Effect of Tube pitch on shell and tube side pressure drop ..............................................38

Figure 4. 14: Effect of Tube pitch on shell length ................................................................................39

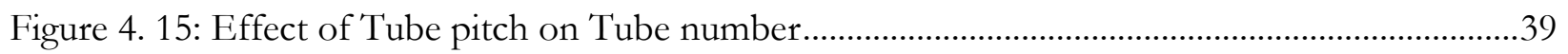


Figure 5.1: Temperature distribution of $\mathrm{CO}_{2}$

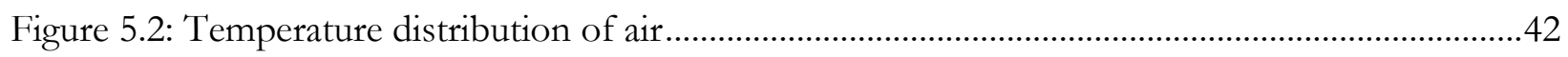

Figure 5.3: Temperature distribution of tubes ....................................................................................... 43

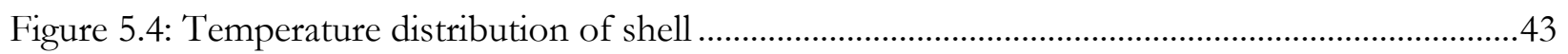

Figure 5.5: Temperature distribution in central line of heat exchanger device......................................44

Figure 5.6: Thermal analysis of heat exchanger device …......................................................................4

Figure 5.7:Variable of the allowable stress with changes in temperature ..............................................45 


\section{LIST OF TABLES}

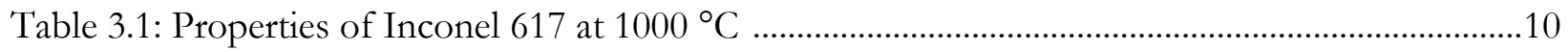

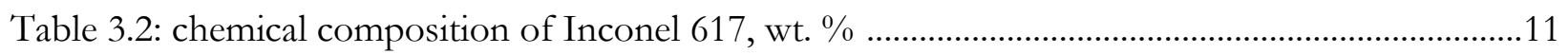

Table 3.3 design parameters for the heat exchanger..............................................................................12

Table 3.4 Thermo physical properties of the Air at 1.13 bar .................................................................13

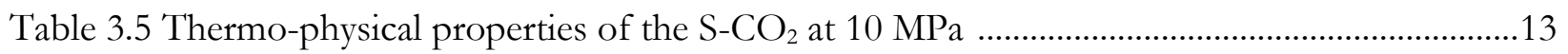

Table 4. 1: Effect of shell inner diameter on the design and performance parameters $\mathrm{di}=0.0092 \mathrm{~m}$,

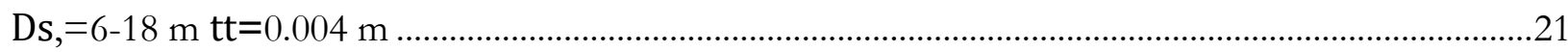

Table 4. 2: Effect of inner tube diameter on the design and performance parameters, $D s=8 \mathrm{~m}$,

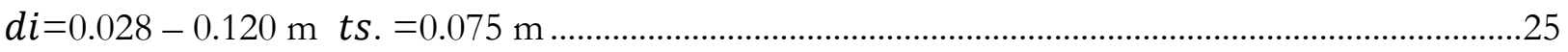

Table 4. 3: Effect of tube and shell diameter on tube number .............................................................28

Table 4. 4: Effect of tube and shell diameter on shell length, $\mathrm{m}$........................................................29

Table 4. 5: Effect of tube diameter on surface area to volume ratio, m..................................................30

Table 4. 6: Effect of tube and shell diameter on total volume of tube material, $\mathrm{m}^{3}$............................31

Table 4. 7: Effect of tube and shell diameter on volume of shell material, $\mathrm{m}^{3}$.....................................32

Table 4. 8: Effect of tube and shell diameter on tube side pressure drop, Pa .....................................33

Table 4. 9: Effect of tube and shell diameter on shell side pressure drop, bar........................................34

Table 4. 10: Effect of shell and tube diameter on the velocity of air, $\mathrm{m} / \mathrm{s}$..........................................34

Table 4. 11: Effect of tube and shell diameter on overall heat transfer coefficient, $\mathrm{W} / \mathrm{m}^{2} \mathrm{~K}$..............35

Table 4. 12: Effect of tube and shell diameter tube internal side surface area, $\mathrm{m}^{2}$...............................36

Table 4. 13: Effect of Tube pitch on shell and tube side pressure drop …...........................................37

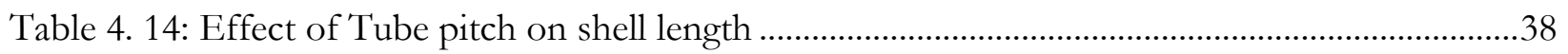

Table 4. 15: Effect of Tube pitch on Tube number .................................................................................

Table 4. 16: Design parameters for the selected heat exchanger ............................................................40 


\section{LIST OF VARIABLES}

$A_{c}=$ Shaded area

$A_{i}=$ Tube internal side surface area

$A_{o}=$ Tube external side surface area

$A_{\text {overall }}=$ Overall heat transfer surface area

$A_{s}=$ Crossflow area of shell

$A U R=$ Air utilization ratio

$B=$ Baffle space

$c=$ Corrosion allowance

$C L=$ Tube layout constant

$c_{p}=$ Specific heat capacity

$C T P=$ Tube count constant

$D_{e}=$ Equivalent diameter

$d_{o}=$ Outer tube diameter

$d_{i}=$ Inner tube diameter

$D_{s}=$ Shell diameter

$f=$ Friction factor

$f_{c}=$ Material allowable stress of the material of construction 
$F_{d}=$ Design factor

$F_{e}=$ Longitudinal joint factor

$F_{t}=$ Temperature derating factor

$h_{i}=$ Heat transfer coefficient of $\mathrm{CO}_{2}$

$h_{o}=$ Heat transfer coefficient of air

$J=$ Joint efficiency

$k=$ Thermal conductivity

$k_{\text {inc }}=$ Inconel conductivity

$L=$ Length of shell

$\dot{m}=$ Mass flow rate

$\mathrm{Nu}=$ Nusselt number

$\mathrm{N}_{\mathrm{t}}=$ Tube number

$\mathrm{N}_{\mathrm{p}}=$ Number of passes

$\mathrm{p}=$ Design pressure

$\mathrm{PR}=$ Pitch ratio

$\operatorname{Pr}=$ Prandtl number

$\mathrm{Pt}=$ Tube pitch

$Q=$ Total heat transfer rate 
$R e_{D}=$ Reynold number

$S_{y}=$ Yield strength of Inconel 617

$T_{\text {in }}=$ Inlet temperature

$T_{\text {out }}=$ Outlet temperature

$\Delta T=$ Temperature difference

$t_{t}=$ Tube thickness

$\mathrm{t}_{\mathrm{s}}=$ Shell thickness

$\mathrm{U}=$ Overall heat transfer coefficient 


\section{LIST OF GREEK SYMBOLS}

$\Delta p_{s}=$ Shell side pressure drop

$\Delta p_{f}=$ Tube side pressure drop

$\Delta T_{l m}=$ Logarithmic mean temperature

$\rho=$ Density

$\mu=$ Dynamic viscosity 


\section{NOMENCLATURE}

ASME: American Society of Mechanical Engineers

CCGT: Combined cycle gas turbine

GE-GR: General Electric Global Research team

GTI: Gas Technology Institute

ORC: Organic Rankine cycle

$\mathrm{S}-\mathrm{CO}_{2}$ : Supercritical $\mathrm{CO}_{2}$

SWRI: Southwest Research Institute

STHXs: Shell tube heat exchangers 


\section{INTRODUCTION}

\subsection{Super critical $\mathrm{CO}_{2}$ power cycle}

There are power plants that uses $\mathrm{CO}_{2}$ in its supercritical state as its working fluid[1]. The supercritical $\mathrm{CO}_{2}\left(\mathrm{~S}-\mathrm{CO}_{2}\right)$ power cycles have numerous benefits over other working fluid used for thermal and power generating cycles. Firstly, it doesn't go through a constant-temperature boiling process at elevated temperature. Secondly, it has a continuous reduction in density which occurs as the fluid is heated and is abundantly available at a very cheap cost[2]. Also, it is stable in all region of interest and could be set up in a compact style of arrangement. S- $\mathrm{CO}_{2}$ turbines are very compact and very efficient with small, single casing body design.

Several power cycles are used for power generation and they include Organic Rankine Cycle (ORC), steam Rankine cycle, air Brayton cycle, Combined cycle gas turbine (CCGT), and S-CO $\mathrm{Cirect}$ and indirect cycles[3]. The $\mathrm{S}-\mathrm{CO}_{2}$ based Brayton cycle is a good alternative to the conventional steam power cycles because of high cycle efficiency, compact turbo machinery and compact heat exchangers[4]. A closed Brayton cycle consists five components including a compressor, recuperator, heat exchanger, turbine and precooler. Fluid from the compressor enters recuperator and then to the heat exchanger where the energy from a heat source is transferred into the fluid to drive the shaft in rotary motion[5]. Bryton cycles offers better fuel-power conversion efficiency but requires high turbine inlet temperatures for efficient operation. In [6], at high density of $\mathrm{S}-\mathrm{CO}_{2}$ near the critical point, S-CO $\mathrm{CO}_{2}$ Bryton cycles tend to have reduced compressor power consumption and increased efficiency. The S-CO ${ }_{2}$ Bryton cycle allows several heat exchangers which include shell and tube, hybrid exchangers, spiral wound exchangers, finned tube and shell exchangers, plate and shell exchangers and porous media exchangers in its operation[7]. 
The ORC principle is based on a turbo-generator working as a conventional steam turbine to convert the thermal energy into mechanical energy and finally into electric energy through an electrical generator. Instead of generating steam from water, the organic Rankine cycle system vaporizes an organic fluid, characterized by a molecular mass higher than that of water, which leads to a slower rotation of the turbine, lower pressures and no erosion of the metal parts and blades. [8] The ORC uses an organic, high molecular mass fluid with a liquid-vapor phase change, or boiling point, occurring at a lower temperature than the water-steam phase change [9]. The heating of $\mathrm{CO}_{2}$ is done directly using volumetric and tubular receiver. The indirectly fired closed-loop S-CO $\mathrm{C}_{2}$ cycles [1] has the working fluid heated directly by a heat source through a heat exchanger. Another indirectly heated $\mathrm{S}-\mathrm{CO}_{2}$ cycle is the recuperated closed-loop Brayton cycle. It has a thermal recuperator that is introduced between the turbine and the compressor which helps to improve the cycle efficiency by reducing the heat loss in $\mathrm{CO}_{2}$ cooler. A semi-closed direct oxyfuel Brayton cycle has the heat exchanger replaced by a pressurized oxy-fuel combustor which burns fuel in oxygen producing $\mathrm{CO}_{2}$ which is used to drive the turbine [1]. A S-CO $\mathrm{CO}_{2}$ power cycle using a shell and tube heat exchanger is shown in Figure 1.1. Hot air simulating hot combustion gases from a boiler move into a shell and tube heat exchanger where thermal energy is transferred to $\mathrm{S}-\mathrm{CO}_{2}$ needed to drive a power generating turbine which produce electricity through a generator. 


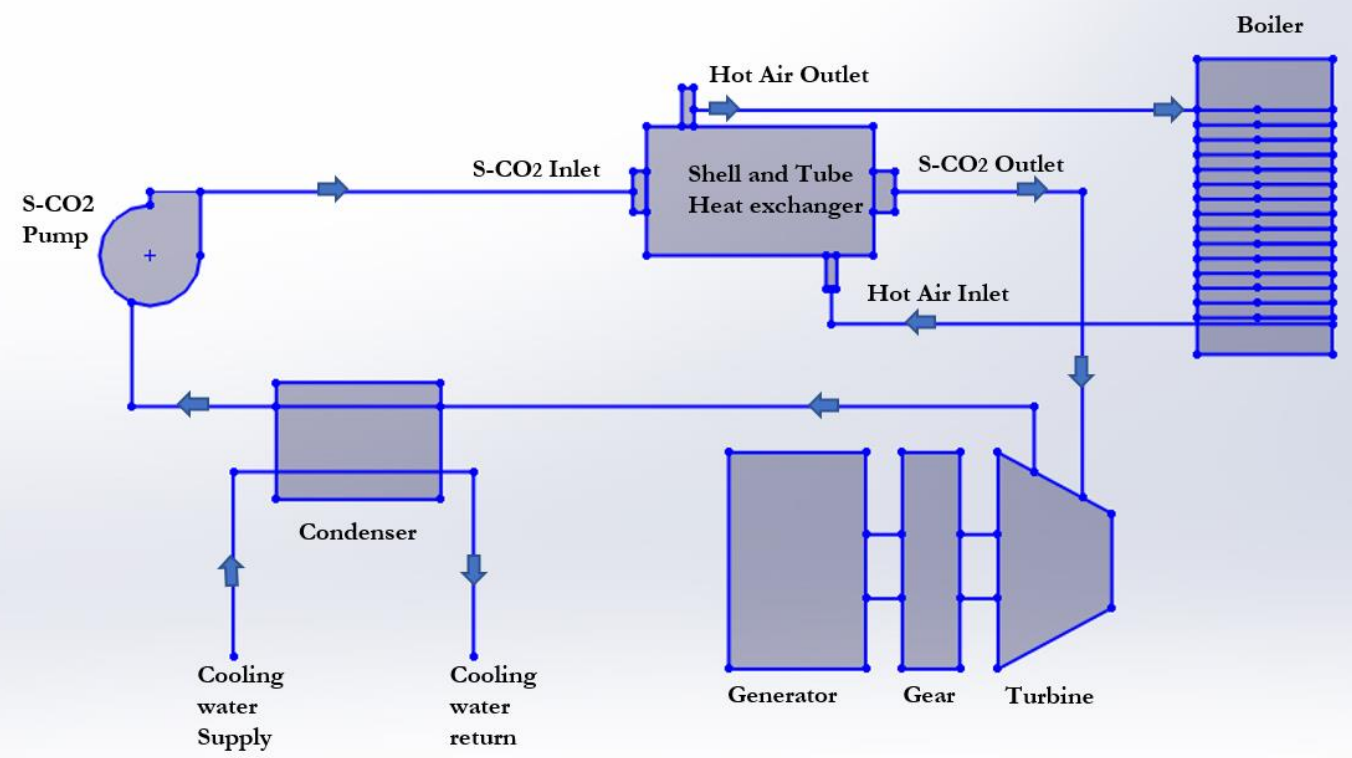

Figure 1. 1: Supercritical $\mathrm{CO}_{2}$ power cycle

\subsection{Objective of this study}

The objective of this work is to design a S-CO $\mathrm{CO}_{2}$ heat exchanger device. The focus of the study will be at specifying the

i. Design of the heat exchanger in accordance with standard working principles.

ii. Key cost factor and operation parameters such as volume of tube material and pressure drop;

iii. Temperature distribution of the fluids within the shell and tube using CFD.

iv. Temperature distribution within the heat exchanger using CFD.

v. Thermal analysis of the heat exchanger using CFD. 


\section{LITERATURE REVIEW}

Studies on the use of $\mathrm{S}-\mathrm{CO}_{2}$ for power generation have taken place since the 1960 s but little or no development was done due to technological limitations [10]. Several publications on heat exchanger design has since surfaced and among which was the design of a tubular type heat exchanger which endures high-temperature and high-pressure conditions under $\mathrm{S}-\mathrm{CO}_{2}$ fluid flow. The device was evaluated using an in-house code, a 3-dimensional flow and thermal stress analysis which aimed at testing the tube integrity. The result indicated that the stress level of the heat exchanger device satisfied the American Society of Mechanical Engineers (ASME) criteria. Further research on $\mathrm{S}-\mathrm{CO}_{2}$ in efficient power generation was conducted in [11]where $\mathrm{S}-\mathrm{CO}_{2}$ direct cycles was compared with conventional Rankine cycles at inlet turbine temperature of $550{ }^{\circ} \mathrm{C}$ and $700{ }^{\circ} \mathrm{C}$. A result showing 45 $\%$ and $53 \%$ efficiency with greater cost reduction was achieved. This shows the benefit of the S-CO direct cycle over other power cycles at different turbine inlet temperature. Generally, it was shown that the efficiency of power plants is directly proportional to the enthalpy of the working fluid at the turbine inlet.

In [12] the US Department of Energy through its supercritical transformational electric power program awarded a $\$ 3.9$ million project to three design company’s which are Echogen Power Systems in Ohio, the Gas Technology Institute (GTI) in Illinois and the Southwest Research Institute (SWRI) in Texas to develop initial plans to design a $10 \mathrm{MW} \mathrm{S-CO}$ Brayton Cycle test facility. The project was to support future supercritical Brayton Cycle energy conversion systems which would help achieve national climate and energy goals while promoting domestic job creation and providing the country with a clean and cheaper power. Ongoing work has already been done by SWRI in Texas, the GTI and the General Electric Global Research team (GE-GR) [13][14].They are performing a steady state

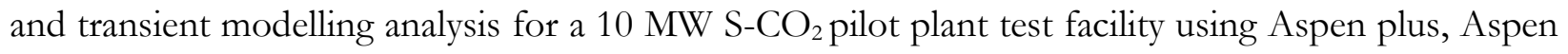


Hysys and Numerical propulsion system simulation software's to arrive at comparable results giving increased confidence in the analysis.

In [15], Zhu reviewed the latest development in $\mathrm{S}-\mathrm{CO}_{2}$ power cycles technologies in relation to power generation. Zhu highlighted the unique properties of $\mathrm{S}-\mathrm{CO}_{2}$ which makes it an ideal working fluid. Zhu also described the types of Brayton cycles with emphasis on the open and closed Brayton cycles. The technical difficulties of the $\mathrm{S}-\mathrm{CO}_{2}$ power cycles were discussed with focus on limited operational experience of $\mathrm{S}-\mathrm{CO}_{2}$ power turbines for commercial operations and challenges experienced in turbo machinery design for equipment operating at elevated turbine inlet temperature.

\subsection{Heat exchanger}

Heat exchanger is a device used to transfer heat energy between two or more fluids, between a solid particulates or surface and a fluid at different temperatures [16]. They are utilized for controlling heat energy and can regulate efficient heat transfer from one fluid to another. The fluids can be single or two phase and, depending on the exchanger type, it may be separated or in direct contact. In [17], heat exchangers are classified based on flow configuration and by equipment type of construction. The categories based on flow configurations are described in Figure 2.1 and are the counter flow, cocurrent flow, crossflow and cross/counter flow. Heat exchangers classification by equipment type of construction are either recuperators or regenerators. Recuperators are direct transfer type of heat exchanger where the fluids are separated by wall which prevent mixing or leakage of the fluids. Regenerators are indirect transfer types of heat exchangers where fluid interact via intermittent heat exchange with each other through thermal energy storage. Regenerators normally have fluid leakage due to pressure differences and matrix rotation [16],[17]. The heat exchangers usually seen in our environment are the cooling towers, automobile radiators, condensers, evaporators and air preheaters. 
Heat exchangers are classified into various categories such as the classification on transfer process (indirect contact type and direct contact type), number of fluids( two or more fluids), surface compactness (gas to liquid or liquid to liquid and phase change), flow arrangement which include the single-pass and multi-pass arrangements. The multi-pass heat exchanger has the extended surface, shell and tube and plate heat exchangers. The classification based on type of construction have the shell and tube, plate, agitated film and batch pan heat exchangers. Another major classification is on energy utilization (steam and vapor recompression). Lastly is the classification based on reboilers which includes the natural and forced circulation.
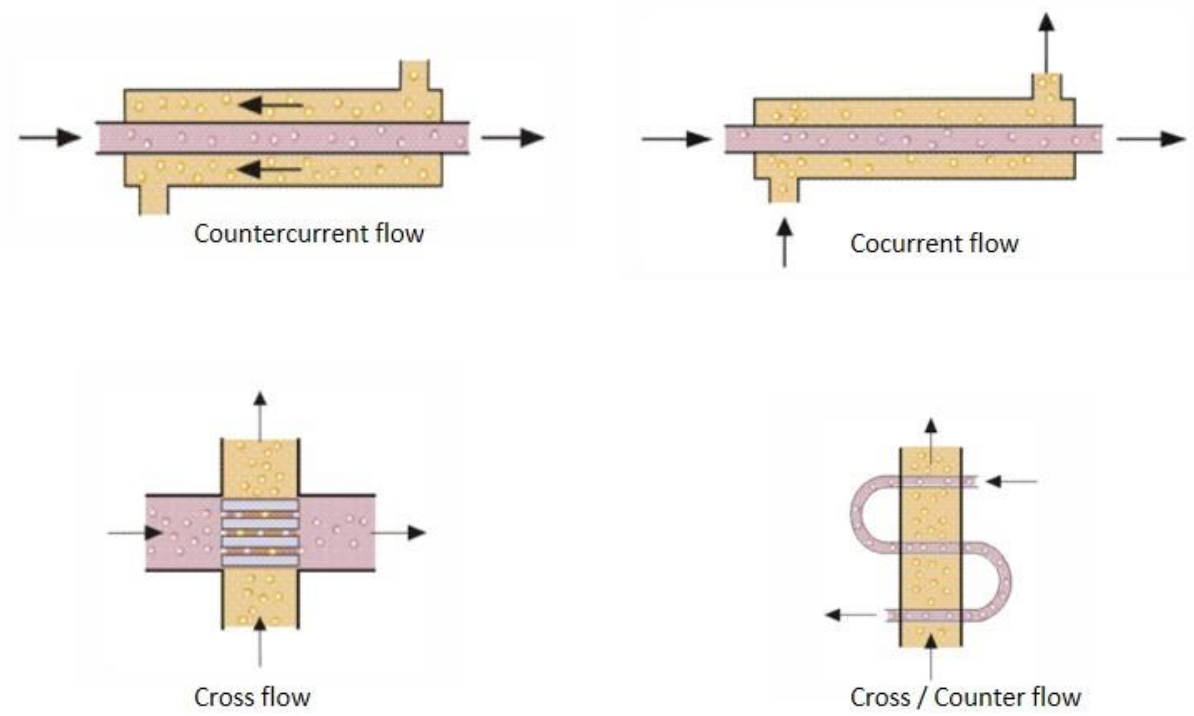

Figure 2. 1: Heat exchanger classification based on flow configuration [17].

\subsection{Shell and Tube heat exchanger}

Shell and tube heat exchangers (STHXs) are very much in use due to the flexibility they offer for a wide range of temperature and pressure [18]. A shell and tube heat exchanger is made of a large pressure container and several number of tubes inside it. STHXs also have various types of baffles configuration among which are conventional segmental baffles, deflector baffles, disk and doughnut baffles and spaced optimized baffles [19].The design of STHXs include the thermal and mechanical 
stage [20], the thermal stage includes the selection of fluids, temperature specification, setting of pressure drops, velocity limits and heat transfer area. The mechanical stage are selection of tube and shell dimensions, setting the tube pitch, tube arrangement, baffle spacing and baffle design. 


\section{METHODOLOGY}

\subsection{System description}

A shell and tube heat exchanger with straight tubes that are secured at both ends to tubesheets welded to the shell was selected because of its low cost, simple construction and minimal leakage of the shell side fluid. The schematic of the shell and tube heat exchanger is shown in Figure 3.1. The major components are tubes, shell, buffers, flanges, stationary tube sheet, support bracket and shell

cover.

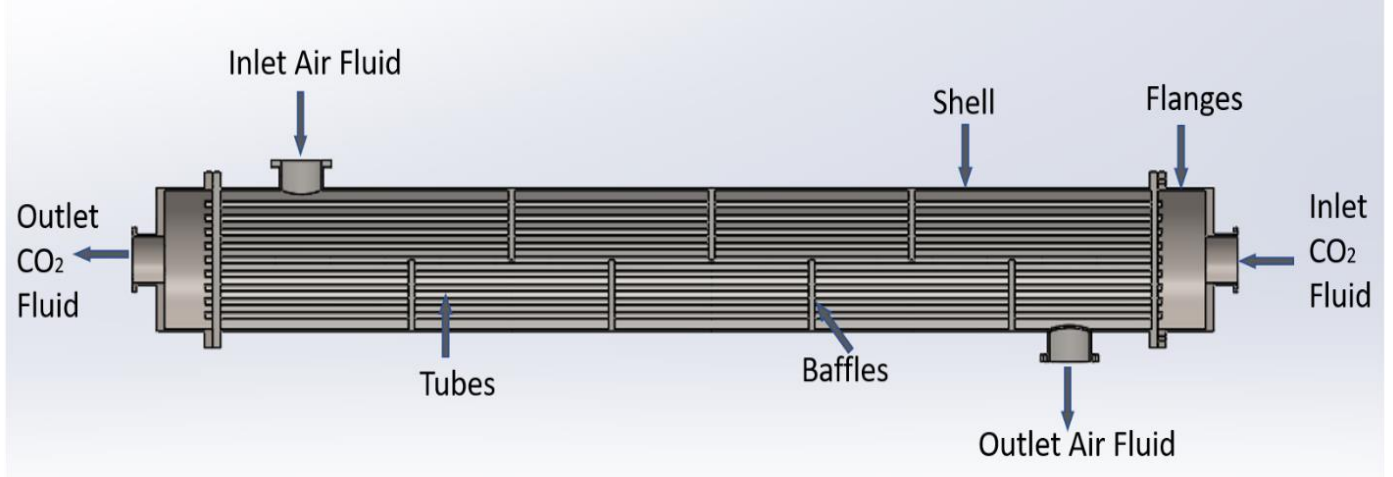

Figure 3.1: Shell and tube heat exchanger

\subsubsection{Baffles}

Baffles are metal separators used in the shell side of the shell and tube heat exchangers. Baffles are also used to support tubes and enable a desirable velocity for the fluid to be maintained at the shell side and prevent failure of tubes due to flow-induced vibration. Baffles enable better contact of the shell side fluid (air) with the tube surface. They also support the tube bundles and minimize the potential damage caused by flow induced vibration in the tubes.

\subsubsection{Baffles spacing}

This should have minimum value of one fifth of the shell internal diameter while the maximum baffle spacing should not be greater than the shell internal diameter. Closely placed baffles could mean a 
poor penetration of the tubes by shell fluid (air). A large baffle spacing means the shell side fluid (air) flows freely along the direction of the tubes thereby decreasing the heat transfer and overall efficiency. Baffle spacing are normally between 0.3 and 0.6 times of the shell internal diameter. Baffle spaces could also be same size as the shell diameter to achieve a low shell side pressure drop. The baffle spacing for this analysis was set at 0.7 times the shell internal diameter.

\subsubsection{Tube layout and pitch}

Tubes layout for shell-tube heat exchangers are of two major types, the triangular pattern and the square pattern layouts. The square tube layout shown in Figure 3.3 is used when frequent cleaning is required while the triangular layout is used when more tubes is to be fitted in a given space. Tube pitch is the minimum center to center distance between two tubes. Tube pitch is normally set as 1.25 or 1.5 times tube outer diameter. Tube spacing which helps in controlling shell side pressure drop is given by tube pitch divided by tube diameter ratio. Tube diameter ratio is defined as the tube outer diameter

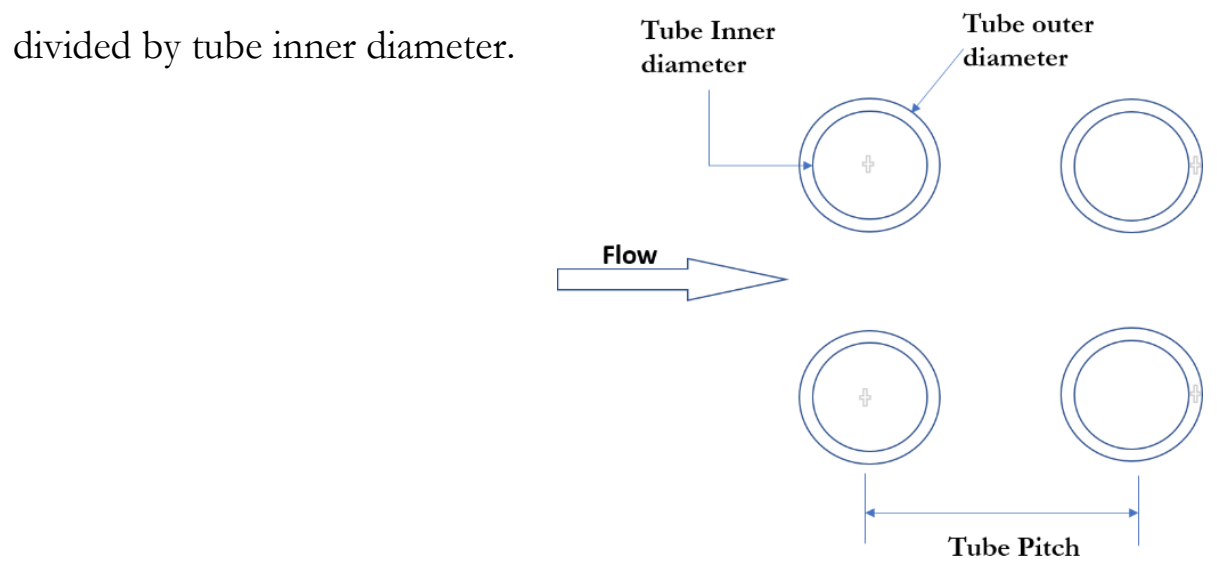

Figure 3.2: Square pitch tube layout

\subsubsection{Shell fluid selection}

The choice of fluid for the shell side are based on requirement for higher flow rate and higher fluid viscosity which results is needed for increased heat transfer coefficient and overall heat transfer [21]. 
Air has a high thermal conductivity that increases with temperature [22] and was selected for this design.

\subsubsection{Tube material selection}

The main factors that influenced the selection of materials for the shell and tube heat exchanger are high thermal conductivity, low coefficient of thermal expansion, high endurance at extreme temperature and pressure conditions, good tensile, good fatigue, corrosion fatigue, creep-fatigue and creep characteristics. The material must have high fatigue toughness and high impact strength to prevent fast cracking [23]. The recommended materials for the shell and tube heat exchangers are ferritic steels, austenitic steels, wrought nickel-based steels and the precipitation-strengthened alloy 740 [24]. The nickel-based alloy, Inconel 617 was selected due to its suitability and high endurance at extreme temperature and pressure conditions. It also offers exclusive blend of high strength, oxidation resistance and corrosion resistance at up to $980^{\circ} \mathrm{C}$. The physical properties of Nickel based alloys Inconel 617 are listed in Table 3. 1. The chemical composition of Inconel 617 is presented in Table 3.2

Table 3.1: Properties of Inconel 617 at $1000^{\circ} \mathrm{C}[25]$

\begin{tabular}{ll}
\hline Inconel 617 & Value \\
\hline Tensile strength & $893 \mathrm{MPa}$ \\
Yield Strength & $389 \mathrm{MPa}$ \\
Tensile Modulus & $149 \mathrm{GPa}$ \\
Shear Modulus & $61 \mathrm{GPa}$ \\
Poisson's ratio & 0.3 \\
Specific heat capacity under constant pressure & $662 \mathrm{~J} / \mathrm{kg} \cdot{ }^{\circ} \mathrm{C}$ \\
Thermal conductivity & $28.7 \mathrm{~W} / \mathrm{m} \cdot{ }^{\circ} \mathrm{C}$ \\
Maximum allowable stress & $12.5 \mathrm{MPa}$ \\
Corrosion resistance & $35 \mathrm{~g} / \mathrm{m}^{2}$ \\
Coefficient of expansion & $16.3 \mu \mathrm{m} / \mathrm{m}^{\circ} \mathrm{C}$ \\
Density & $8360 \mathrm{~kg} / \mathrm{m}^{3}$ \\
\hline
\end{tabular}


Table 3.2: chemical composition of Inconel 617, wt. \% [25]

\begin{tabular}{|l|c|c|c|c|c|c|c|c|c|c|c|c|c|c|c|}
\hline Alloy & $N i$ & $C r$ & $S$ & $B$ & $T i$ & $C o$ & $F e$ & $M n$ & $M o$ & $A l$ & $T i$ & $C u$ & $P$ & $S i$ & $C$ \\
\hline Inconel 617 & 45 & 22 & 0.1 & 0.05 & 1 & 13 & 3 & 1 & 9 & 1.2 & 0.6 & 0.5 & 0.1 & 1 & 0.1 \\
\hline
\end{tabular}

3.1.6 Maximum allowable working pressure of the tube

The maximum allowable working pressure of the tube is calculated by equation:

$P=\frac{2 \times S_{y} \times F_{d} \times F_{e} \times F_{t} \times \mathrm{t}}{d_{i}}$

$S_{y}=$ yield strength of Inconel 617

$F_{d}=$ design factor

$F_{e}=$ longitudinal joint factor

$F_{t}=$ temperature derating factor

$t_{t}=$ tube thickness

$d_{i}=$ inner tube diameter

\subsection{Problem description}

The model developed in this work solves a steady-state heat transfer problem between a hot flowing air and a counter flow $\mathrm{S}-\mathrm{CO}_{2}$ fluid in a shell and tube heat exchanger configuration. The design is expected to serve a 300 MW gas turbine system with expected thermal efficiency about $50 \%$. The heat input $Q_{\text {in }}$ is projected at $600 \mathrm{MW}$ in order to meet this demand. The $\dot{m}_{\mathrm{CO}_{2}}$ was calculated as $806.74 \mathrm{~kg} / \mathrm{s}$ using the preset $T_{\text {in }, \mathrm{CO}_{2}}$, and $T_{\text {out }, \mathrm{CO}_{2}}$, of $450 \mathrm{~K}$ and $1050 \mathrm{~K}$ respectively since a moderate 
turbine inlet temperature lies between 996 - $1246 \mathrm{~K}$ [21]. In order to derive the $\dot{m}_{\text {Air }}, T_{\text {in,Air }}$ was set at $1500 \mathrm{~K}$. A relationship was created between air utilization ratio $(A U R), \dot{m}_{A i r}, T_{i n, A i r}$ with the assumption that $T_{\text {out,Air }} \geq T_{\text {in, } \mathrm{CO}_{2}}$. After several iterations, a $\dot{m}_{\text {Air }}$ of $760 \mathrm{~kg} / \mathrm{s}$ at $T_{\text {out,Air }}$ of $802 \mathrm{~K}$ was selected as it offers a suitable geometry design parameter for a effective heat exchanger. Table 3.3 shows the design parameter generated for the shell and tube heat exchanger device.

Table 3. 3: design parameters for the heat exchanger

Design input parameters of the heat exchanger

$\mathrm{CO}_{2}$ inlet temperature, $(\mathrm{K})$

$\mathrm{CO}_{2}$ outlet temperature, $(\mathrm{K})$

$\mathrm{CO}_{2}$ mass flow rate $(\mathrm{kg} / \mathrm{s})$

Air inlet temperature, $(\mathrm{K})$

Air outlet temperature $(\mathrm{K})$

Air mass flow rate $(\mathrm{kg} / \mathrm{s})$
450

1050

806.74

802

760.00

The mass flow rate and inlet temperatures were specified at entry positions while the outlet temperatures was specified at exit positions. The alloy Inconel 617 is selected as the material for the shell and tube heat exchanger due to its suitability and high endurance at extreme temperature and pressure conditions [27]. The thermo-physical properties of the fluid domain are constant, and the values of density $(\rho)$ specific heat $\left(c_{p}\right)$ thermal conductivity $(k)$, dynamic viscosity $(\mu)$, Prandtl number $(P r)$ are provided in Table 3.4 and Table 3.5 
Table 3. 4: Thermo physical properties of the Air at 1.13 bar [22]

\begin{tabular}{llcc}
\hline & $\mathrm{T}_{\mathrm{h}, \mathrm{i}}$ & $\mathrm{T}_{\mathrm{h}, \mathrm{o}}$ & $\mathrm{T}_{\mathrm{h}, \mathrm{a}}$ \\
\hline Temperature $(\mathrm{K})$ & 1500 & 802 & 1151 \\
\hline$\rho$, density $\left(\mathrm{kg} / \mathrm{m}^{3}\right)$ & 0.2353 & 0.6419 & 0.3209 \\
$\mu$, dynamic viscosity $\left(\mathrm{N} . \mathrm{s} / \mathrm{m}^{2}\right)$ & 0.00005264 & 0.00002849 & 0.00004511 \\
$c_{p}$, specific heat under constant pressure $(\mathrm{J} / \mathrm{kg} . \mathrm{K})$ & 1211.2 & 1039.8 & 1167 \\
$k$, Conductivity $(\mathrm{W} / \mathrm{m} . \mathrm{K})$ & & & 0.0733 \\
$\operatorname{Pr}$, Prandtl number & 0.08831 & 0.04357 & 0.708 \\
\hline
\end{tabular}

Table 3. 5: Thermo-physical properties of the $\mathrm{S}_{-} \mathrm{CO}_{2}$ at $10 \mathrm{MPa}$ [28]

\begin{tabular}{llll}
\hline & $\mathrm{T}_{\mathrm{c}, \mathrm{i}}$ & $\mathrm{T}_{\mathrm{c}, \mathrm{o}}$ & $\mathrm{T}_{\mathrm{c}, \mathrm{a}}$ \\
\hline Temperature $(\mathrm{K})$ & 450 & 1050 & 750 \\
\hline$\rho$, density $\left(\mathrm{kg} / \mathrm{m}^{3}\right)$ & 131.6 & 49.31 & 71.5 \\
$\mu$, dynamic viscosity $\left(\mathrm{N} . \mathrm{s} / \mathrm{m}^{2}\right)$ & 0.00002358 & 0.00004285 & 0.0000315 \\
$c_{p}$, specific heat under constant pressure $(\mathrm{J} / \mathrm{kg} . \mathrm{K})$ & 1208.346 & 1270.7593 & 1239.55 \\
$k$, conductivity $(\mathrm{W} / \mathrm{m} . \mathrm{K})$ & 0.03392 & 0.07524 & 0.05 \\
$\operatorname{Pr}$, Prandtl number & 0.8399 & 0.7237 & 0.7809 \\
\hline
\end{tabular}

3.3 Design calculations

3.3.1 The total heat transfer rate

$Q=\dot{m}_{A i r} \times c_{p A i r} \times \Delta T_{A i r}=\dot{m}_{C_{2}} \times c_{p C O_{2}} \times \Delta T_{C O_{2}}$

$Q=$ total heat transfer rate

$\dot{m}_{\text {Air }}=$ mass flow rate of air

$\dot{m}_{\mathrm{CO}_{2}}=$ mass flow rate of $\mathrm{CO}_{2}$ 
$c_{p, \text { air }}=$ specific heat of air under constant pressure

$c_{p, \mathrm{CO} 2}=$ specific heat of $\mathrm{CO}_{2}$ under constant pressure

$\Delta T_{A i r}=$ temperature difference in air (between air inlet and outlet)

$\Delta T_{\mathrm{CO}_{2}}=$ temperature difference in $\mathrm{CO}_{2}$ (between $\mathrm{CO}_{2}$ inlet and outlet)

3.3.2 Logarithmic mean temperature difference

$\Delta T_{l m}=\frac{\Delta T_{1}-\Delta T_{2}}{\operatorname{Ln}\left(\frac{\Delta T_{1}}{\Delta T_{2}}\right)}$

$\Delta T_{1}=$ Temperature difference between air and $C O_{2}$ at one end of the heat exchanger

$\Delta T_{2}=$ Temperature difference between air and $\mathrm{CO}_{2}$ at the other end of the heat exchanger

3.3.3 The number of tubes

$N_{t}=\frac{\pi}{4}\left(\frac{C T P}{C L}\right) \frac{D_{S}^{2}}{P R^{2} d_{o}^{2}}$

$C T P=$ tube count constant $(0.93$ for one tube pass, 0.9 for two tube passes, 0.85 for three tube passes)

$D_{s}=$ shell diameter

$P t=H \times d_{o}=$ tube pitch

$\mathrm{H}=$ constant (usually $1.25 \& 1.5$ )

$C L=$ tube layout constant $\left(1\right.$ for ' $90^{\circ} \& 45^{\circ}$, 0.866 for ' $30^{\circ} \& 60^{\circ}$ ')

$d_{o}=$ Tube outer diameter

$P R=\frac{P t}{d_{o}}$

3.3.4 The overall heat transfer coefficient

$U=\frac{1}{\left[\frac{1}{h_{i}}+\frac{1}{h_{o}}+\ln \left(\frac{d_{o}}{d_{i}}\right) \times\left(\frac{d_{i}}{2\left(k_{\text {inc }}\right)}\right)\right]}$

$h_{i}=$ heat transfer coefficient of $\mathrm{CO}_{2}$ flowing within tube

$h_{o}=$ Heat transfer coefficient of air flowing outside tube

$d_{o}=$ tube outer diameter 
$d_{i}=$ tube inner diameter

$k_{\text {inc }}=$ Inconel thermal conductivity

$A_{o}=\pi \times d_{i} \times N_{t} \times L=$ tube external side surface area

$A_{i}=\pi \times d_{0} \times N_{t} \times L=$ tube internal side surface area

3.3.5 Reynold number of tube fluid

$R e_{D, \mathrm{CO}_{2}}=\frac{\dot{m}_{\mathrm{CO}_{2}} \times d_{i}}{A_{c} \times \mu_{\mathrm{CO}}}$

$\dot{m}_{\mathrm{CO}_{2}}=$ mass flow rate of $\mathrm{CO}_{2}$

$\mu_{\mathrm{CO}_{2}}=$ dynamic viscosity of $\mathrm{CO}_{2}$

$d_{i}=$ Inner tube diameter

$A_{c}=\frac{\pi}{4} \times \frac{d_{1}^{2} N_{t}}{N_{p}}$

$N_{p}=$ number of passes

$N_{t}=$ number of tubes

3.3.6 Friction factor of tube fluid

$f=\left(1.58 \times \ln R e_{D, \mathrm{CO}_{2}}-3.28\right)^{-2}$

$R e_{D, \mathrm{CO}_{2}}=$ Reynold number of $\mathrm{CO}_{2}$

$f=$ friction factor

3.3.7 Nusselt number of tube fluid

$\mathrm{Nu}_{\mathrm{CO}_{2}}=\frac{\frac{f}{2} \times\left(\mathrm{Re}_{D, \mathrm{CO}_{2}}-1000\right) \times \mathrm{Pr}}{\left[1+12.7\left(\frac{f}{2}\right)^{\frac{1}{2}} \times(\mathrm{Pr})^{\frac{2}{3}}-1\right]}$

$f=$ friction factor

$R e_{D, \mathrm{CO}_{2}}=$ Reynold number of $\mathrm{CO}_{2}$

$\mathrm{Pr}_{\mathrm{CO}_{2}}=$ Prandtl number of $\mathrm{CO}_{2}$ 
3.3.8 Heat transfer coefficient of $\mathrm{CO}_{2}$

$h_{\mathrm{CO}_{2}}=\frac{N u_{\mathrm{CO}_{2}} \times k_{\mathrm{CO}_{2}}}{d_{i}}$

$d_{i}=$ Inner tube diameter

$k_{\mathrm{CO}_{2}}$ Thermal conductivity of $\mathrm{CO}_{2}$

3.3.9 The length of the shell

$L=\frac{Q}{N_{t} \times U \times \pi \times d_{o} \times \Delta T_{l m}}$

$\mathrm{Q}=$ Total heat transfer rate

$N_{t}$ : Number of tubes

$U$ : Overall heat transfer coefficient;

$\Delta T_{l m}=$ logarithmic mean temperature difference

3.3.10 Crossflow area of shell

$A_{s}=\frac{D_{s} \times C_{t} \times B}{P_{t}}$

..................... [29]

$B=D_{s}=$ Baffle space

$P t=H \times d_{o}=$ tube pitch

$\mathrm{H}=$ constant (usually $1.25 \& 1.5$ )

$D_{s}=$ shell diameter

$C_{t}=P_{t}-d_{o}$

3.3.11 Equivalent diameter

$D_{e}=4 \times\left(P t^{2}-\frac{\pi \times d_{o}^{2}}{4}\right) /\left(\pi \times d_{o}\right) \ldots .$. Square pitch

$P t=H \times d_{o}=$ tube pitch

$d_{o}=$ Outer tube diameter

3.3.12 Reynold number of air

$R e_{D, A i r}=\frac{\dot{m}_{a i r} \times D_{e}}{A_{s} \times \mu_{A i r}}$

...........[29] 
$\mu_{\text {Air }}=$ dynamic viscosity of air

$D_{e}=$ equivalent diameter

$A_{s}=\frac{D_{s} \times C_{t} \times B}{P_{t}}$

$\dot{m}_{\text {air }}=$ mass flow rate of air

3.3.13 Nusselt number of air

$N u_{D, A i r}=0.36 \times R e_{D, \text { Air }}^{0.55} \times \operatorname{Pr}_{\text {Air }}^{\frac{1}{3}} \times\left(\mu / \mu_{w}\right)^{0.14}$

$R e_{D, \boldsymbol{A i r}}=$ Reynold number of air

$P r_{\text {Air }}=$ Prandtle number of air

$\mu_{w}=\mu$ of air at $\ldots \ldots \ldots \ldots \ldots \ldots T_{w}$

3.3.14 Heat transfer coefficient of air

$h_{\text {air }}=\frac{N u_{\text {Air }} \times k_{\text {Air }}}{D_{e}}$

$D_{e}=$ equivalent diameter

$k_{\text {Air }}=$ Air conductivity

3.3.15 Overall heat transfer surface area

$A_{\text {overall }}=\frac{Q}{U \times \Delta T_{l m}}$

$U=$ Overall heat transfer coefficient

$A_{\text {overall }}=$ Overall heat transfer surface area

$\Delta T_{l m}=$ logarithmic mean temperature difference

$\Delta T_{l m}=\frac{\Delta T_{1}-\Delta T_{2}}{\operatorname{Ln}\left(\frac{\Delta T_{1}}{\Delta T_{2}}\right)}$

$Q=$ Total heat transfer rate

3.3.16 Shell side pressure drop

$\Delta p_{s}=\frac{f G_{s}^{2}\left(N_{b}+1\right) D_{s}}{2 \rho_{A i r} D_{e} \times\left(\mu / \mu_{w}\right)^{0.14}}$

$f=\exp \left(0.576-0.19 \ln R e_{D, A i r}\right)$ 
$\mu_{\text {Air }}=$ dynamic viscosity of air

$D_{s}=$ shell diameter

$G_{S}=\dot{m}_{A i r} / A_{S}$

$\dot{m}_{\text {air }}=$ mass flow rate of air

$A_{s}=\frac{D_{s} \times C_{t} \times B}{P_{t}}$

$N_{b}=$ number of baffles

$\mu_{w}=\mu$ at $\ldots \ldots \ldots \ldots \ldots \ldots T_{w}$

$T_{w}=\frac{1}{2}\left[\frac{T_{c i}+T_{c o}}{2}+\frac{T_{h i}+T_{h o}}{2}\right]$

3.3.17 Tube side pressure drop

$\Delta p_{f}=4\left[\frac{f \times L}{d_{1}}+1\right] \times N_{p} \times \rho_{\mathrm{CO}_{2}} \frac{\mu_{C O_{2}}^{2}}{2}$

$f=\left(1.58 \times \ln R e_{D, \mathrm{CO}_{2}}-3.28\right)^{-2}$

$N_{p}=$ number of passes

$L=$ length of shell

$d_{i}=$ tube inner diameter

$\rho_{\mathrm{CO}_{2}}=$ density of $\mathrm{CO}_{2}$

$\mu_{\mathrm{CO}_{2}}=$ dynamic viscosity of $\mathrm{CO}_{2}$

3.3.18 Shell thickness

$t_{s}=\frac{p D_{s}}{f_{c} \times J-0.6 p}+c$

$t_{s}=$ shell thickness

$p=$ design pressure

$f_{c}=$ maximum allowable stress of the material of construction

$J=$ Joint efficiency (varies from 0.7 to 0.9 )

$D_{s}=$ shell diameter

$c=$ corrosion allowance 
3.3.19 Tube thickness

$t_{t}=\frac{p d_{o}}{2\left(f_{c} \times J+0.4 p\right)}$

$t_{t}=$ tube thickness

$d_{o}=$ tube outer diameter

$f_{c}=$ maximum allowable stress of the material of construction

$J=$ Joint efficiency (varies from 0.7 to 0.9 )

$p=$ design pressure 


\section{PRELIMINARY DESIGN AND OPTIMIZATION USING EMPIRICAL EQUATION}

The preliminary design of the $\mathrm{S}-\mathrm{CO}_{2}$ heat exchanger was conducted using empirical equations 3.3.1 to 3.3.19. The inner tube diameter selected varies from $0.028 \mathrm{~m}$ to $0.13 \mathrm{~m}$. The shell diameter selected varies from $4 \mathrm{~m}$ to $18 \mathrm{~m}$. Other constant parameters are specified in table 3.4 and 3.5 Also, the tube is one pass at initial set of $P t=1.5 \times d_{o} \& B=1.7 \times D_{s}$

4.1 Effect of shell inner diameter on the design and performance parameters $\boldsymbol{d}_{\boldsymbol{i}}=0.0092 \mathrm{~m}, \boldsymbol{D}_{\boldsymbol{s}},=6$ $18 \mathrm{~m} \boldsymbol{t}_{\boldsymbol{t}}=0.004 \mathrm{~m}$

Table 4.1 shows the effect of shell diameter on design details of the heat exchanger when the tube inner diameter is set as $0.092 \mathrm{~m}$. The values presented shows that the number of tubes, tube internal side surface area, tube external side surface area, volume of shell material, total volume of tube material, overall surface area and mass of material increases as the shell diameter increases. This is due to increase in cross sectional area [37]. However, the shell length, the number of baffles, overall heat transfer coefficient, the shell side pressure drop and tube side pressure drop all decreases as shell diameter increases, this is attributed to a reduced velocity caused by the increased total cross section area of tubes and baffle space [38]. These relations are presented in Figures 4.1 (a) to 4.1 (e). Smaller shell diameters are preferred as they offer fewer tube numbers, moderate shell and tube side pressure drop, reduced mass of heat exchanger material and a better overall heat transfer coefficient. This is seen in Table 4.1 for shell diameter $6 \mathrm{~m}$ and $18 \mathrm{~m}$. 
Table 4. 1: Effect of shell inner diameter on the design and performance parameters $\mathbf{d}_{\mathbf{i}}=0.0092 \mathrm{~m}$, $\mathbf{D}_{\mathbf{s}},=6-18 \mathrm{~m} \mathrm{t}_{\mathbf{t}}=0.004 \mathrm{~m}$

\begin{tabular}{|c|c|c|c|c|c|c|c|}
\hline \multirow{2}{*}{$\begin{array}{l}\text { Parameters } \\
\text { Shell Outer diameter }(\mathrm{m})\end{array}$} & \multicolumn{7}{|c|}{ Data } \\
\hline & 6.11 & 8.15 & 10.19 & 12.23 & 14.26 & 16.31 & 18.34 \\
\hline Shell Inner diameter (m) & 6 & 8 & 10 & 12 & 14 & 16 & 18 \\
\hline Shell Side Pressure drop (Bar) & 7.76 & 2.26 & 0.87 & 0.40 & 0.21 & 0.12 & 0.07 \\
\hline Shell length (m) & 36.67 & 30.25 & 26.10 & 23.16 & 20.96 & 19.23 & 17.85 \\
\hline Surface Area of Inner Shell $\left(\mathrm{m}^{2}\right)$ & 691.30 & 760.36 & 820.06 & 873.22 & 921.99 & 966.73 & $1,009.52$ \\
\hline Volume of Shell material $\left(\mathrm{m}^{3}\right)$ & 39.43 & 57.56 & 77.81 & 99.16 & 120.97 & 151.29 & 173.24 \\
\hline Tube number & 1,682 & 2,992 & 4,675 & 6,732 & 9,162 & 11,967 & 15,146 \\
\hline Tube Side Pressure drop $(\mathrm{Pa})$ & 364.04 & 110.05 & 43.72 & 20.63 & 10.96 & 6.35 & 3.93 \\
\hline Volume of tube material $\left(\mathrm{m}^{3}\right)$ & 0.04 & 0.04 & 0.03 & 0.03 & 0.03 & 0.02 & 0.02 \\
\hline Total volume of tubes material $\left(\mathrm{m}^{3}\right)$ & 74.42 & 109.20 & 147.22 & 188.11 & 231.70 & 277.65 & 326.19 \\
\hline Total length of tubes $(\mathrm{m})$ & 61,679 & 90,508 & 122,018 & 155,913 & 192,036 & 230,125 & 270,356 \\
\hline Tube internal side surface area $\left(\mathrm{m}^{2}\right)$ & 17,829 & 26,163 & 35,271 & 45,069 & 55,511 & 66,521 & 78,150 \\
\hline Tube external side surface area $\left(\mathrm{m}^{2}\right)$ & 19,380 & 28,438 & 38,338 & 48,988 & 60,338 & 72,305 & 84,946 \\
\hline Baffle number & 8 & 5 & 3 & 2 & 1 & 1 & 1 \\
\hline Overall heat transfer coefficient $\left(\mathrm{W} / \mathrm{m}^{2} \mathrm{~K}\right)$ & 84.02 & 57.31 & 42.51 & 33.26 & 27.00 & 22.53 & 19.18 \\
\hline Overall Area $\left(\mathrm{m}^{2}\right)$ & 17,899 & 26,240 & 35,379 & 45,215 & 55,686 & 66,751 & 78,387 \\
\hline Mass of material (kg) & 951,734 & $1,394,133$ & $1,881,234$ & $2,401,596$ & $2,948,302$ & $3,586,002$ & $4,175,253$ \\
\hline
\end{tabular}

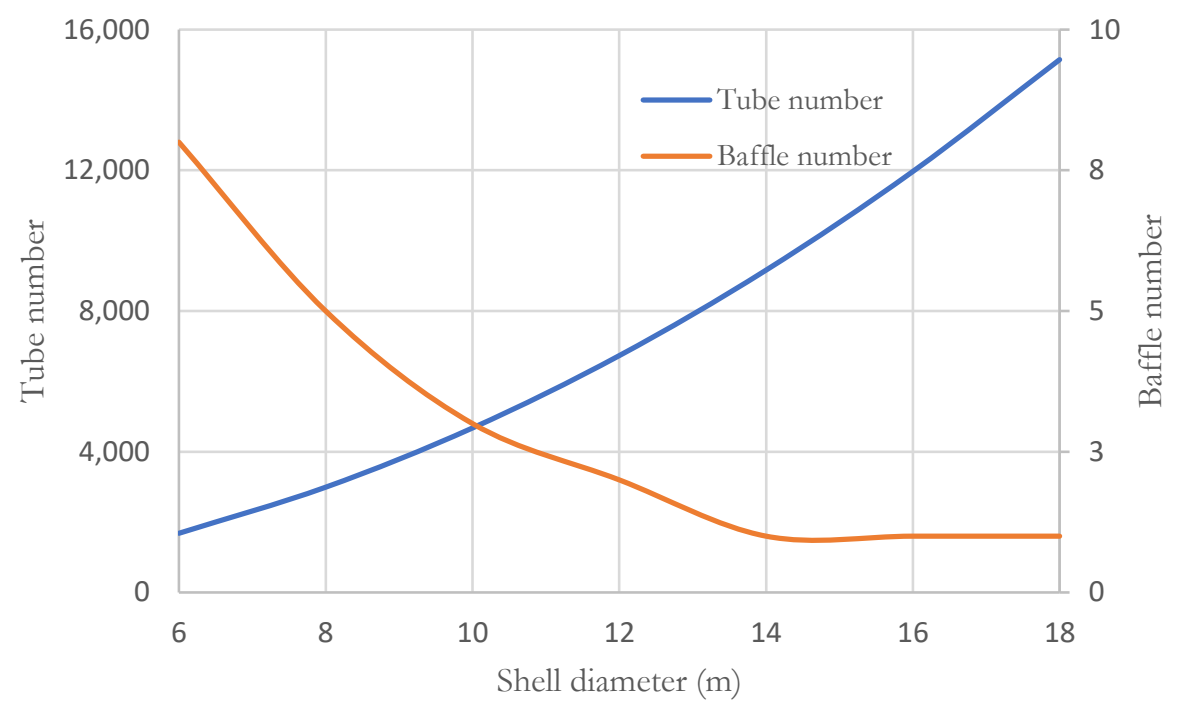

(a) Tube number and baffle number 


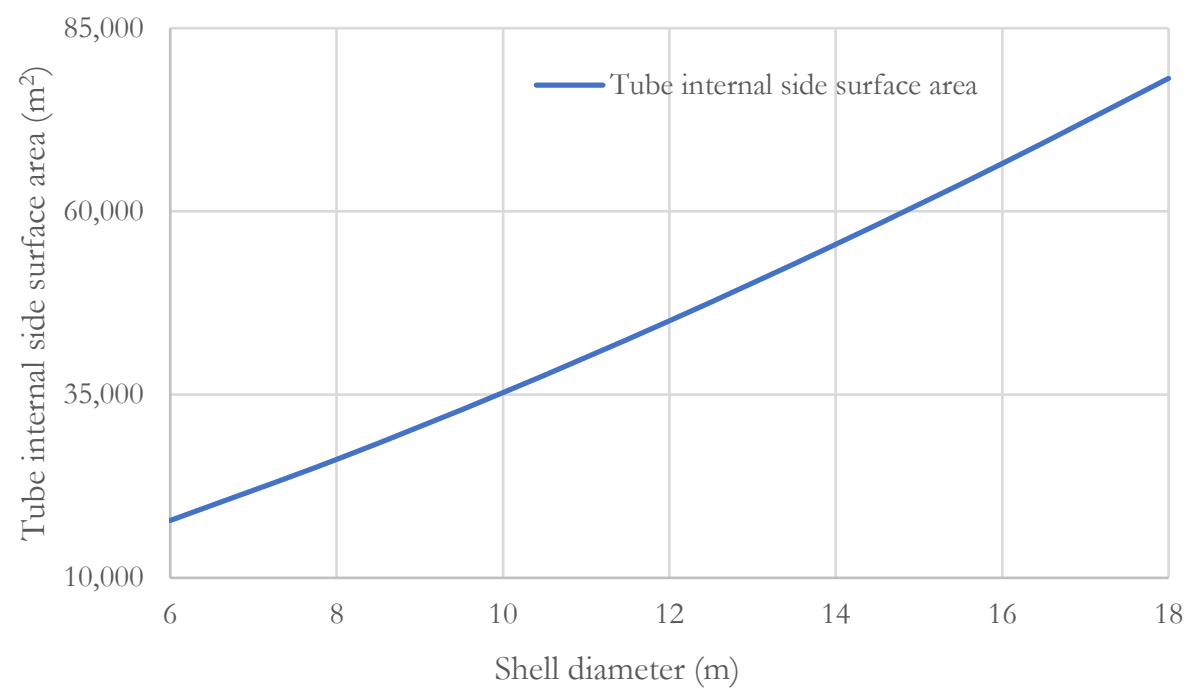

(b) Total tube internal side surface area

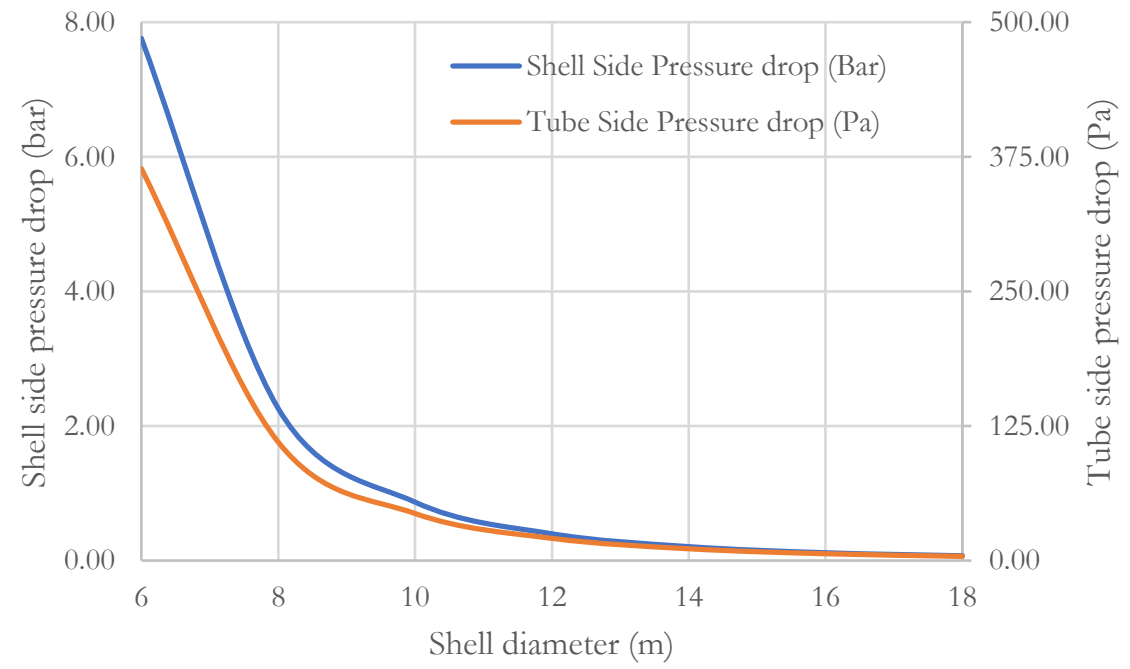

(c) shell side pressure drop and tube side pressure drop 


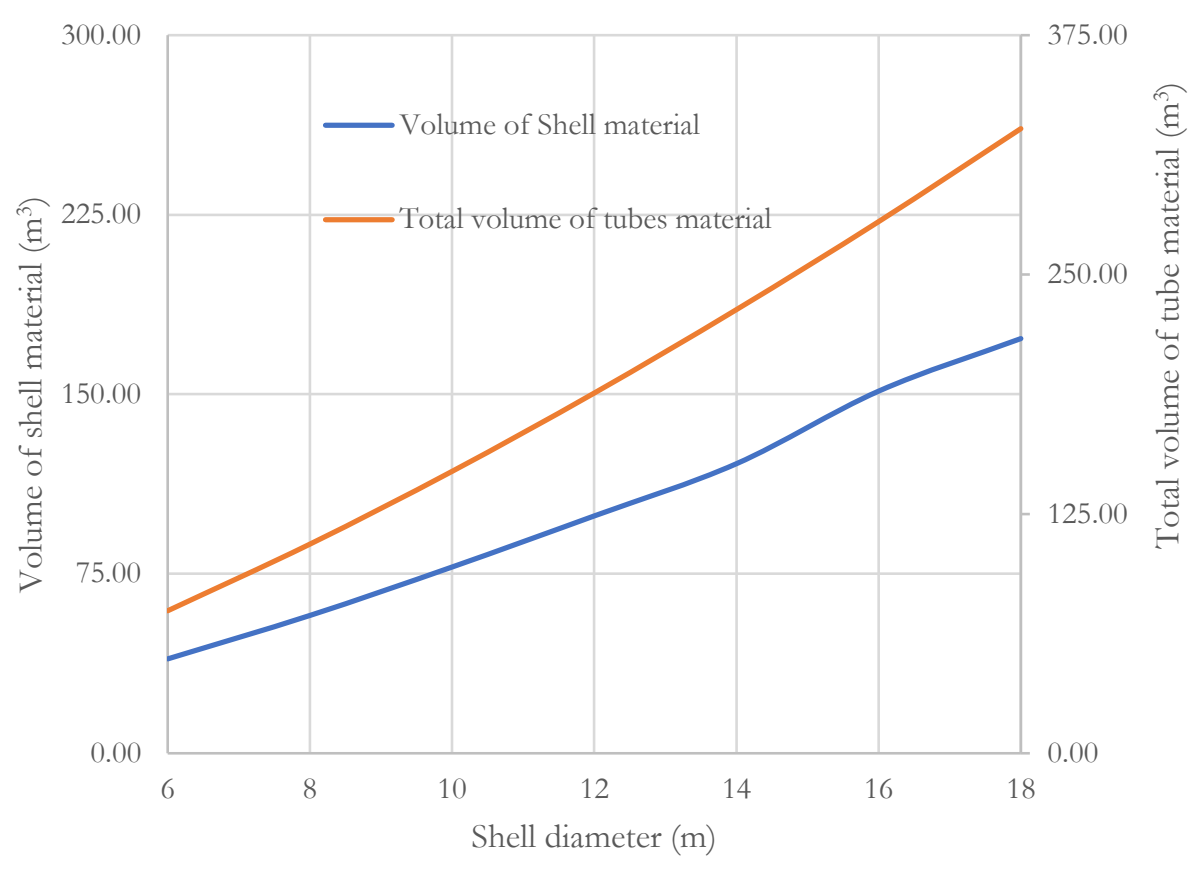

(d) volume of shell and total volume of tubes materials

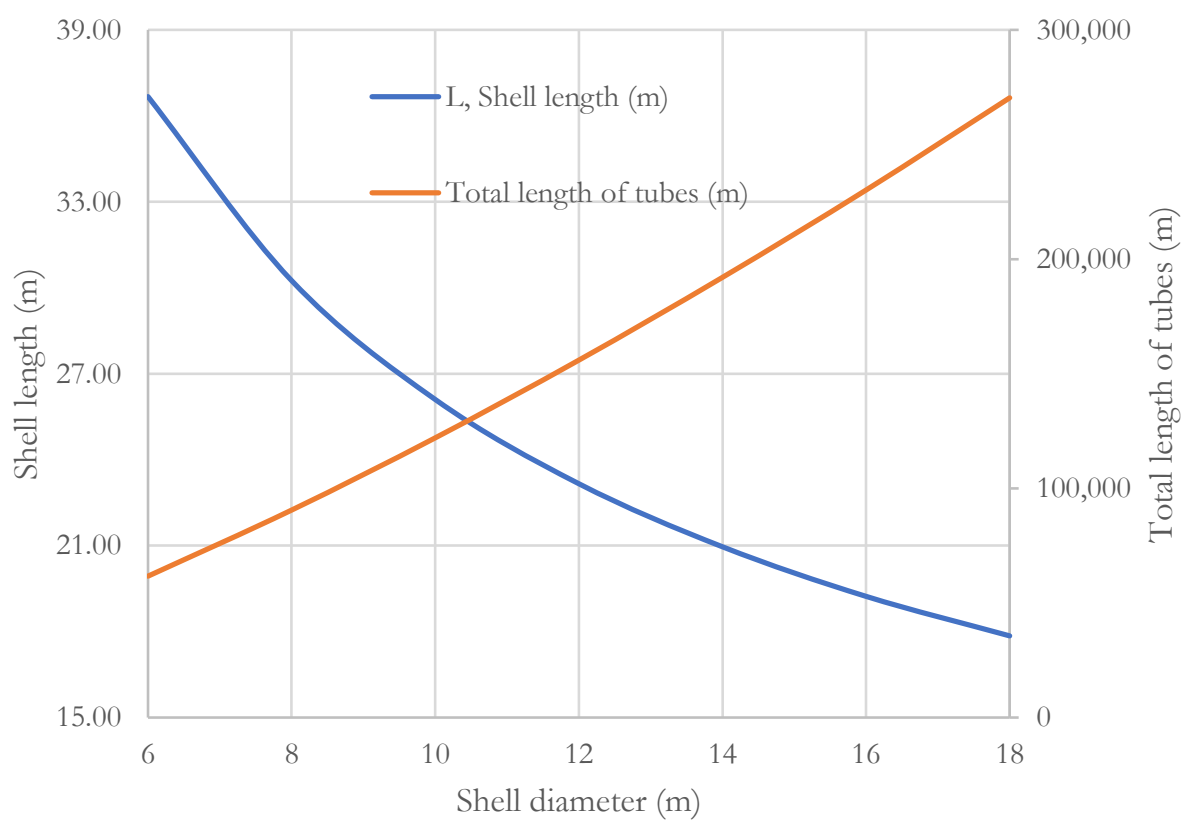

(e) Shell length and total length of tubes

Figure 4. 1: Effect of shell inner diameter on the design and performance parameters $\mathbf{d}_{\mathbf{i}}=0.0092 \mathrm{~m}$, $\mathbf{D}_{\mathbf{s}},=6-18 \mathrm{~m} \mathbf{t}_{\mathbf{t}}=0.004 \mathrm{~m}$ 
4.2 Effect of inner tube diameter on the design and performance parameters, $\mathbf{D}_{\mathbf{s}}=8 \mathrm{~m}, \mathbf{d}_{\mathbf{i}}=0.028-$ $0.120 \mathrm{~m} \mathrm{t}_{\mathbf{s}} .=0.075 \mathrm{~m}$

Table 4.2 shows the effect of inner tube diameter on the key design parameters which include the number of baffles, number of tubes, total surface area of shell, total surface area of tubes, volume of shell, total volume of tubes, shell length, the shell side pressure drop and tube side pressure drop when shell diameter is kept as $8 \mathrm{~m}$. Increasing the tube diameter increases the shell length, volume of tube, number of baffles, shell side pressure drop, tube side pressure drop, overall surface area of device, heat transfer area of inside tubes and heat transfer area of outside tubes. The overall heat transfer coefficient, total length of tubes and number of tubes decreases as tube diameter increases. These relations are presented in figures 4.2 (a) to (e). A tube diameter increase lead to decrease in the number of tubes arranged in the shell because the shell can accommodate less number of larger tubes than smaller one. The number of baffles is directly proportional to shell length. This is so because the number of baffles is a division of shell length by baffle space. It is important to also note that the total heat transfer coefficient increases as the tube diameter decreases, this is because of the increase in number of tubes arranged in the shell resulting in higher collision of the particles of the fluid moving round the tubes. 
Table 4. 2: Effect of inner tube diameter on the design and performance parameters, $\boldsymbol{D}_{\boldsymbol{s}}=8 \mathrm{~m}$, $\boldsymbol{d}_{\boldsymbol{i}}=0.028-0.120 \mathrm{~m} \boldsymbol{t}_{\boldsymbol{s}} .=0.075 \mathrm{~m}$

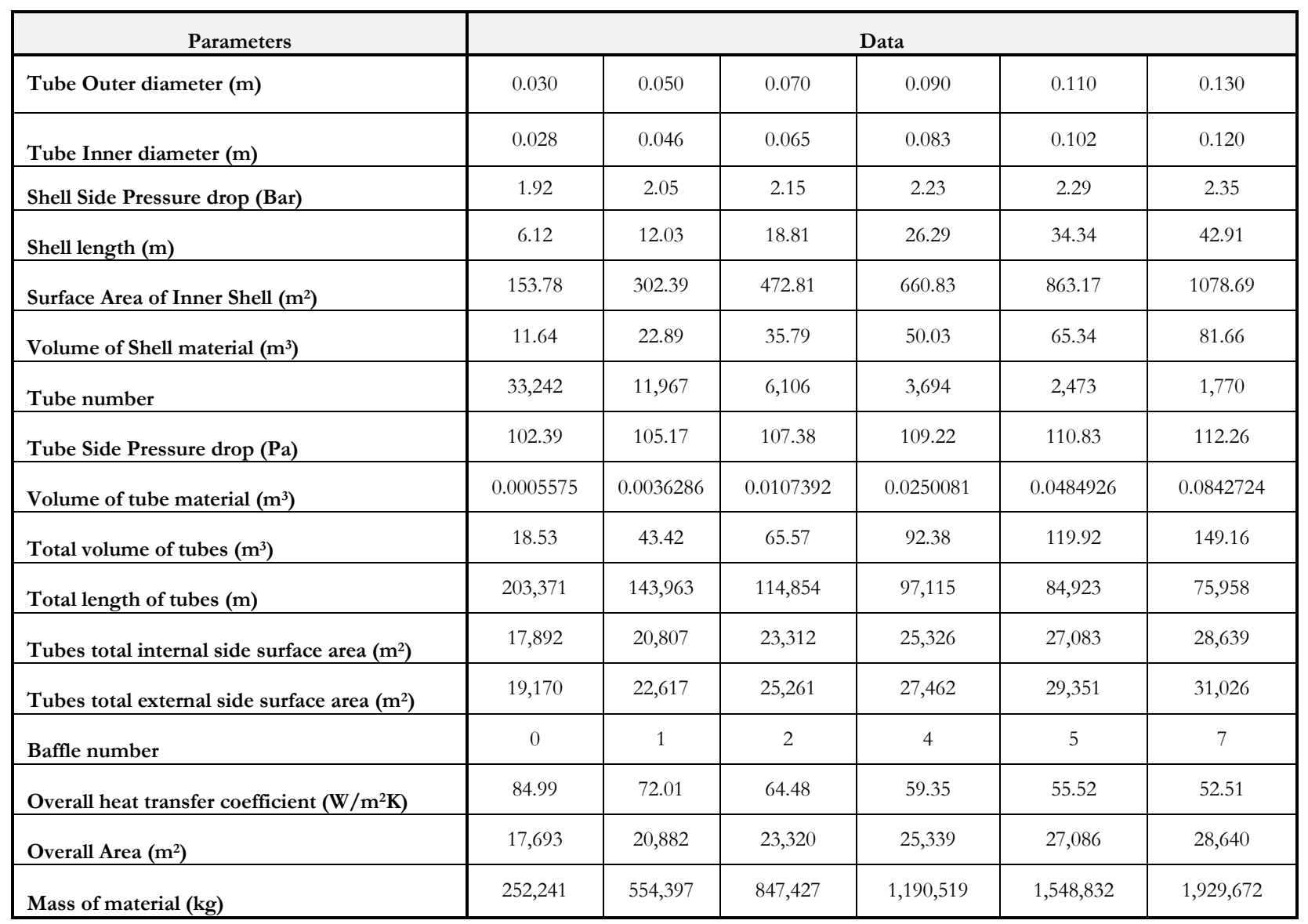

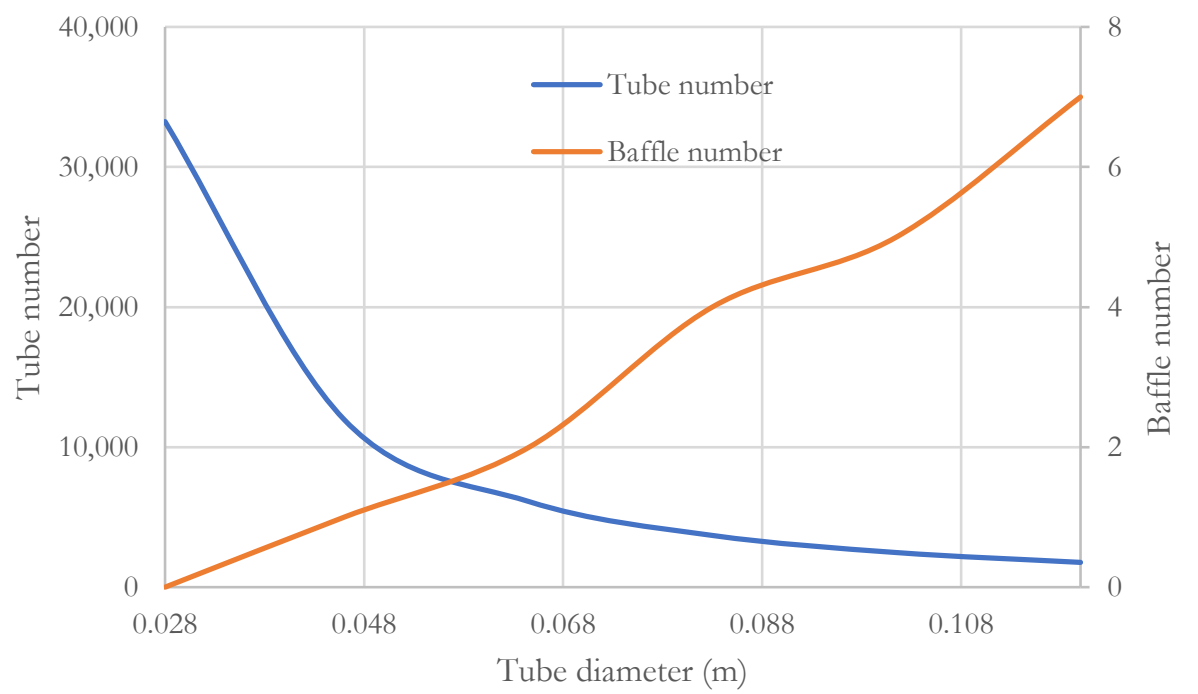

(a) Tube number and baffle number 


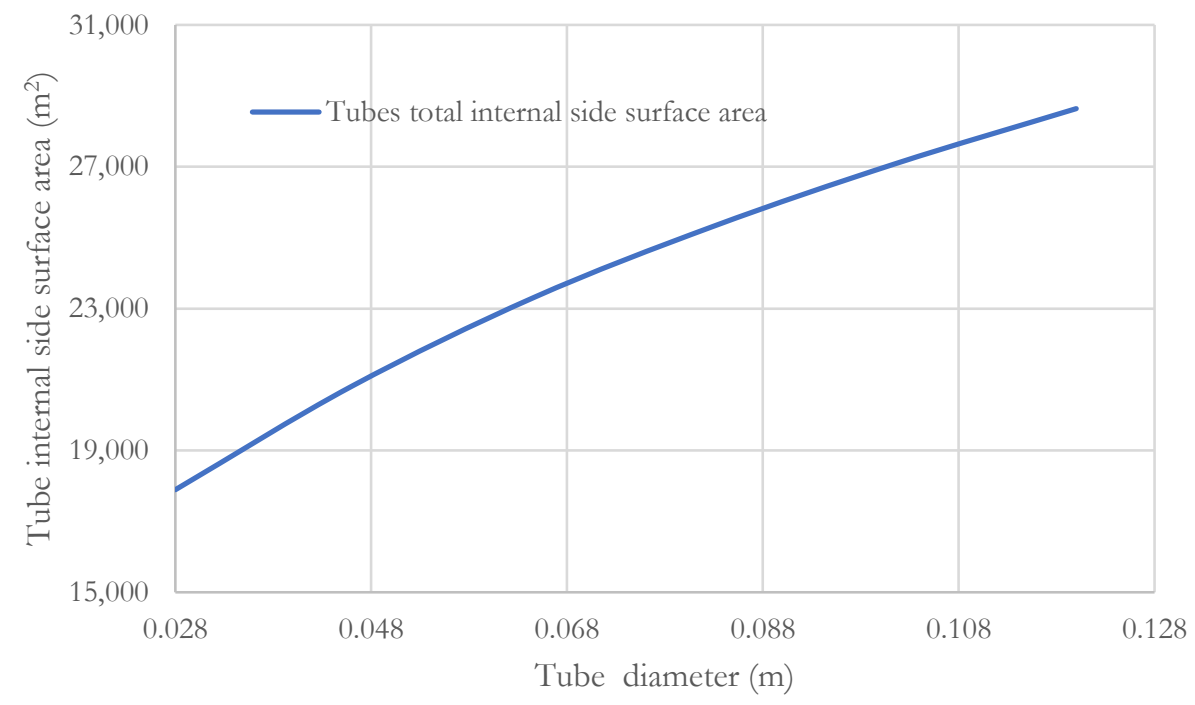

(b)Tubes total internal surface area

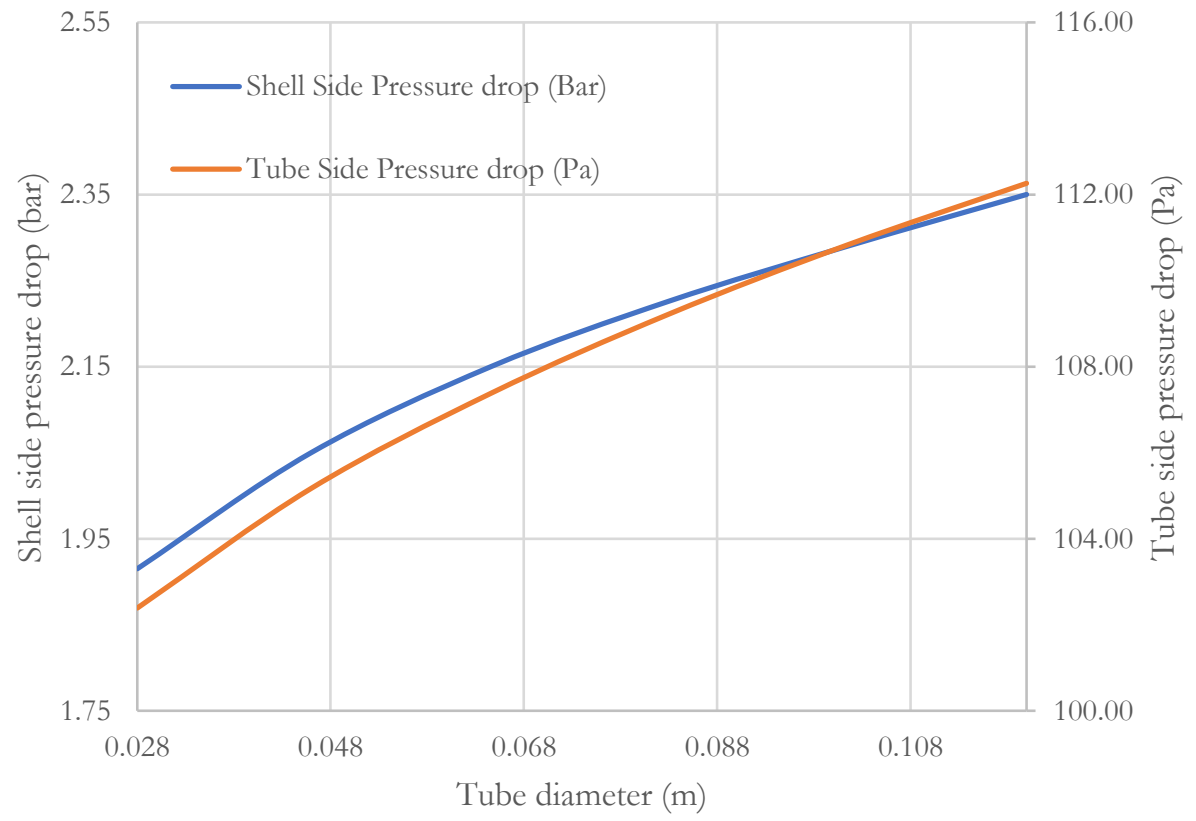

(c) Shell side pressure drop and tube side pressure drop 


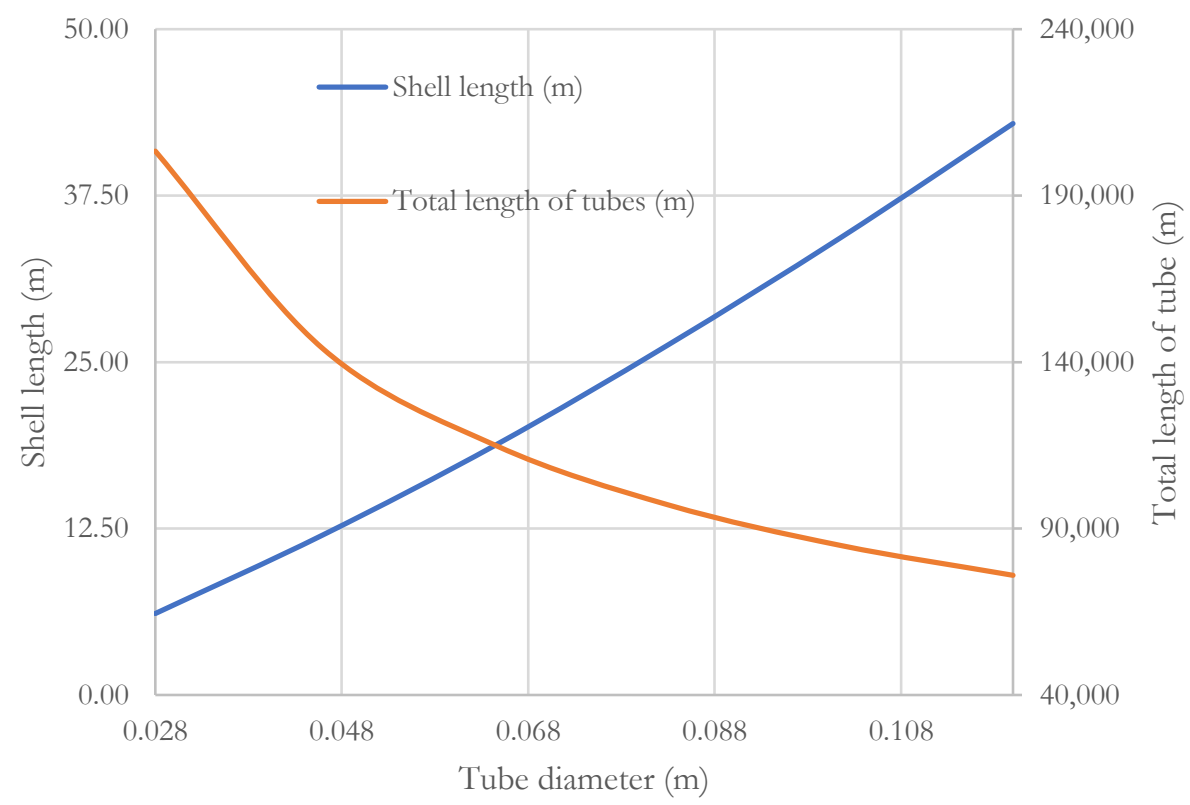

(d) Shell length and total length of tubes

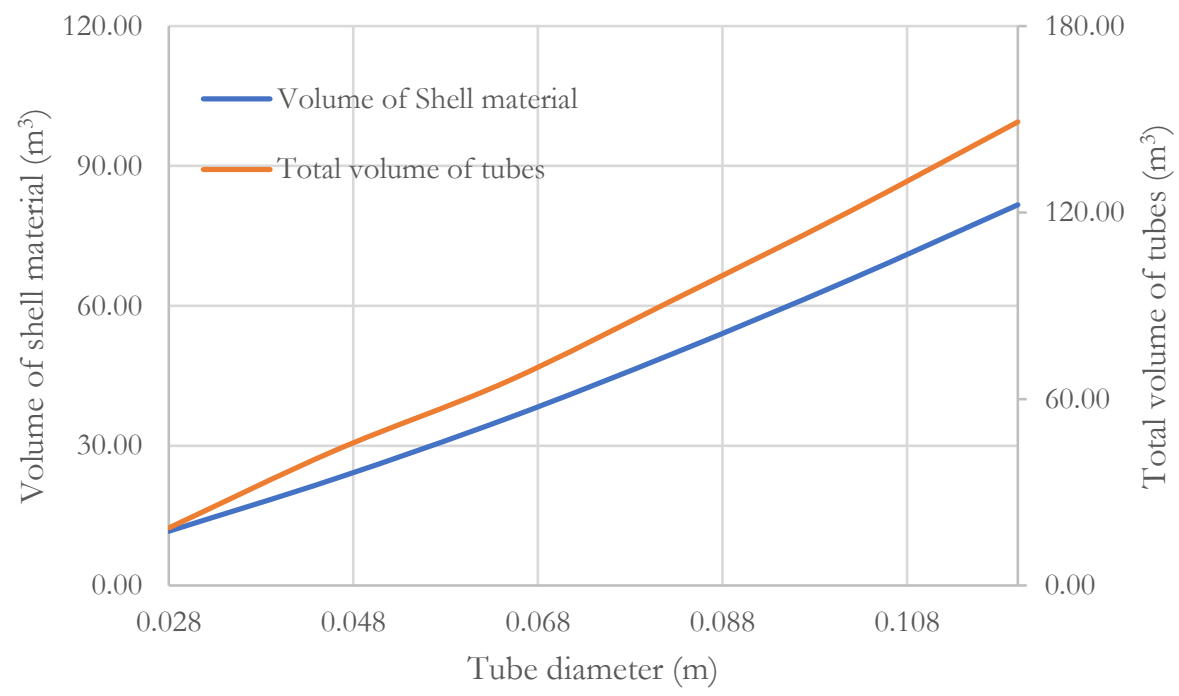

(e)Volume of shell and total volume of tubes

Figure 4. 2: Effect of inner tube diameter on the design and performance parameters, $\boldsymbol{D}_{\boldsymbol{s}}=8 \mathrm{~m}$, $\boldsymbol{d}_{\boldsymbol{i}}=0.028-0.120 \mathrm{~m} \boldsymbol{t}_{\boldsymbol{s}} .=0.075 \mathrm{~m}$ 
4.3 Effect of tube and shell diameter on the design and performance parameters, $D_{s},=4-16 \mathrm{~m}$ $d_{i}=0.05,0.09 \& 0.13 \mathrm{~m}$.

The combined effects of tube diameter and shell diameter have been checked against tube number, shell length, volume of tube material, volume of shell material, shell side pressure drop, tube side pressure drop, total surface area for heat transfer, and overall heat transfer coefficient.

Table 4.3 and Figure 4.3 show the effect of tube and shell diameter on tube numbers. The tube number increases with the increased shell diameter and decreased tube diameter. This signifies that more tubes are required to fill a shell diameter space for smaller tube diameters as compared to larger tubes.

Table 4. 3: Effect of tube and shell diameter on tube number

\begin{tabular}{|l|c|c|c|c|c|c|c|}
\hline \multicolumn{1}{|c|}{ Parameter } & \multicolumn{7}{c|}{ Data } \\
\hline Shell Outer diameter $(\mathbf{m})$ & 4.08 & 6.11 & 8.15 & 10.19 & 12.23 & 14.26 & 16.30 \\
\hline Shell Inner diameter $(\mathbf{m})$ & 4 & 6 & 8 & 10 & 12 & 14 & 16 \\
\hline Tube number $\mathbf{d}_{\mathbf{i}}=\mathbf{0 . 0 5} \mathbf{~ m}$ & 2,992 & 6,732 & 11,967 & 18,699 & 26,926 & 36,649 & 47,868 \\
\hline Tube number $\mathbf{d}_{\mathbf{i}}=\mathbf{0 . 0 9} \mathbf{~ m}$ & 923 & 2,078 & 3,694 & 5,771 & 8,310 & 11,311 & 14,774 \\
\hline Tube number $\mathbf{d}_{\mathbf{i}}=\mathbf{0 . 1 3} \mathbf{~ m}$ & 443 & 996 & 1,770 & 2,766 & 3,983 & 5,422 & 7,081 \\
\hline
\end{tabular}

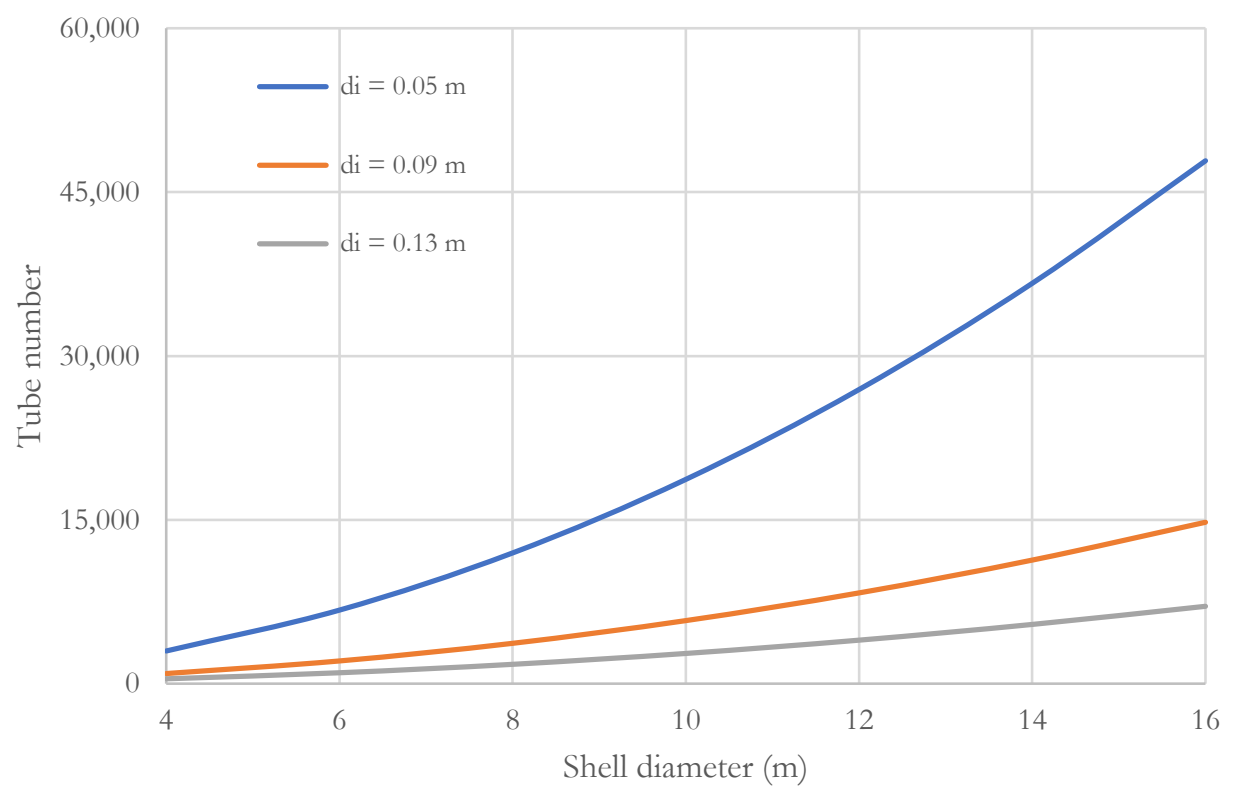

Figure 4. 3: Effect of tube and shell diameter on tube number 
4.4 Effect of tube and shell diameter on shell length

Table 4.4 and Figure 4.4 shows the effect of shell and tube diameter on the length of shell needed for this heat exchanger to achieve the heat transfer needed. As expected, decreasing the tube diameter decreases the length needed for the same shell diameter. Decreasing tube diameter from $0.13 \mathrm{~m}$ to $0.05 \mathrm{~m}$ at $8 \mathrm{~m}$ shell diameter decreased the shell length from $60.18 \mathrm{~m}$ to $16.35 \mathrm{~m}$, which is $72.83 \%$ of the shell length observed at tube diameter of $0.13 \mathrm{~m}$. This is due to the increased surface area/volume ratio of the smaller tube compared to the large one as shown in Table 4.5 and Figure 4.5. In comparison, increasing shell diameter also decreases the length of the heat exchanger but at relatively less scale. For example, the shell length observed at $16 \mathrm{~m}$ shell diameter and $0.13 \mathrm{~m}$ tube diameter is $36.46 \mathrm{~m}$ which is $63.05 \%$ of the $60.18 \mathrm{~m}$ shell length derived at shell diameter of $8 \mathrm{~m}$. It is evident that decreasing shell diameter is more effective in reducing shell length

Table 4. 4: Effect of tube and shell diameter on shell length, $m$

\begin{tabular}{|c|c|c|c|c|c|c|c|}
\hline Parameter & \multicolumn{5}{|c|}{ Data } \\
\hline Shell Outer diameter $(\mathbf{m})$ & 4.08 & 6.11 & 8.15 & 10.19 & 12.23 & 14.26 & 16.30 \\
\hline Shell Inner diameter $\mathbf{( m )}$ & 4 & 6 & 8 & 10 & 12 & 14 & 16 \\
\hline Shell length $(\mathbf{m}) \mathbf{d}_{\mathbf{i}}=\mathbf{0 . 0 5} \mathbf{~ m}$ & 27.15 & 20.14 & 16.35 & 13.95 & 12.26 & 11.02 & 10.06 \\
\hline Shell length $(\mathbf{m}) \mathbf{d}_{\mathbf{i}}=\mathbf{0 . 0 9} \mathbf{~ m}$ & 60.94 & 44.95 & 36.42 & 30.98 & 27.18 & 24.36 & 22.19 \\
\hline Shell length $(\mathbf{m}) \mathbf{d}_{\mathbf{i}}=\mathbf{0 . 1 3} \mathbf{~ m}$ & 101.30 & 74.45 & 60.18 & 51.12 & 44.80 & 40.10 & 36.46 \\
\hline
\end{tabular}

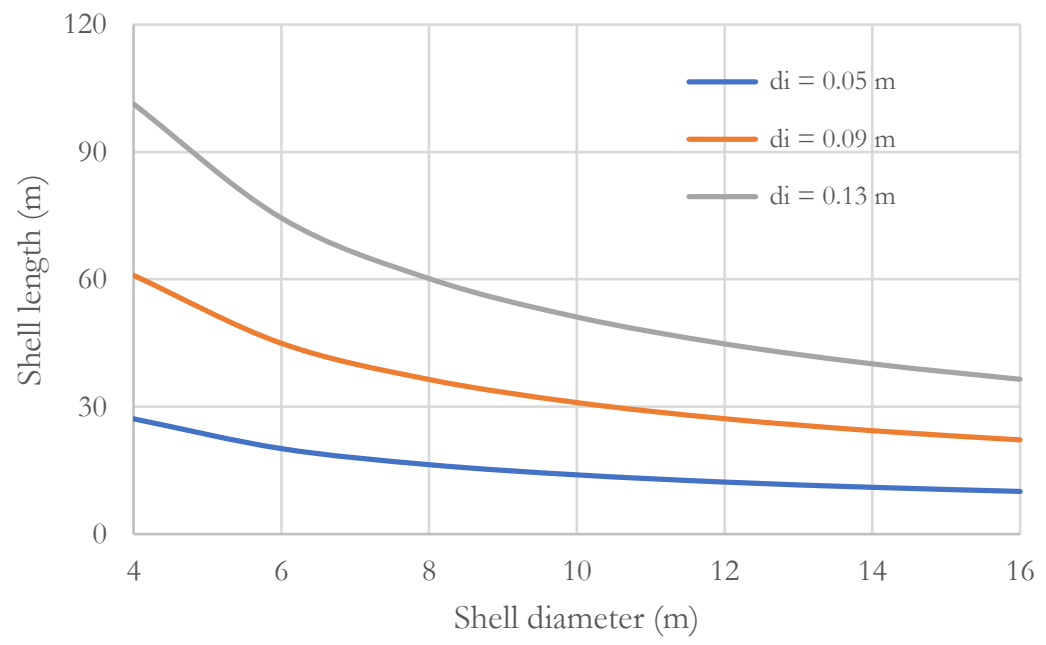

Figure 4. 4: Effect of tube and shell diameter on shell length, $\mathrm{m}$ 
Table 4. 5: Effect of tube diameter on surface area to volume ratio, $\mathrm{m}$

\begin{tabular}{|c|c|c|c|c|c|c|c|}
\hline Tube Outer diameter (m) & 0.010 & 0.030 & 0.050 & 0.070 & 0.090 & 0.110 & 0.130 \\
\hline Tube Inner diameter (m) & 0.009 & 0.028 & 0.046 & 0.065 & 0.083 & 0.102 & 0.120 \\
\hline Side surface area to volume ratio of tube $\left(\mathrm{m}^{-1}\right)$ & 2496 & 832 & 499.2 & 356.57 & 277.33 & 226.91 & 192 \\
\hline
\end{tabular}

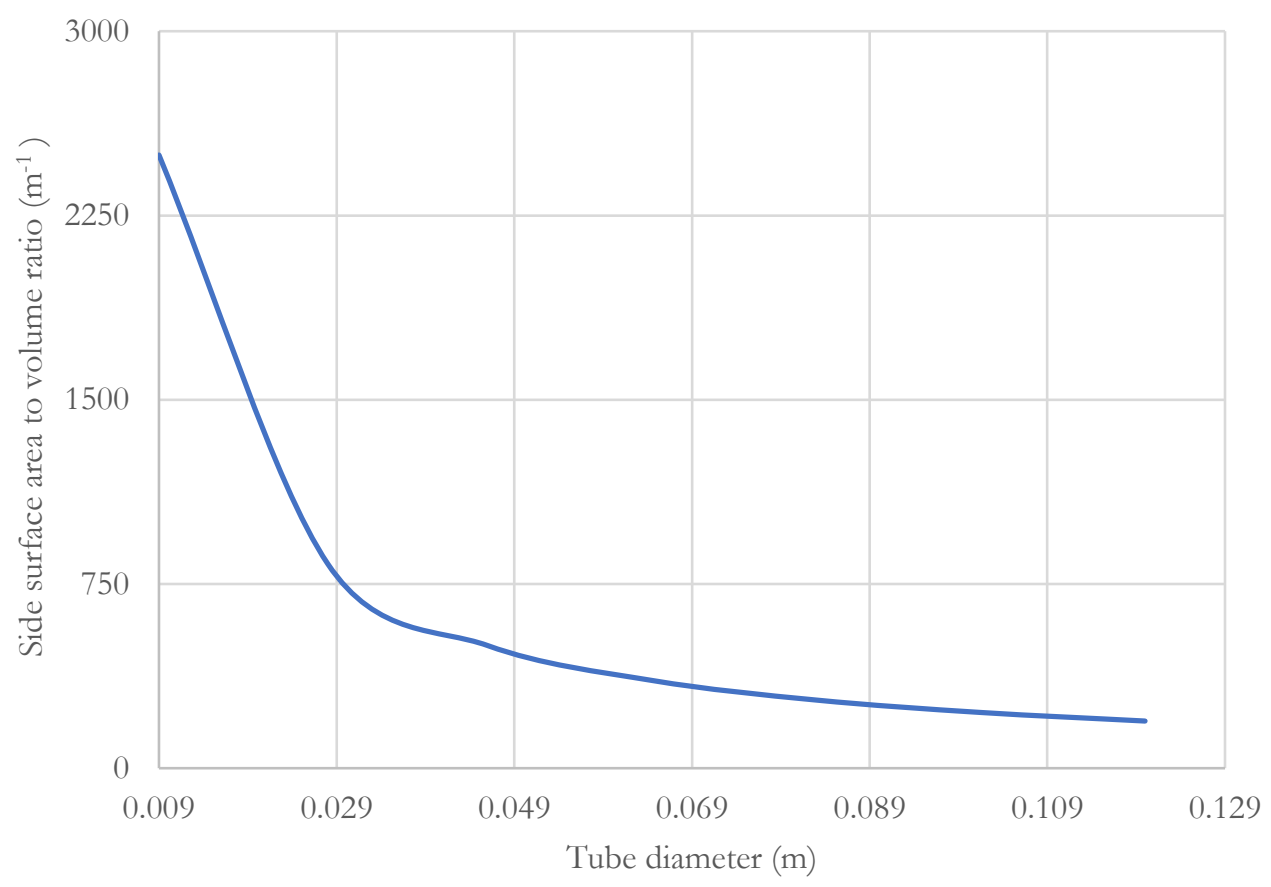

Figure 4. 5: Effect of tube diameter on side surface area to volume ratio.

4.5 Effect of tube and shell diameter on total volume of tube material, $\mathrm{m}^{3}$

As shown in Table 4.6 and Figure 4.6, the total volume of tube material decreases significantly with the decreasing shell diameter for tube diameter $0.13 \mathrm{~m}$ when compared to tube diameter $0.09 \mathrm{~m}$ and $0.05 \mathrm{~m}$. For bigger tubes, the decrease in volume of tube material is sharply noticed while for smaller tubes, the changes is relatively small. Decreasing the diameter of the tube decreases the total volume of tube material due to the increased surface area for heat transfer and reduced tube thickness from $5.00 \mathrm{~mm}$ to $1.90 \mathrm{~mm}$. The heat exchanger should be designed as small shell diameter, with small tubes. 
Table 4. 6: Effect of tube and shell diameter on total volume of tube material, $\mathrm{m}^{3}$

\begin{tabular}{|l|c|c|c|c|c|c|c|}
\hline \multicolumn{1}{|c|}{ Parameter } & \multicolumn{7}{c|}{ Data } \\
\hline Shell Outer diameter $(\mathbf{m})$ & 4.08 & 6.11 & 8.15 & 10.19 & 12.23 & 14.26 & 16.30 \\
\hline Shell Inner diameter $(\mathbf{m})$ & 4 & 6 & 8 & 10 & 12 & 14 & 16 \\
\hline Total volume of tube material $\left(\mathbf{m}^{\mathbf{3}}\right) \mathbf{d}_{\mathbf{i}}=\mathbf{0 . 0 5} \mathbf{~}$ & 23.59 & 39.38 & 56.85 & 75.75 & 95.92 & 117.28 & 139.85 \\
\hline Total volume of tube material $\left(\mathbf{m}^{\mathbf{3}}\right) \mathbf{d}_{\mathbf{i}}=\mathbf{0 . 0 9} \mathbf{~ m}$ & 52.96 & 87.96 & 126.60 & 168.27 & 212.58 & 259.30 & 308.27 \\
\hline Total volume of tube material $\left(\mathbf{m}^{3}\right) \mathbf{d}_{\mathbf{i}}=\mathbf{0 . 1 3} \mathbf{~ m}$ & 88.04 & 145.68 & 209.22 & 277.68 & 350.38 & 426.92 & 506.97 \\
\hline
\end{tabular}

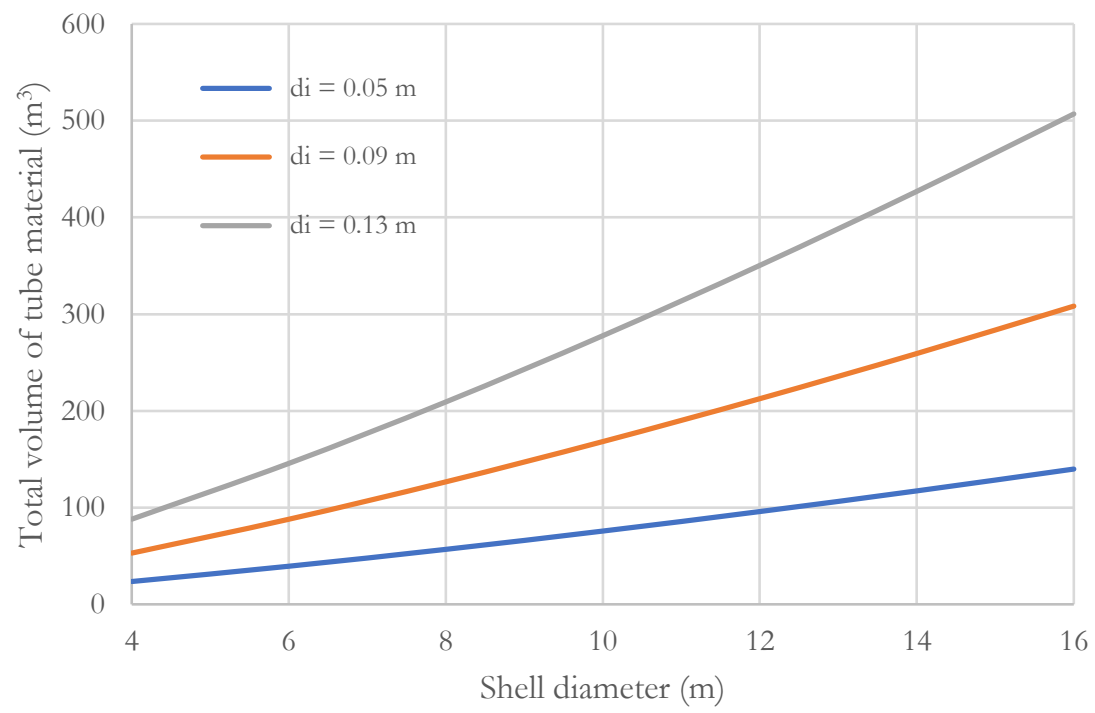

Figure 4. 6: Effect of tube and shell diameter on total volume of tube material, $\mathrm{m}^{3}$

4.6 Effect of tube and shell diameter on volume of shell material

In Table 4.7 and Figure 4.7, the volume of shell materials increases significantly for tube diameter 0.05 $\mathrm{m}, 0.09 \mathrm{~m}$ and $0.13 \mathrm{~m}$ at about same proportion. This is to further buttress the observation from figure 4.1 and figure 4.2. It is seen that at shell diameter $6 \mathrm{~m}$, a decrease in volume of shell material by 72.96 $\%$ when tube diameter was reduced from $0.13 \mathrm{~m}$ to $0.05 \mathrm{~m}$. A decrease in volume of shell material by $48.0 \%$ is seen at tube diameter $0.05 \mathrm{~m}$ when shell diameter decreases from $10 \mathrm{~m}$ to $6 \mathrm{~m}$. A conclusion that reduction in tube diameter helps greatly in decreasing the amount of shell material is noticed. 
Table 4. 7: Effect of tube and shell diameter on volume of shell material, $\mathrm{m}^{3}$

\begin{tabular}{|l|c|c|c|c|c|c|c|}
\hline \multicolumn{1}{|c|}{ Parameter } & \multicolumn{7}{c|}{ Data } \\
\hline Shell Outer diameter $(\mathbf{m})$ & 4.08 & 6.11 & 8.15 & 10.19 & 12.23 & 14.26 & 16.30 \\
\hline Shell Inner diameter $(\mathbf{m})$ & 4 & 6 & 8 & 10 & 12 & 14 & 16 \\
\hline Volume of Shell material $\left(\mathbf{m}^{\mathbf{3}}\right) \mathbf{d}_{\mathbf{i}}=\mathbf{0 . 0 5} \mathbf{~ m}$ & 12.58 & 21.63 & 31.22 & 41.60 & 52.67 & 64.40 & 76.79 \\
\hline Volume of Shell material $\left(\mathbf{m}^{\mathbf{3}}\right) \mathbf{d}_{\mathbf{i}}=\mathbf{0 . 0 9} \mathbf{~ m}$ & 28.08 & 48.30 & 69.52 & 92.40 & 116.73 & 142.38 & 169.28 \\
\hline Volume of Shell material $\left(\mathbf{m}^{\mathbf{3}}\right) \mathbf{d}_{\mathbf{i}}=\mathbf{0 . 1 3} \mathbf{~ m}$ & 48.35 & 79.99 & 114.88 & 152.47 & 192.40 & 234.43 & 278.38 \\
\hline
\end{tabular}

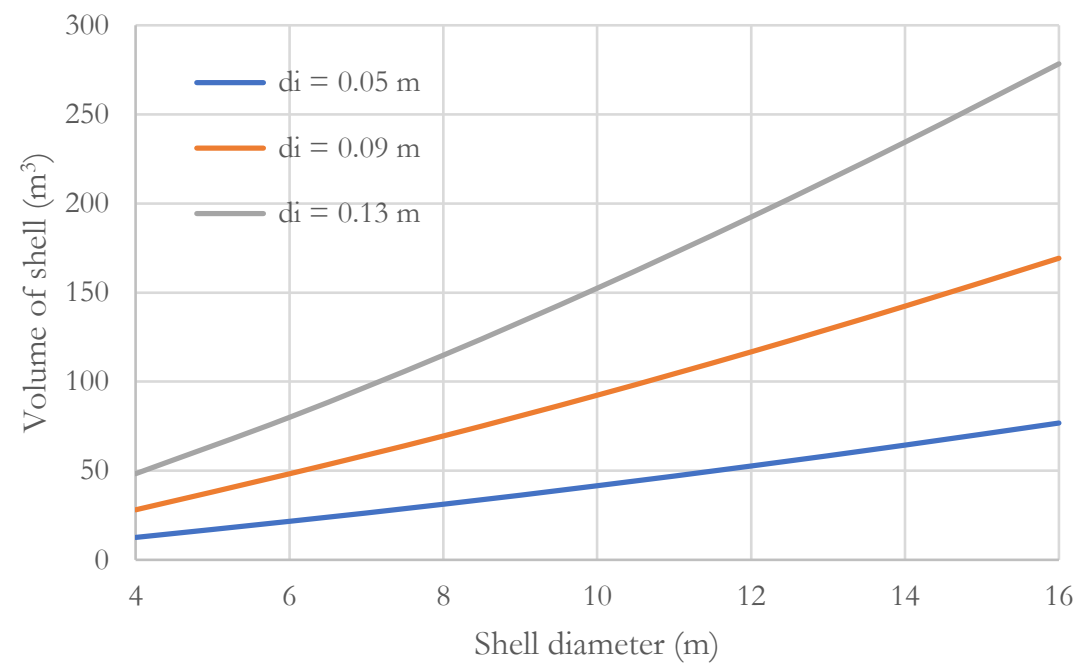

Figure 4. 7: Effect of tube and shell diameter on volume of shell material, $\mathrm{m}^{3}$

4.7 Effect of tube and shell diameter on tube side pressure drop

Table 4.8 and Figure 4.8 shows the effect of tube diameter and shell diameter on pressure drop of $\mathrm{CO}_{2}$ flowing in the tube. As expected, increasing shell diameter decreases the pressure drop as more tubes are used which decrease the velocity of $\mathrm{CO}_{2}$ and length of tube (shell). In comparison, the effect of tube diameter on pressure drop is negligible with the range of tube diameter examined. It should be noted that the pressure drop in tube is very small compared to the $10 \mathrm{MPa}$ working pressure of $\mathrm{CO}_{2}$ in tube. 
Table 4. 8: Effect of tube and shell diameter on tube side pressure drop, $\mathrm{Pa}$

\begin{tabular}{|l|c|c|c|c|c|c|c|}
\hline Parameter & \multicolumn{7}{c|}{ Data } \\
\hline Shell Outer diameter $(\mathbf{m})$ & 4.08 & 6.11 & 8.15 & 10.19 & 12.23 & 14.26 & 16.30 \\
\hline Shell Inner diameter $(\mathbf{m})$ & 4 & 6 & 8 & 10 & 12 & 14 & 16 \\
\hline Tube Side Pressure drop $\mathbf{( P a )} \mathbf{d}_{\mathbf{i}}=\mathbf{0 . 0 5} \mathbf{~ m}$ & $2,341.58$ & 422.00 & 126.62 & 50.03 & 23.53 & 12.47 & 7.22 \\
\hline Tube Side Pressure drop $\mathbf{( P a )} \mathbf{d}_{\mathbf{i}}=\mathbf{0 . 0 9} \mathbf{~ m}$ & $2,529.05$ & 450.34 & 133.82 & 52.52 & 24.55 & 12.94 & 7.45 \\
\hline Tube Side Pressure drop $\mathbf{( P a )} \mathbf{d}_{\mathbf{i}}=\mathbf{0 . 1 3} \mathbf{~ m}$ & $2,668.00$ & 470.95 & 139.16 & 54.38 & 25.33 & 13.32 & 7.64 \\
\hline
\end{tabular}

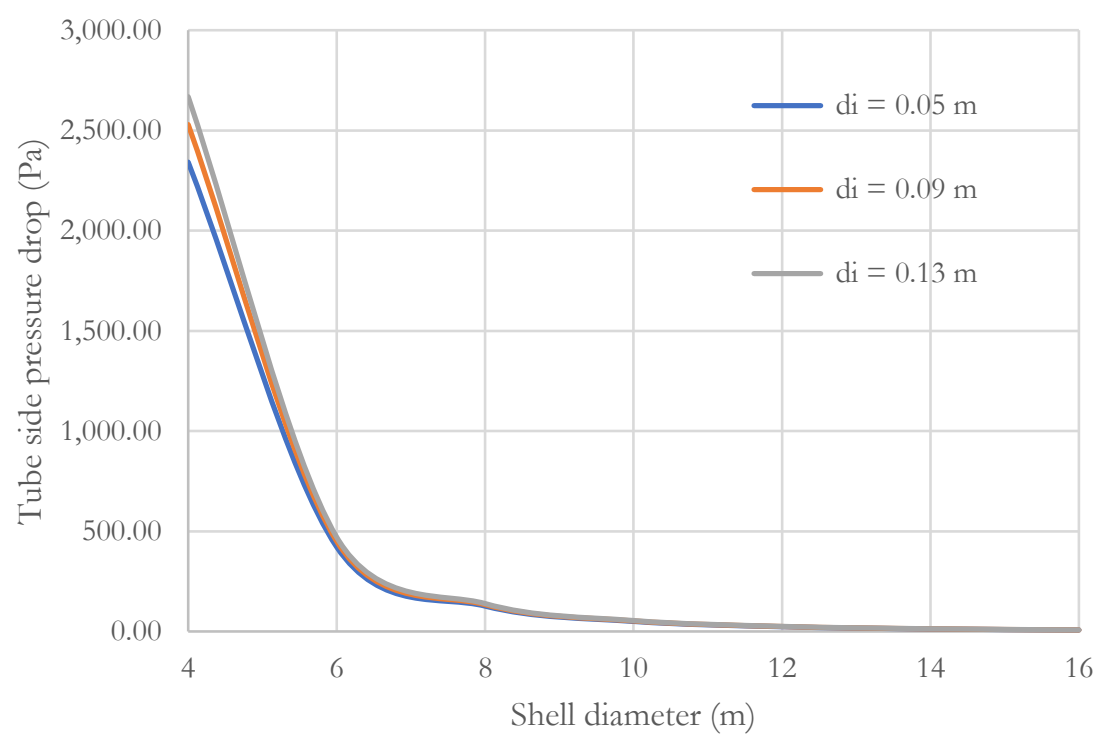

Figure 4. 8: Effect of tube and shell diameter on tube side pressure drop, $\mathrm{Pa}$

4.8 Effect of tube and shell diameter on shell side pressure drop

Table 4.9 and Figure 4.9 shows the effect of tube and shell diameters on the pressure drop in shell side. It is evident that the pressure drop in shell side is dominated by shell diameter. Increasing shell diameter increases the cross-section area and decrease the velocity of air. Table 4.10 and Figure 4.10 shows the effect of shell and tube diameter on the velocity of air in shell examined. The changes in velocity is dominated by the shell diameter. The decreased shell length at large shell diameter also linearly decreases the pressure drop in shell side. It was observed that shell side pressure drops had a major decrease as shell diameter increased from $4 \mathrm{~m}$ to $16 \mathrm{~m}$ showing that low shell side pressure drop 
is achieved as shell diameter increases. This is in further compliance with the observations of session

\section{1 and 4.2}

Table 4. 9: Effect of tube and shell diameter on shell side pressure drop, bar

\begin{tabular}{|l|c|c|c|c|c|c|c|}
\hline \multicolumn{1}{|c|}{ Parameter } & \multicolumn{7}{c|}{ Data } \\
\hline Shell Outer diameter $(\mathbf{m})$ & 4.08 & 6.11 & 8.15 & 10.19 & 12.23 & 14.26 & 16.30 \\
\hline Shell Inner diameter $(\mathbf{m})$ & 4 & 6 & 8 & 10 & 12 & 14 & 16 \\
\hline Shell Side Pressure drop (Bar) $\mathbf{d}_{\mathbf{i}}=\mathbf{0 . 0 5} \mathbf{~ m}$ & 10.120 & 1.730 & 0.496 & 0.189 & 0.085 & 0.044 & 0.025 \\
\hline Shell Side Pressure drop (Bar) $\mathbf{d}_{\mathbf{i}}=\mathbf{0 . 0 9} \mathbf{~ m}$ & 11.289 & 1.920 & 0.548 & 0.208 & 0.094 & 0.048 & 0.027 \\
\hline Shell Side Pressure drop (Bar) $\mathbf{d}_{\mathbf{i}}=\mathbf{0 . 1 3} \mathbf{~ m}$ & 12.120 & 2.050 & 0.585 & 0.222 & 0.100 & 0.051 & 0.029 \\
\hline
\end{tabular}

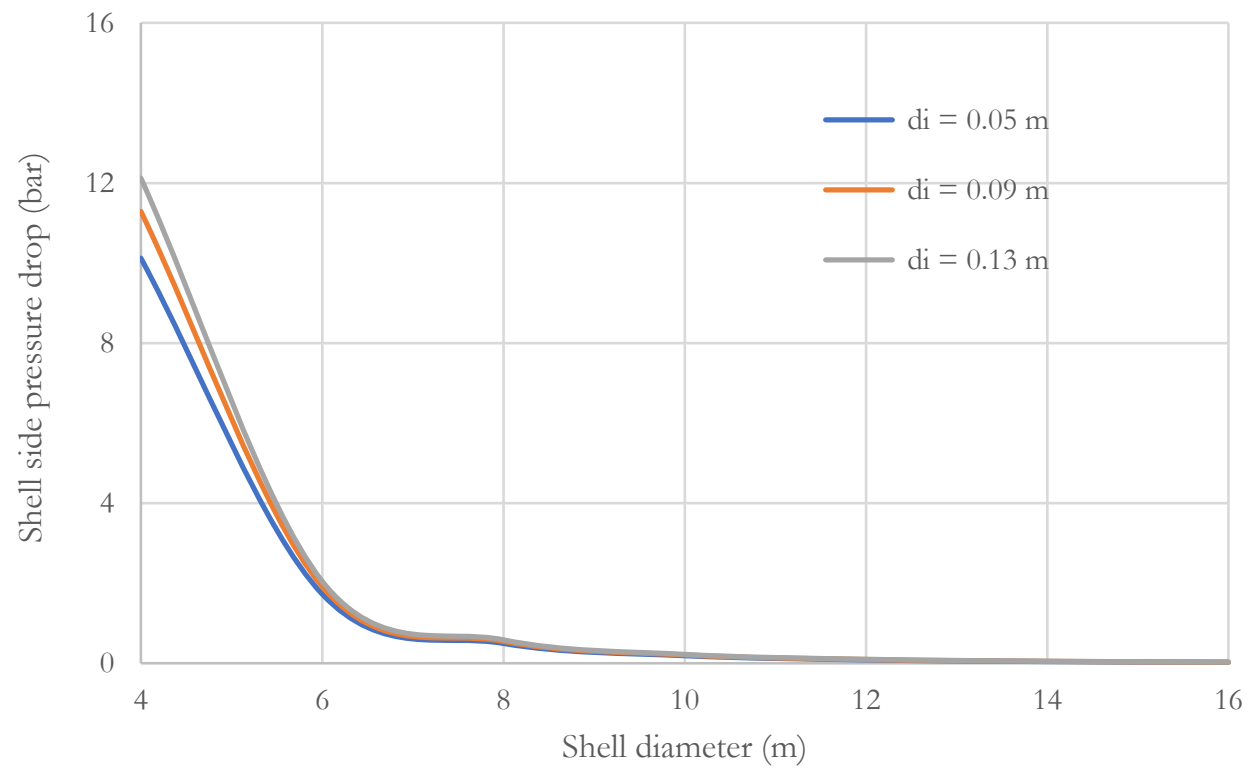

Figure 4. 9: Effect of tube and shell diameter on shell side pressure drop, bar

Table 4. 10: Effect of shell and tube diameter on the velocity of air, $\mathrm{m} / \mathrm{s}$

\begin{tabular}{|c|c|c|c|c|c|c|c|}
\hline Parameter & \multicolumn{7}{|c|}{ Data } \\
\hline Shell Outer diameter $(\mathrm{m})$ & 4.08 & 6.11 & 8.15 & 10.19 & 12.23 & 14.26 & 16.30 \\
\hline Shell Inner diameter $(\mathrm{m})$ & 4 & 6 & 8 & 10 & 12 & 14 & 16 \\
\hline Velocity of Air $(\mathrm{m} / \mathrm{s}) \mathrm{d}_{\mathrm{i}}=0.05 \mathrm{~m}$ & 448.34 & 199.26 & 112.09 & 71.74 & 49.82 & 36.60 & 28.02 \\
\hline Velocity of Air $(\mathrm{m} / \mathrm{s}) \mathrm{d}_{\mathrm{i}}=0.09 \mathrm{~m}$ & 448.34 & 199.26 & 112.09 & 71.74 & 49.82 & 36.60 & 28.02 \\
\hline Velocity of Air $(\mathrm{m} / \mathrm{s}) \mathrm{d}_{\mathrm{i}}=0.13 \mathrm{~m}$ & 448.34 & 199.26 & 112.09 & 71.74 & 49.82 & 36.60 & 28.02 \\
\hline
\end{tabular}




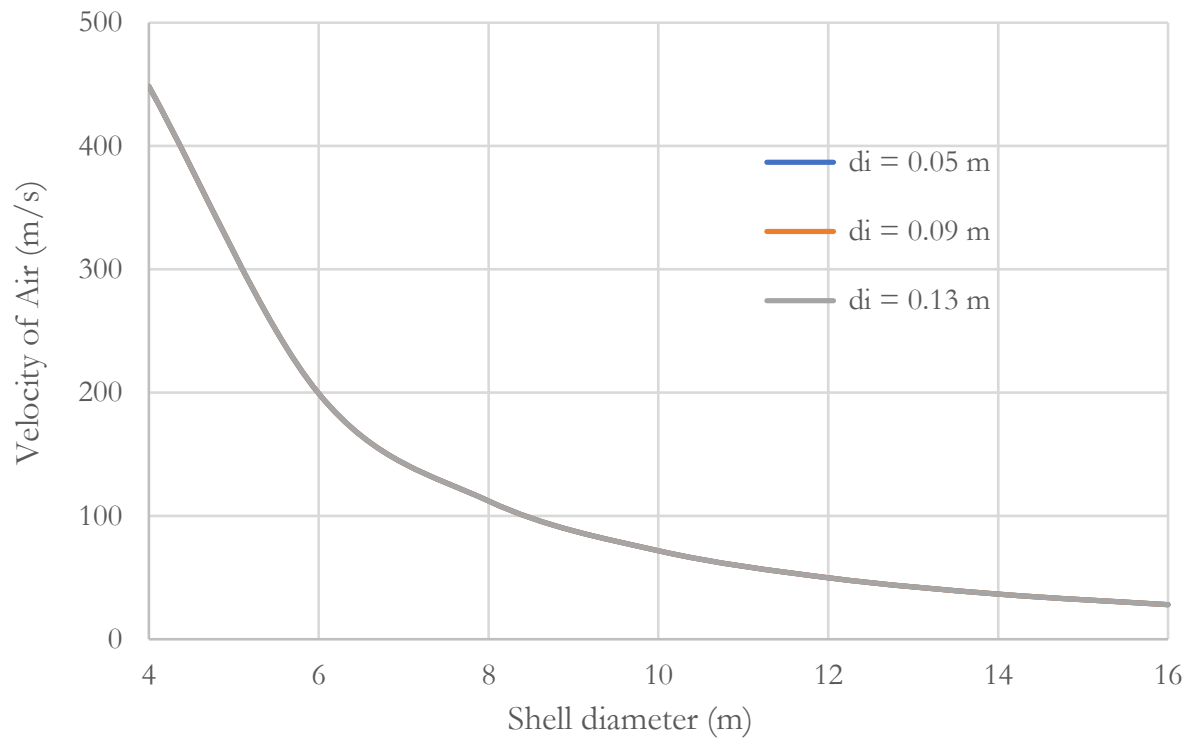

Figure 4. 10: Effect of shell and tube diameter on the velocity of air, m/s

\subsection{Effect of tube and shell diameter on overall heat transfer coefficient}

Table 4.11 and Figure 4.11 presents the effect of tube and shell diameter on overall heat transfer coefficient. The overall heat transfer coefficient decreases as shell diameter and tube diameter increases. It is noticed at shell diameter $6 \mathrm{~m}$, the heat transfer coefficient dropped by $29.71 \%$ from tube diameter $0.05 \mathrm{~m}$ to $0.13 \mathrm{~m}$ whereas at tube diameter $0.05 \mathrm{~m}$ a drop of $48.01 \%$ was observed from shell diameter $6 \mathrm{~m}$ to $10 \mathrm{~m}$. It is evident that the variation in shell diameter has a higher effect on overall heat transfer coefficient compared to the change in tube diameter.

Table 4. 11: Effect of tube and shell diameter on overall heat transfer coefficient, $\mathrm{W} / \mathrm{m}^{2} \mathrm{~K}$

\begin{tabular}{|l|c|c|c|c|c|c|c|}
\hline \multicolumn{1}{|c|}{ Parameter } & \multicolumn{5}{c|}{ Data } \\
\hline Shell Outer diameter $(\mathbf{m})$ & 4.08 & 6.11 & 8.15 & 10.19 & 12.23 & 14.26 & 16.30 \\
\hline Shell Inner diameter $\mathbf{( m )}$ & 4 & 6 & 8 & 10 & 12 & 14 & 16 \\
\hline Overall heat transfer coefficient $\left(\mathbf{W} / \mathbf{m}^{\mathbf{2}} \mathbf{K}\right) \mathbf{d}_{\mathbf{i}}=\mathbf{0 . 0 5} \mathbf{~ m}$ & 127.70 & 76.50 & 52.98 & 39.77 & 31.41 & 25.69 & 21.54 \\
\hline Overall heat transfer coefficient $\left(\mathbf{W} / \mathbf{m}^{\mathbf{2}} \mathbf{K}\right) \mathbf{d}_{\mathbf{i}}=\mathbf{0 . 0 9} \mathbf{m}$ & 102.39 & 61.65 & 42.84 & 32.23 & 25.51 & 20.91 & 17.59 \\
\hline Overall heat transfer coefficient $\left(\mathbf{W} / \mathbf{m}^{\mathbf{2}} \mathbf{K}\right) \mathbf{d}_{\mathbf{i}}=\mathbf{0 . 1 3} \mathbf{~ m}$ & 88.97 & 53.77 & 37.44 & 28.21 & 22.36 & 18.34 & 15.45 \\
\hline
\end{tabular}




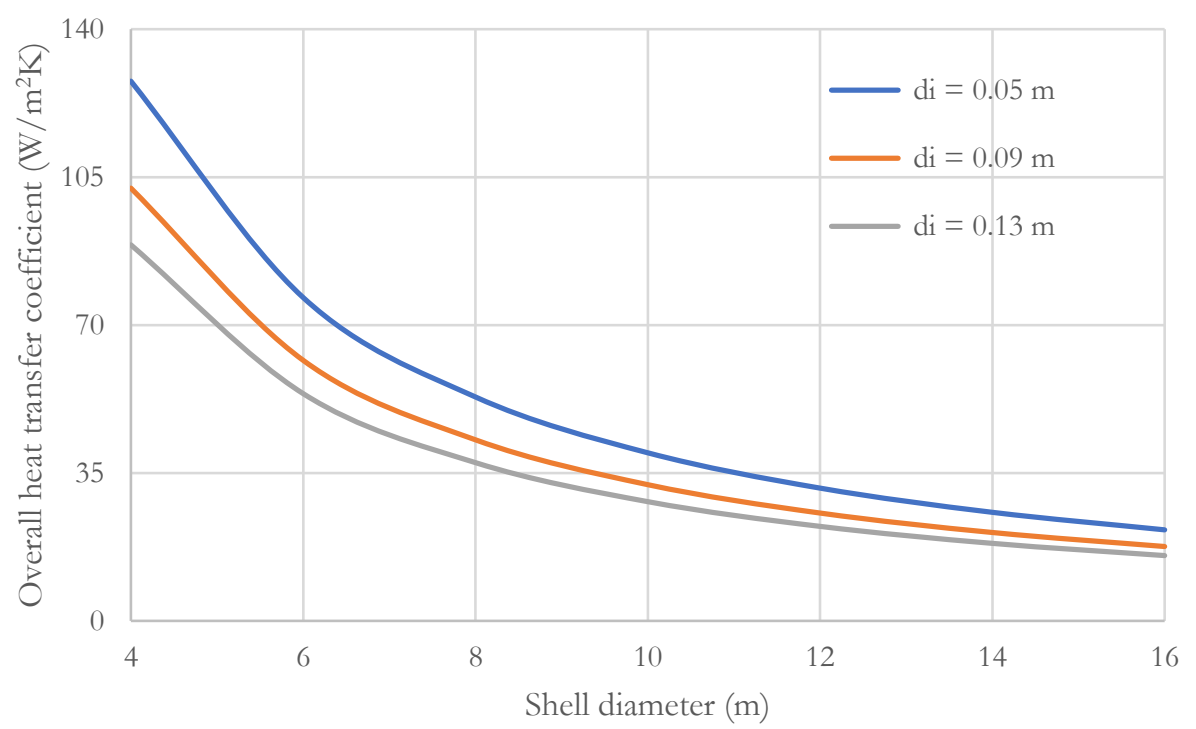

Figure 4. 11: Effect of tube and shell diameter on overall heat transfer coefficient, $\mathrm{W} / \mathrm{m}^{2} \mathrm{~K}$

4.11 Effect of tube and shell diameter tube internal side surface area

Table 4.12 and Figure 4.12 presents the effect of tube and shell diameter on tube internal side surface area. The tube internal side surface area increases as shell diameter and tube diameter increases. It is noticed at shell diameter $6 \mathrm{~m}$, the tube internal side surface area is increased by $42.69 \%$ when tube diameter is increased from $0.05 \mathrm{~m}$ to $0.13 \mathrm{~m}$. In comparison, at tube diameter $0.05 \mathrm{~m}$, a huge increase of $92.93 \%$ was observed when shell diameter was increased from $6 \mathrm{~m}$ to $10 \mathrm{~m}$. Variation in shell diameter has a higher effect on tube internal side surface area compared to variation of tube diameter dimensions.

Table 4. 12: Effect of tube and shell diameter tube internal side surface area, $\mathrm{m}^{2}$

\begin{tabular}{|c|c|c|c|c|c|c|c|}
\hline \multirow{2}{*}{$\frac{\text { Parameter }}{\mathrm{D}_{\mathrm{s}}, \text { Shell Outer diameter }(\mathrm{m})}$} & \multicolumn{7}{|c|}{ Data } \\
\hline & 4.08 & 6.11 & 8.15 & 10.19 & 12.23 & 14.26 & 16.30 \\
\hline $\mathrm{D}_{\mathrm{s}}$, Shell Inner diameter $(\mathrm{m})$ & 4 & 6 & 8 & 10 & 12 & 14 & 16 \\
\hline Tube internal side surface area $\left(\mathrm{m}^{2}\right) \mathrm{d}_{\mathrm{i}}=0.05 \mathrm{~m}$ & 11,778 & 19,600 & 28,383 & 37,814 & 47,880 & 58,549 & 69,811 \\
\hline Tube internal side surface area $\left(\mathrm{m}^{2}\right) \mathrm{d}_{\mathrm{i}}=0.09 \mathrm{~m}$ & 14,689 & 24,394 & 35,110 & 46,666 & 58,956 & 71,912 & 85,492 \\
\hline Tube internal side surface area $\left(\mathrm{m}^{2}\right) \mathrm{d}_{\mathrm{i}}=0.13 \mathrm{~m}$ & 16,905 & 27,969 & 40,170 & 53,313 & 67,274 & 81,969 & 97,339 \\
\hline
\end{tabular}




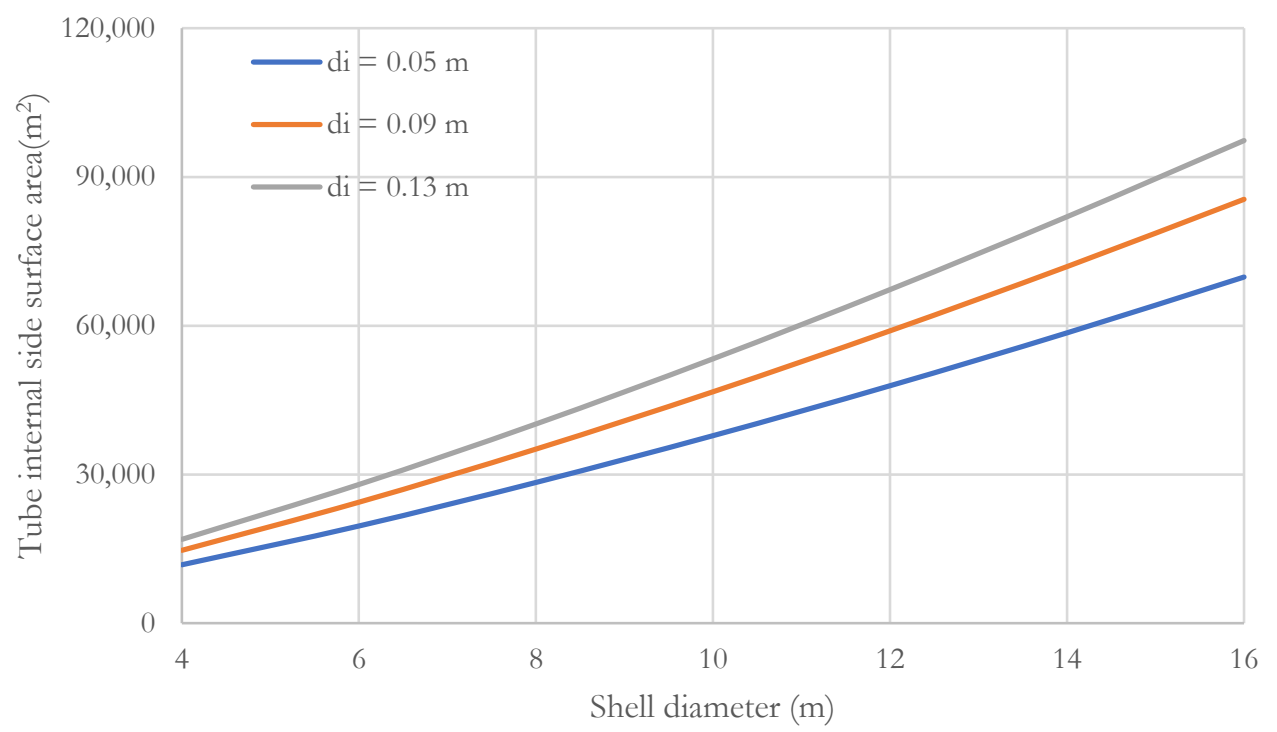

Figure 4. 12: Effect of tube and shell diameter on tube internal side surface area, $\mathrm{m}^{2}$

4.12 Effect of Tube pitch on shell and tube side pressure drop $\boldsymbol{D}_{\boldsymbol{s}}=\mathbf{8} \boldsymbol{m}, \boldsymbol{d}_{\boldsymbol{i}}=\mathbf{0 . 1 0 2 , \boldsymbol { B } =}$ $5.6 \mathrm{~m}, P t=1.2-2.0$

The effect of tube pitch on shell and tube side pressure drop is shown in Table 4.13 and Figure 4.13. The shell side pressure drop decreases with the increase in pitch as it increases the cross section area for air to flow through. However, increasing tube pitch increases the pressure drop in tube as the number of tubes is decreased while shell diameter is kept as constant. The highest shell side pressure drop, 17.70 bar was noticed when the tube pitch was 1.2. The lowest shell side pressure drop, 1.17 bar was observed at a tube pitch of 2.0.

Table 4. 13: Effect of Tube pitch on shell and tube side pressure drop

\begin{tabular}{|c|c|c|c|c|c|c|c|}
\hline Parameters & \multicolumn{7}{|c|}{ Data } \\
\hline Tube Pitch & $2.00 \times d_{o}$ & $1.80 \times d_{o}$ & $1.60 \times d_{o}$ & $1.50 \times d_{o}$ & $1.35 \times d_{o}$ & $1.25 \times d_{o}$ & $1.20 \times d_{o}$ \\
\hline Shell Side Pressure drop (Bar) & 1.17 & 1.49 & 2.17 & 2.88 & 5.40 & 10.60 & 17.10 \\
\hline Tube Side Pressure drop (Pa) & 1324.00 & 708.64 & 360.92 & 252.41 & 143.56 & 96.55 & 78.63 \\
\hline
\end{tabular}




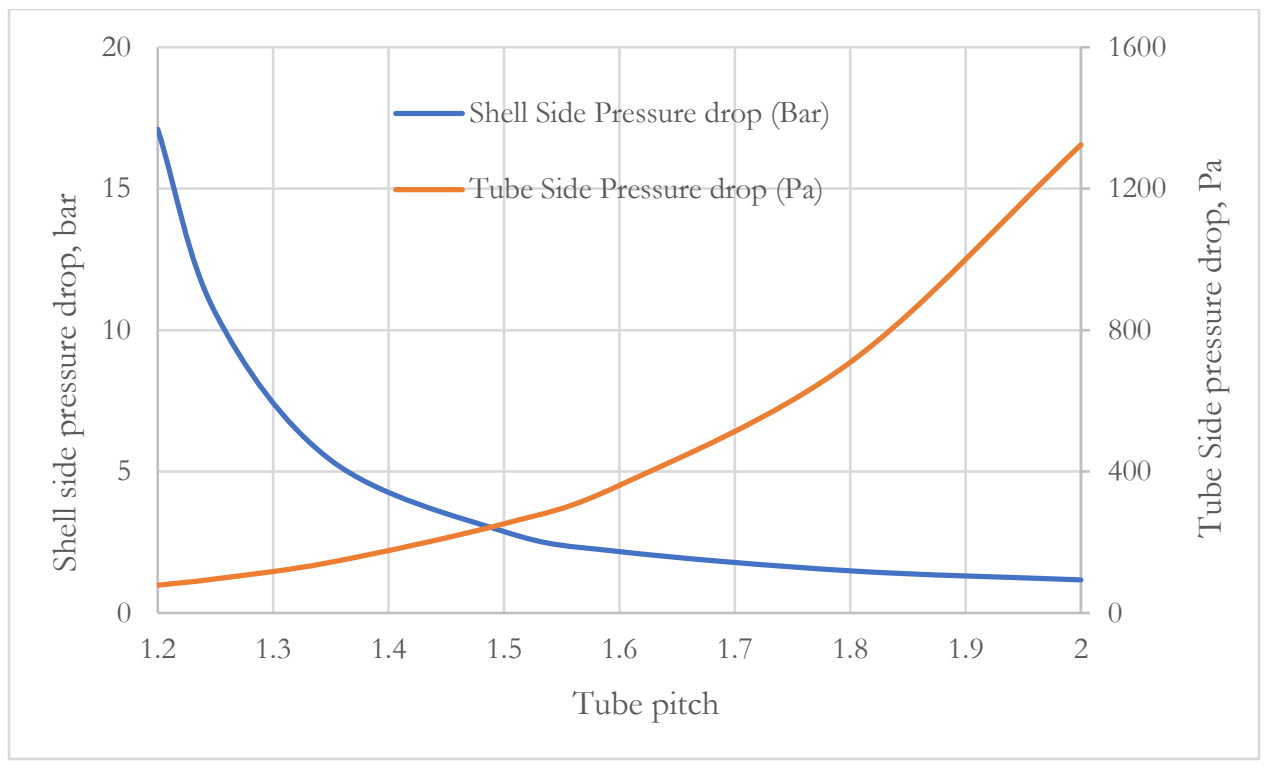

Figure 4. 13: Effect of Tube pitch on shell and tube side pressure drop

The effect of tube pitch on shell length is shown in Table 4.14 and Figure 4.14. Increasing tube pitch increases the length of shell. This is mainly due to the decreased number of tubes when tube pitch is increased when shell diameter is kept constant as shown in Table 4.15 and Figure 4.15. More space is created around the tubes when tube pitch increases, this result in reduced space available for tubes to fit in.

Table 4. 14: Effect of Tube pitch on shell length

\begin{tabular}{|c|c|c|c|c|c|c|c|}
\hline \multicolumn{1}{|c|}{ Parameters } & \multicolumn{9}{|c|}{ Data } \\
\hline Tube Pitch & $2.00 \times d_{o}$ & $1.80 \times d_{o}$ & $1.60 \times d_{o}$ & $1.50 \times d_{o}$ & $1.35 \times d_{o}$ & $1.25 \times d_{o}$ & $1.20 \times d_{o}$ \\
\hline Shell length $(\mathrm{m})$ & 98.99 & 72.46 & 51.62 & 43.13 & 32.57 & 26.84 & 24.35 \\
\hline
\end{tabular}




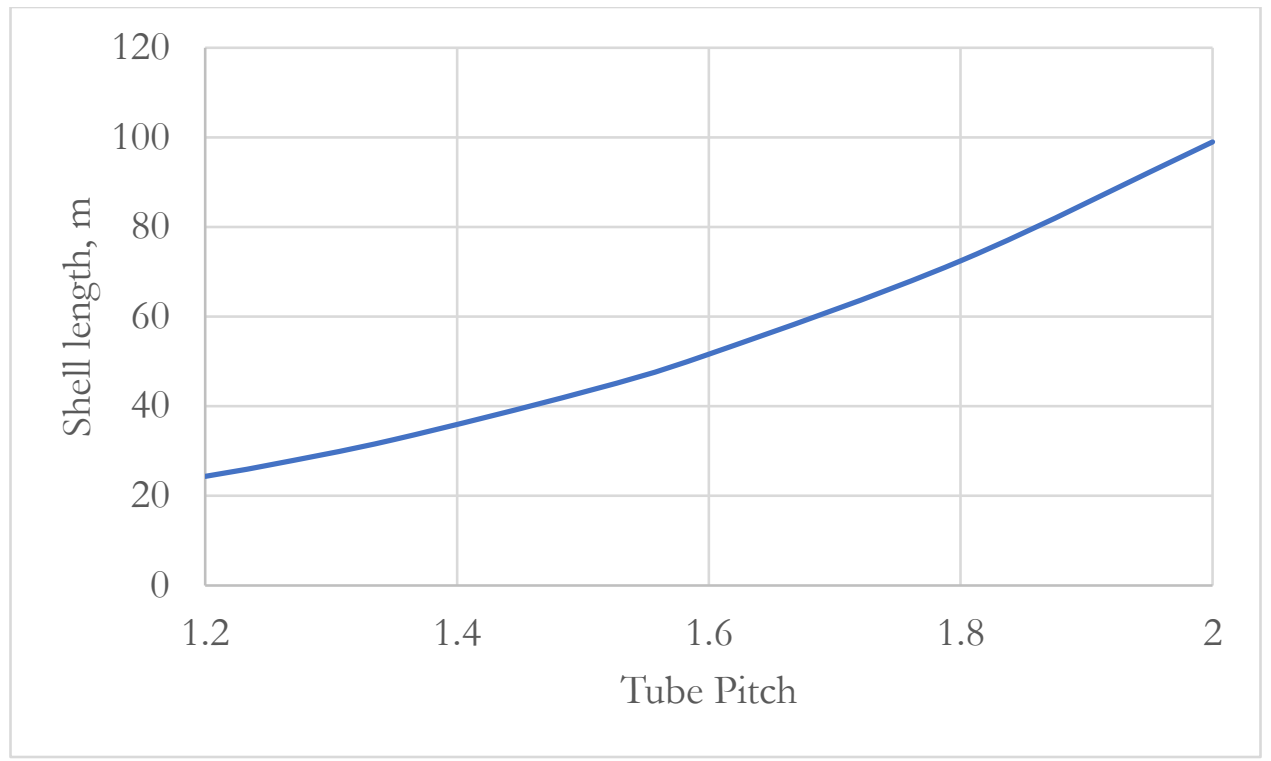

Figure 4. 14: Effect of Tube pitch on shell length

Table 4. 15: Effect of Tube pitch on Tube number

\begin{tabular}{|l|c|c|c|c|c|c|c|}
\hline \multicolumn{1}{|c|}{ Parameters } & \multicolumn{9}{|c|}{ Data } \\
\hline Tube Pitch & $2.00 \times d_{o}$ & $1.80 \times d_{o}$ & $1.60 \times d_{o}$ & $1.50 \times d_{o}$ & $1.35 \times d_{o}$ & $1.25 \times d_{o}$ & $1.20 \times d_{o}$ \\
\hline Tube number & 956 & 1192 & 1509 & 1717 & 2120 & 2473 & 2683 \\
\hline
\end{tabular}

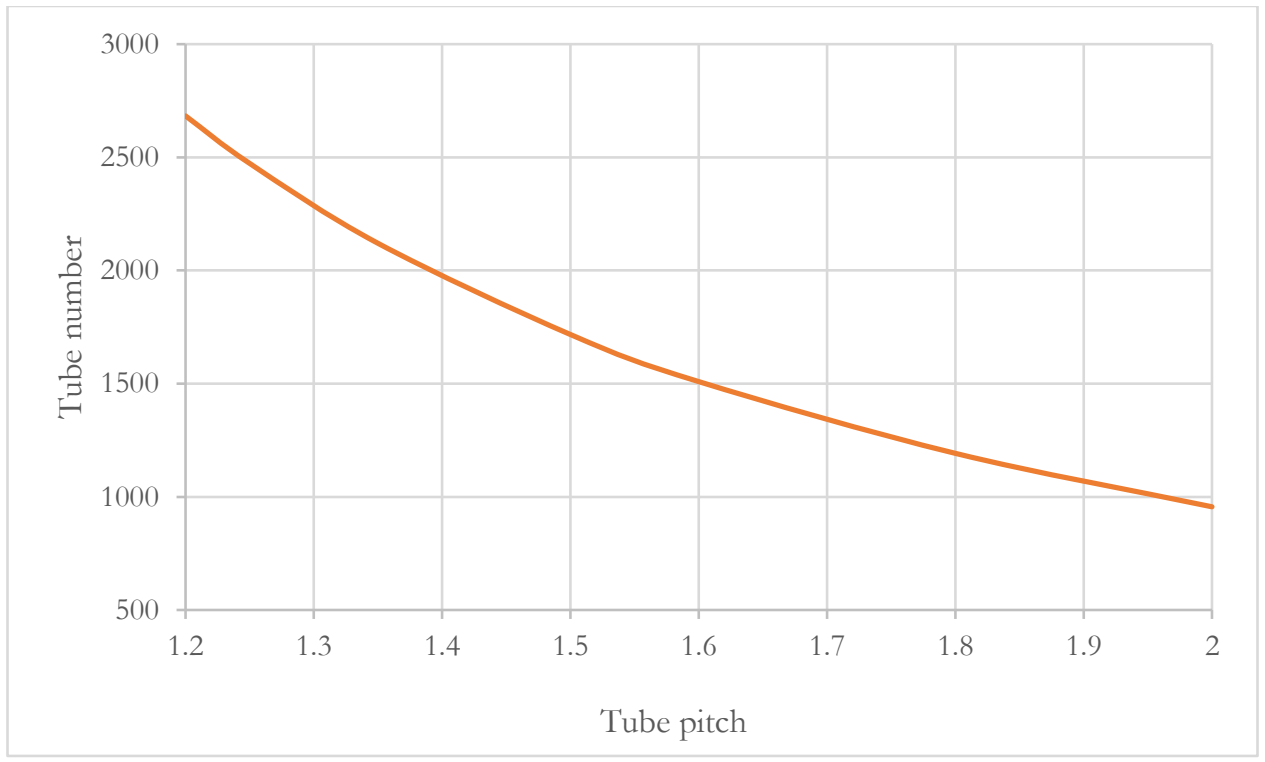

Figure 4. 15: Effect of Tube pitch on Tube number 
4.13 Selected shell and tube heat exchanger

The selected shell and tube heat exchanger parameters are shown in Table 4.16. The selection was made while considering a reasonable pressure drop for both the shell and tube side, the desirability to have a significant ratio for shell diameter to tube length, and a design consideration that allows for a reduced number of tubes and material cost represented by the volume of tube materials.

Table 4. 16: Design parameters for the selected heat exchanger

Design parameters for shell and tube heat exchanger device

Number of Passes

Shell inner diameter(m)

Shell outer diameter $(\mathrm{m})$

Tube inner diameter $(\mathrm{m})$

Tube outer diameter (m)

Number of Baffles

Tube Pitch

Number of Tubes

Baffle spacing (m)

Length of tube (m)

Shell side pressure drop (bar)

Tube side pressure drop $(\mathrm{Pa})$

Overall heat transfer coefficient $\left(\mathrm{W} / \mathrm{m}^{2} \mathrm{~K}\right)$

Overall surface area for heat transfer $\left(\mathrm{m}^{2}\right)$

1

8.00

8.15

0.102

0.110

8

$1.6 \times d_{o}$

1509

5.6

51.62

2.17

360.92

60.51

24852 


\subsection{CFD CALCULATION USING ANSYS-FLUENT}

\section{1: Ansys-Fluent simulation}

The ANSYS fluent software was used in simulation of the shell and tube heat exchanger device. The design details below are the values used in building the prototype of the selected heat exchanger device. The prototype is a $1 / 10000$ th reduction of the original model due to the limitation of the computation resource. The simulation provides the qualitative support to design of the heat exchanger.

\subsection{Temperature distribution of device}

Figures 5.1 to 5.5 show the temperature distribution of the air and $\mathrm{CO}_{2}$ fluid flowing through the heat exchanger device. This was done using the ANSYS 18.1 software. The geometry was built in the design modeler and meshing was developed with over a million nodes and three million elements. Boundary and cell zone conditions were added in the set-up for the inlet and outlet. The shell has inlet temperature of $1500 \mathrm{~K}$, and mass flow rate of $760.01 \mathrm{~kg} / \mathrm{s}$. The tubes have inlet temperature of 450 $\mathrm{K}$ and mass flow rate of $806.74 \mathrm{~kg} / \mathrm{s}$. Inconel 617 was selected as the shell and tube material with properties listed in Table 3.1, shell fluid was air and tube fluid was $\mathrm{CO}_{2}$.

The temperature distribution of the air fluid is presented in Figure 5.1. High temperature air at about $1500 \mathrm{~K}$ flows into the top part of the shell and move to the bottom part of the shell where the temperature falls to about $1300 \mathrm{~K}$ and later falls to about $800 \mathrm{~K}$ due to heat transfer from air to the $\mathrm{CO}_{2}$ through the Inconel 617 tubes. As shown in Figure 5.2, $\mathrm{CO}_{2}$ fluid at $450 \mathrm{~K}$ enters into the Inconel 617 tubes and gain heat from hot air thereby increasing to about $800 \mathrm{~K}$ at halfway through the tube length and reaching $1000 \mathrm{k}$ towards exit of the tubes. As shown in Figure 5.3, the wall of the shell material is at elevated temperature of about $1220 \mathrm{~K}$ to $1350 \mathrm{~K}$ at around the body of the shell and falls to between $800 \mathrm{~K}-900 \mathrm{~K}$ towards the shell outlet. As shown in Figure 5.4, the Inconel 617 tubes shows elevated temperature of $940 \mathrm{~K}-1080 \mathrm{~K}$ at most part of the tube length, which is between the 
temperature of air and $\mathrm{CO}_{2}$. Figure 5.5 shows a sectional view of the shell and tube heat exchanger with air and $\mathrm{CO}_{2}$ fluid running through the shell and tubes, respectively.

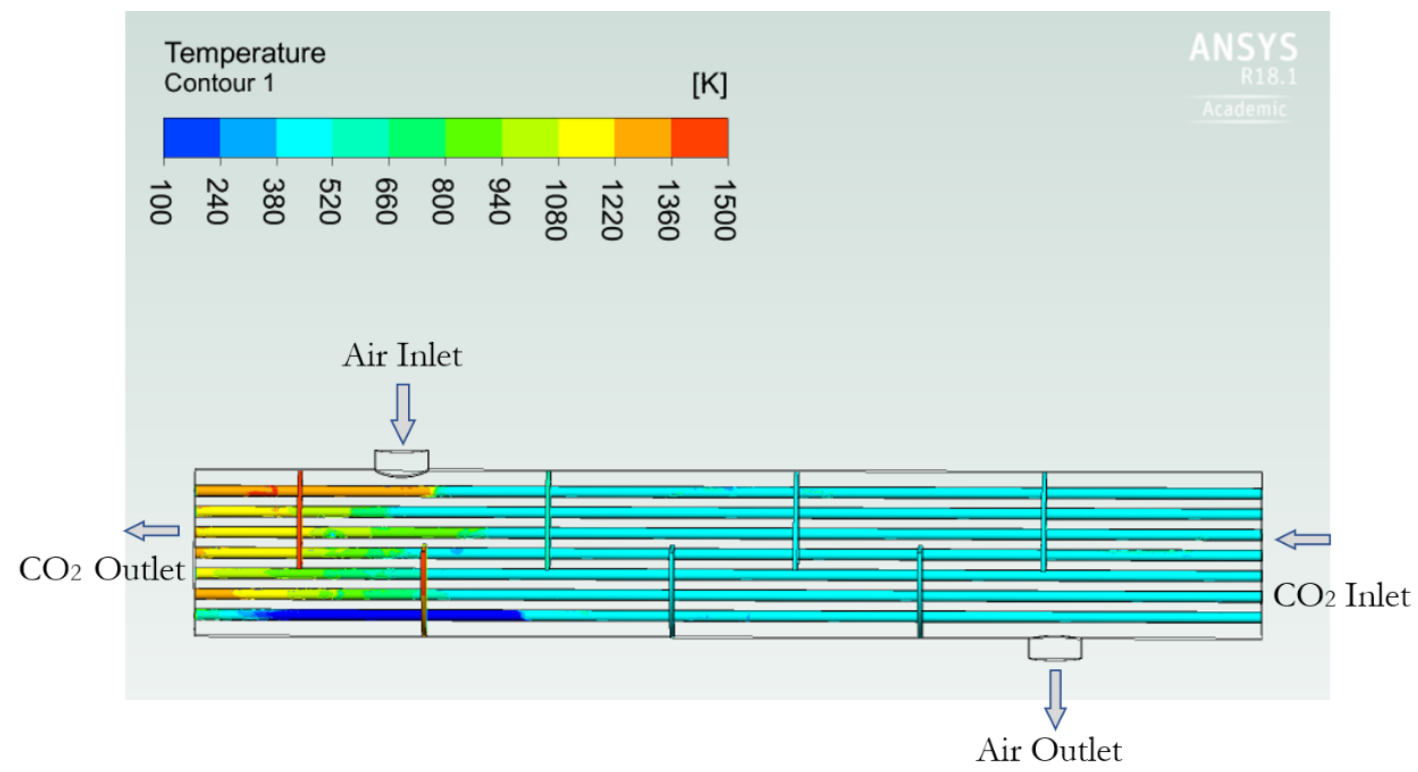

Figure 5.1: Temperature distribution of $\mathrm{CO}_{2}$

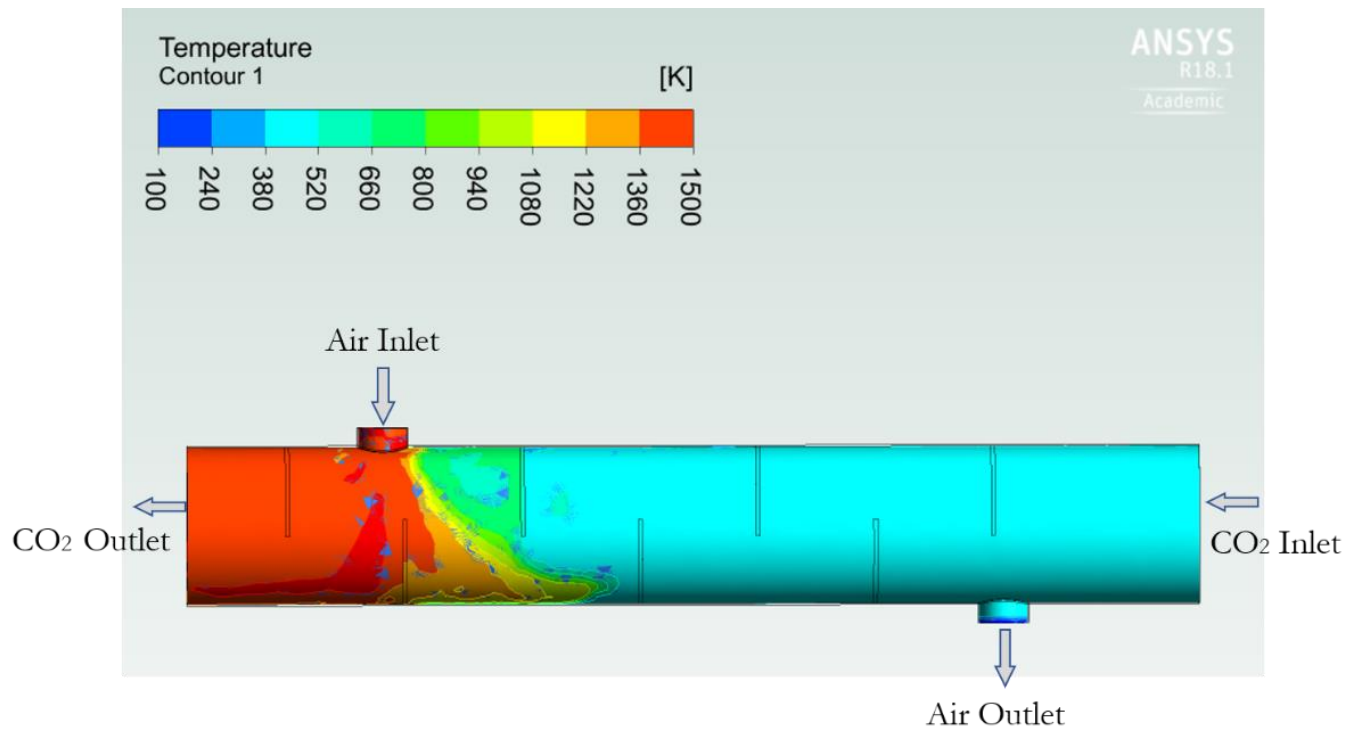

Figure 5.2: Temperature distribution of air 


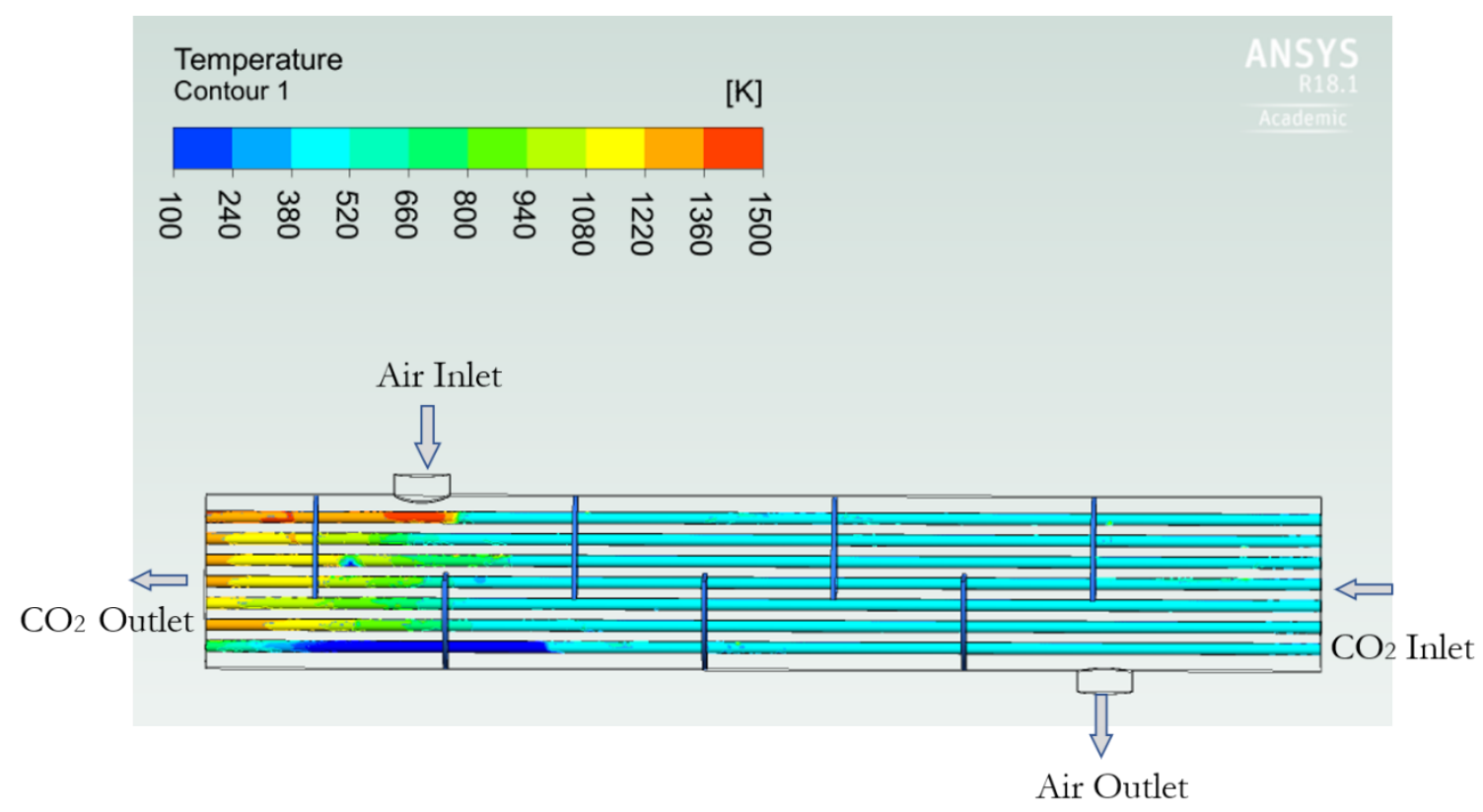

Figure 5.3: Temperature distribution of tubes

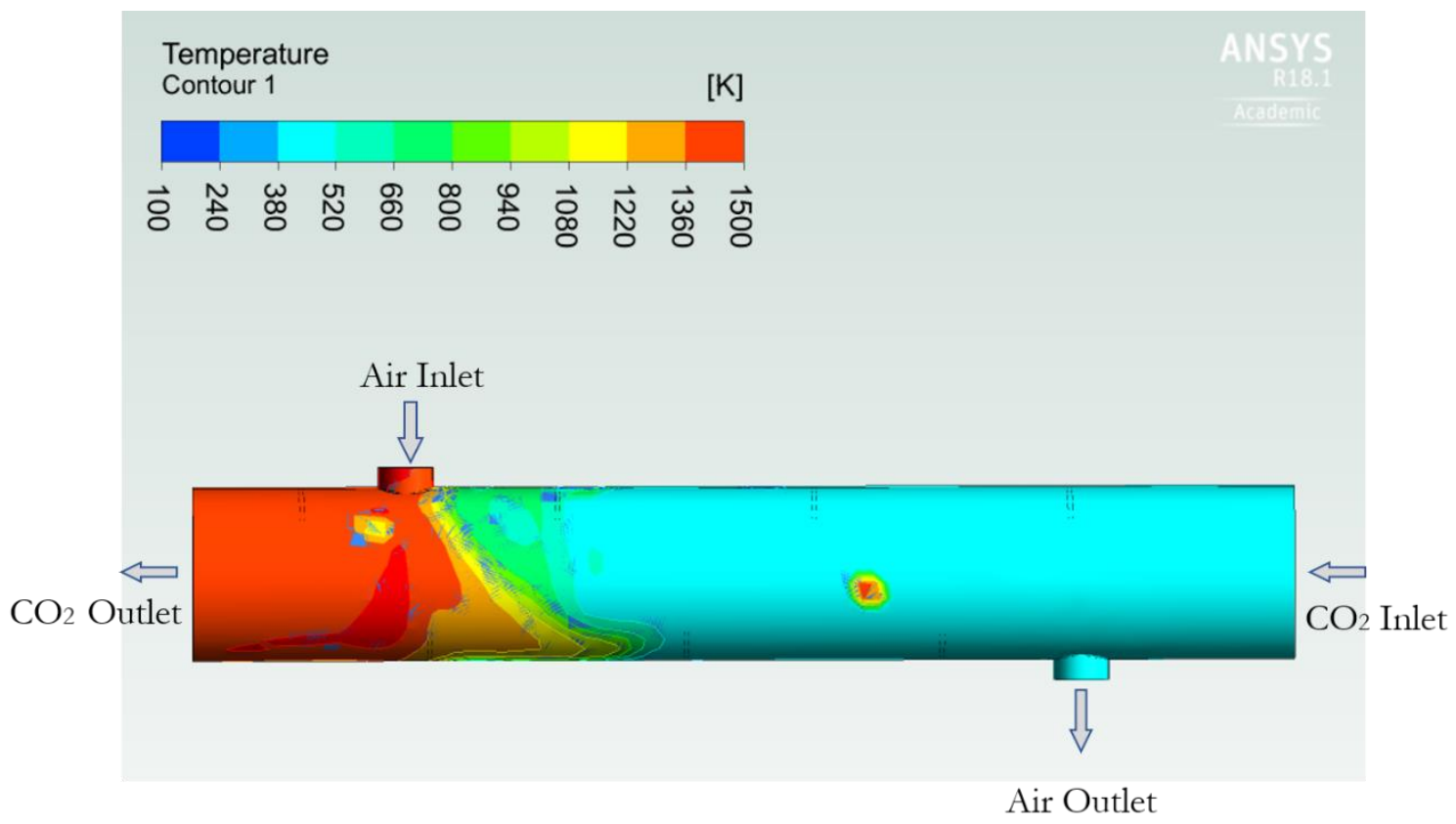

Figure 5.4: Temperature distribution of shell 


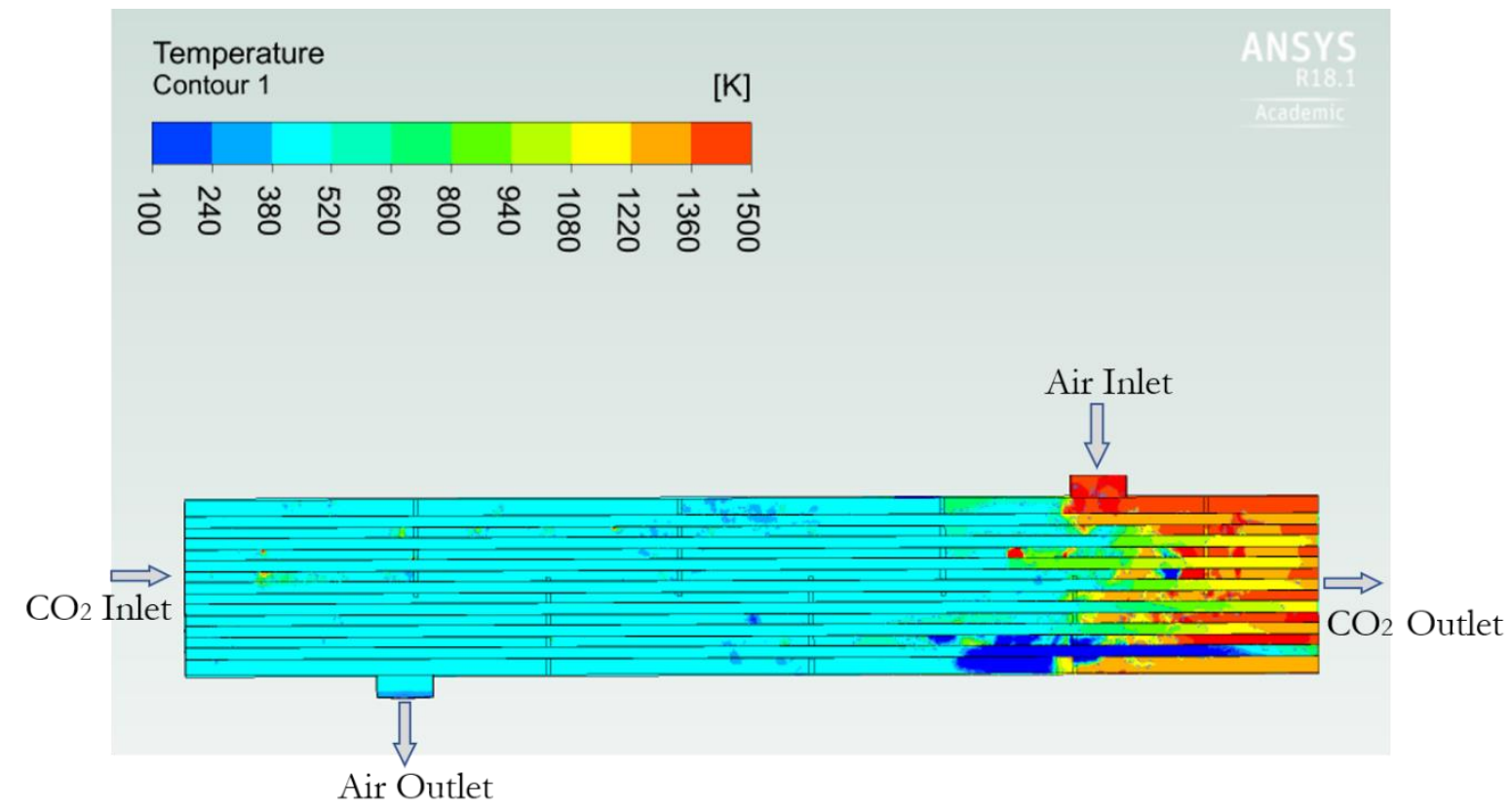

Figure 5.5: Temperature distribution in central line of heat exchanger device

\subsection{Thermal analysis}

The thermal analysis was done using ANSYS 18.1 software. The engineering data for Inconel 617 was added as presented in Table 3.1 while the geometry was built, and edge and body size meshing were done. The loading conditions were added as temperatures conditions on shell inlet, shell outlet, shell side region, tube inlet, tube outlet and tube side region. The temperature distribution was calculated and evaluated and presented in Figure 5.6 while Figure 5.7 plots the variation of the allowable stress with changes in temperature along the tubes. The result below shows how the shell and tube material conduct heat when hot air flows into it. Maximum temperature of $1500 \mathrm{~K}$ is observed at air inlet region and minimum temperature of $450 \mathrm{~K}$ to $600 \mathrm{~K}$ is observed at $\mathrm{CO}_{2}$ inlet. An average temperature of $1047.8 \mathrm{~K}$ to $1049.3 \mathrm{~K}$ is seen around the inside surface of the tube. The variation in temperature of the Inconel 617 material under loading further buttress its quality of high thermal. 


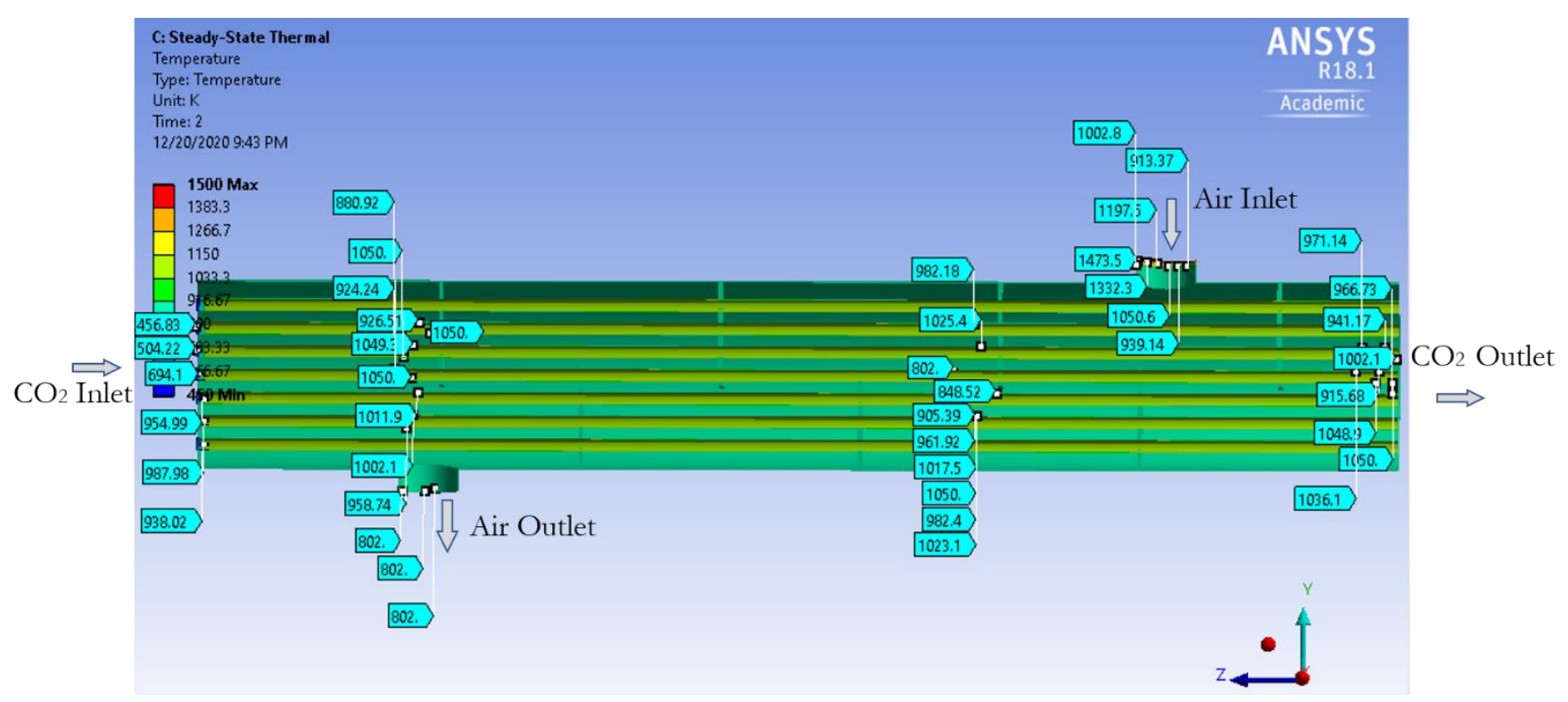

Figure 5.6: Thermal analysis of heat exchanger device

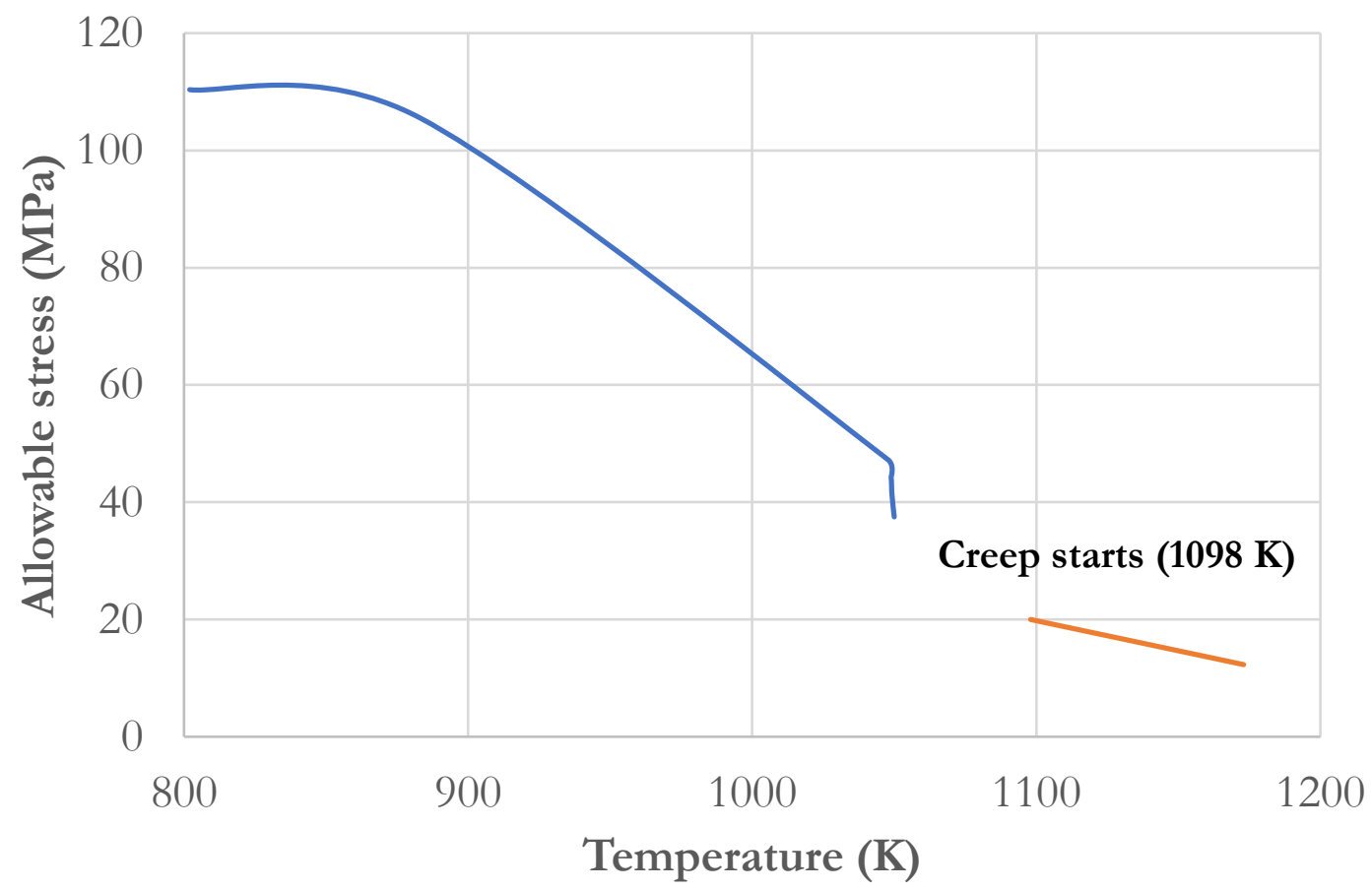

Figure 5.7:Variable of the allowable stress with changes in temperature 


\subsection{CONCLUSION AND FUTURE WORK}

\subsection{Conclusion}

The procedure designing supercritical $\mathrm{CO}_{2}$ heat exchanger was developed and applied to design a S$\mathrm{CO}_{2}$ heat exchanger for a $300 \mathrm{MW} \mathrm{S}-\mathrm{CO}_{2}$ turbine. The design of a shell and tube heat exchanger was conducted using preliminary equations with several sample tests done using shell diameters values of $6 \mathrm{~m}$ to $18 \mathrm{~m}$ and tube diameters $0.028 \mathrm{~m}$ to $0.12 \mathrm{~m}$. Smaller shell diameter of between $8 \mathrm{~m}$ to $12 \mathrm{~m}$ is preferable as they offer a limited number of tubes and less volume of shell material, a shell side pressure drop of 0.4 bar to 2.26 bars, tube side pressure drop of $20.63 \mathrm{~Pa}$ to $110.05 \mathrm{~Pa}$, increased overall heat transfer coefficient of $33.26 \mathrm{~W} / \mathrm{m}^{2} \mathrm{~K}$ to $57.31 \mathrm{~W} / \mathrm{m}^{2} \mathrm{~K}$.

It could also be concluded that smaller tubes values of $0.083 \mathrm{~m}$ to $0.12 \mathrm{~m}$ are good for construction as they offer higher overall heat transfer coefficient of $52.51 \mathrm{~W} / \mathrm{m}^{2} \mathrm{~K}$ to $59.35 \mathrm{~W} / \mathrm{m}^{2} \mathrm{~K}$ and shell side pressure drop of 2.23 bar to 2.35 bar.

The main geometry parameters of the shell and tube heat exchanger designed include shell diameter $8 \mathrm{~m}$, tube diameter $0.102 \mathrm{~m}$, and pitch of $1.6 \times d_{o}$. The calculated length of shell is $51.62 \mathrm{~m}$. There are 1509 tubes used with a total length of $77894.58 \mathrm{~m}$. The overall heat transfer coefficient calculated is $60.51 \mathrm{~W} / \mathrm{m} 2 \mathrm{k}$. The pressure drop of air in shell calculated is 2.17 bar while the pressure drop of $\mathrm{CO}_{2}$ in the tubes was $360.92 \mathrm{~Pa}$.

The CFD simulation provides detailed distribution of temperature of fluids, shell and tubes, and material strength.

\subsection{Future works}

This design work is only done for a square-pitch layout and can be extended for a triangular pitch layout for heat transfer analysis on shell and tube heat exchanger for selected applications. Also, the 
design work was restricted to a one-pass tube system and can be tested for a two-pass and three-pass exchanger system.

A CFD simulation of full-scale heat exchanger should be conducted once the computational resource is made available. It is expected that the CFD simulation will help to verify if the system designed can achieve the heat transfer needed. 


\section{REFERENCES}

[1] "What Are Supercritical CO 2 Power Cycles?” https://www.powermag.com/what-aresupercritical-co2-power-cycles/ (accessed Dec. 18, 2020).

[2] T. J. Held, "Supercritical $\mathrm{CO}_{2}$ cycles for gas turbine combined cycle power plants."

[3] Y. Ahn et al., "Review of supercritical $\mathrm{CO}_{2}$ power cycle technology and current status of research and development," Nuclear Engineering and Technology, vol. 47, no. 6. Korean Nuclear Society, pp. 647-661, Oct. 01, 2015, doi: 10.1016/j.net.2015.06.009.

[4] A. Meshram et al., "Modeling and analysis of a printed circuit heat exchanger for supercritical $\mathrm{CO}_{2}$ power cycle applications,” Appl. Therm. Eng., vol. 109, pp. 861-870, Oct. 2016, doi: 10.1016/j.applthermaleng.2016.05.033.

[5] P. Friedman and M. Anderson, “Thermodynamics," in Fundamentals and Applications of Supercritical Carbon Dioxide (SCO2) Based Power Cycles, Elsevier Inc., 2017, pp. 41-66.

[6] E. M. Clementoni and T. L. Cox, "Effect of compressor inlet pressure on cycle performance for a supercritical carbon dioxide brayton cycle," in Proceedings of the ASME Turbo Expo, Aug. 2018, vol. 9, doi: 10.1115/GT2018-75182.

[7] S. Sullivan et al., "Grant O. Musgrove Heat Exchangers for Supercritical $\mathrm{CO}_{2}$ Power Cycle Applications Tutorial: Additional contributions from: Lalit Chordia Marc Portnoff."

[8] “Organic Rankine cycle - Wikipedia.” https://en.wikipedia.org/wiki/Organic_Rankine_cycle (accessed Dec. 18, 2020).

[9] S. Quoilin, M. Van Den Broek, S. Declaye, P. Dewallef, and V. Lemort, "Techno-economic survey of organic rankine cycle (ORC) systems,” Renewable and Sustainable Energy Reviews, vol. 22. Pergamon, pp. 168-186, Jun. 01, 2013, doi: 10.1016/j.rser.2013.01.028. 
[10] H. Seo, J. E. Cha, J. Kim, I. Sah, and Y.-W. Kim, "Design and Performance Analysis of a Supercritical Carbon Dioxide Heat Exchanger,” Appl. Sci., vol. 10, no. 13, p. 4545, Jun. 2020, doi: 10.3390/app10134545.

[11] D. Shiferaw, J. M. Carrero, and R. Le Pierres, "Economic analysis of S-CO 2 cycles with PCHE Recuperator design optimisation.”

[12] "Department of Energy Announces \$128 Million for Sustainable Transportation Research | Department of Energy.” https://www.energy.gov/articles/department-energy-announces128-million-sustainable-transportation-research (accessed Dec. 18, 2020).

[13] M. Huang, C. J. Tang, and A. Mcclung, "Steady State and Transient Modeling for the 10 MWe $\mathrm{SCO}_{2}$ Test Facility Program,” 2018.

[14] S. Kung, J. Shingledecker, I. Wright, A. Sabau, B. Tossey, and T. Lolla, “The 6 th International Supercritical $\mathrm{CO}_{2}$ Power Cycles Symposium Corrosion of Heat Exchanger Alloys in Open-Fired S- $\mathrm{CO}_{2}$ Power Cycles.”

[15] Q. Zhu, "Innovative power generation systems using supercritical $\mathrm{CO}_{2}$ cycles," Clean Energy, vol. 1, no. 1. Oxford University Press, pp. 68-79, 2017, doi: 10.1093/ce/zkx003.

[16] “Heat exchanger - Wikipedia.” https://en.wikipedia.org/wiki/Heat_exchanger (accessed Dec. 18, 2020).

[17] R. Brogan, "Shell and tube heat exchangers," in A-to-Z Guide to Thermodynamics, Heat and Mass Transfer, and Fluids Engineering, Begellhouse.

[18] D. Ameta, "Shell and Tube Heat Exchanger," Int. J. Progress. Sci. Technol., vol. 5, no. 2, pp. 49-52, 2017, Accessed: Dec. 18, 2020. [Online]. Available: http://ijpsat.ijsht-journals.org. 
[19] K. Wusiman and Z. Zhou, "Investigation of Shell and Tube Heat Exchanger with Disc-andDoughnut Baffles,” OALib, vol. 07, no. 09, pp. 1-10, Sep. 2020, doi: 10.4236/oalib.1106762.

[20] S. H. Gawande, S. D. Wankhede, R. N. Yerrawar, V. J. Sonawane, and U. B. Ubarhande, "Design and Development of Shell \&amp; Tube Heat Exchanger for Beverage," Mod. Mech. Eng., vol. 02, no. 04, pp. 121-125, 2012, doi: 10.4236/mme.2012.24015.

[21] "Shell \& tube heat exchanger equations and calculations - EnggCyclopedia." https://www.enggcyclopedia.com/2019/05/shell-tube-heat-exchanger-equations/ (accessed Dec. 18, 2020).

[22] “Dry Air Properties.” https://www.engineeringtoolbox.com/dry-air-properties-d_973.html (accessed Dec. 18, 2020).

[23] "Forging Capabilities and Guide Video | Ferrous And Non Ferrous Metals." https://supermetals.com/industrial-resources/page/2/ (accessed Dec. 18, 2020).

[24] I. G. Wright, B. A. Pint, J. P. Shingledecker, and D. Thimsen, "Materials considerations for supercritical $\mathrm{CO}_{2}$ turbine cycles," in Proceedings of the ASME Turbo Expo, Nov. 2013, vol. 8, doi: 10.1115/GT2013-94941.

[25] "Inconel 617 Tech Data." http://www.hightempmetals.com/techdata/hitempInconel617data.php (accessed Dec. 18, 2020).

[26] "How to Calculate Mawp.” https://sciencing.com/calculate-mawp-8516775.html (accessed Dec. 18, 2020).

[27] “[PDF] Incropera S Principle Of Heat And Mass Transfer Download Online - eBook Sumo PDF.” https://ebooksumo.com/search/incropera-s-principle-of-heat-and-mass-transfer/ 
(accessed Dec. 18, 2020).

[28] “Carbon dioxide - Prandtl Number.” https://www.engineeringtoolbox.com/carbon-dioxideprandtl-number-viscosity-heat-capacity-thermal-conductivity-d_2024.html (accessed Dec. 18, 2020).

[29] R. Dodd, "Thermal design of shell and tube heat exchangers.," no. March, 1983.

[30] Songgang Q., “hX (1),” Renewable Energy, no. c. west virginia university, Morgantown, West Virginia, pp. 241403-241403, 2008. 
APPENDIX 1 . Orthographic projection of heat exchanger device

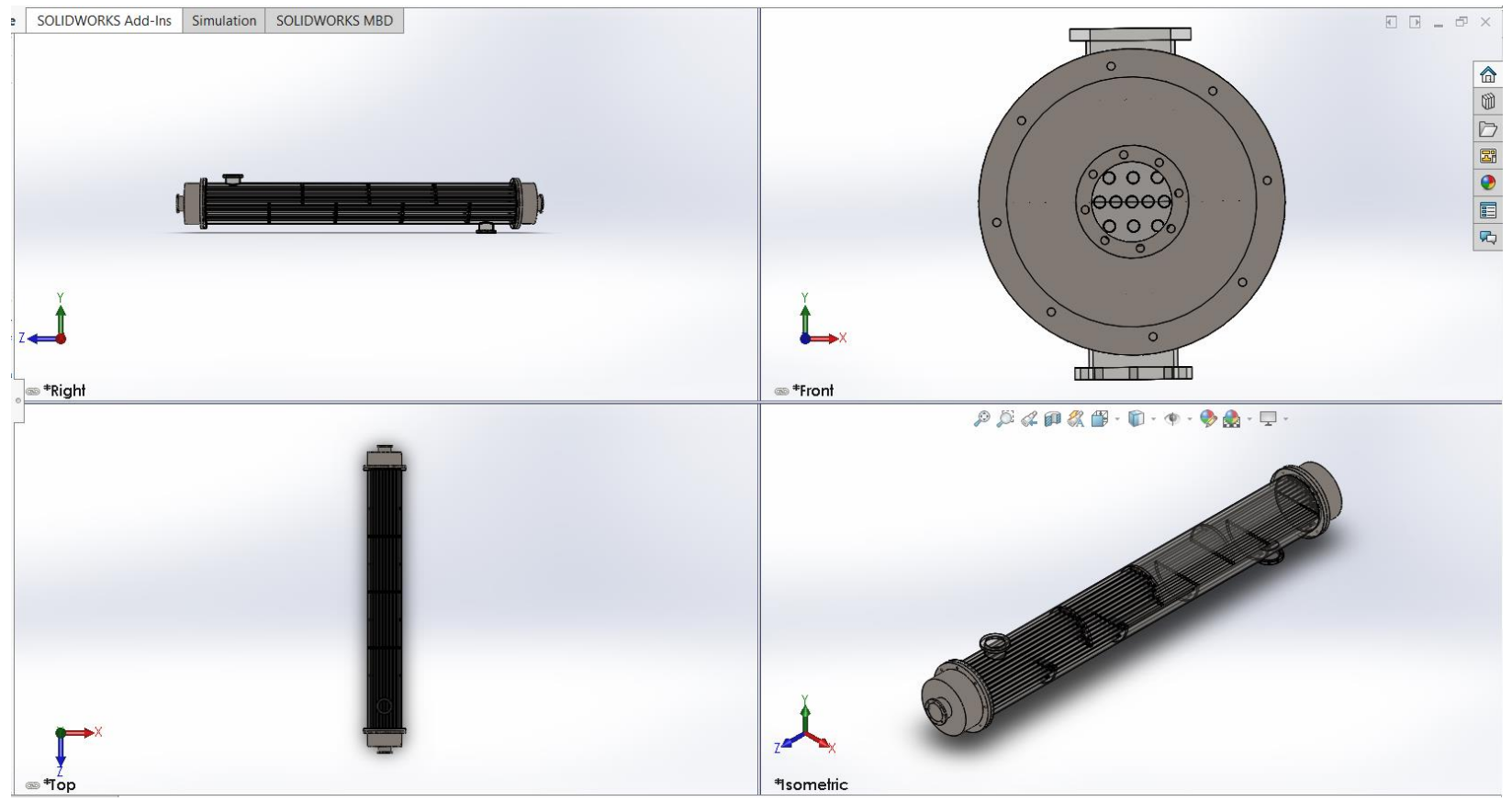

